\title{
The Health Sciences and Technology Academy (HSTA): A Case Study of the Community Impact of a 9th Through 12th Grade After School Pipeline Program
}

\author{
Catherine Morton-McSwain \\ West Virginia University
}

Follow this and additional works at: https://researchrepository.wvu.edu/etd

Part of the Curriculum and Instruction Commons, and the Secondary Education Commons

\footnotetext{
Recommended Citation

Morton-McSwain, Catherine, "The Health Sciences and Technology Academy (HSTA): A Case Study of the Community Impact of a 9th Through 12th Grade After School Pipeline Program" (2013). Graduate Theses, Dissertations, and Problem Reports. 8163.

https://researchrepository.wvu.edu/etd/8163

This Dissertation is protected by copyright and/or related rights. It has been brought to you by the The Research Repository @ WVU with permission from the rights-holder(s). You are free to use this Dissertation in any way that is permitted by the copyright and related rights legislation that applies to your use. For other uses you must obtain permission from the rights-holder(s) directly, unless additional rights are indicated by a Creative Commons license in the record and/ or on the work itself. This Dissertation has been accepted for inclusion in WVU Graduate Theses, Dissertations, and Problem Reports collection by an authorized administrator of The Research Repository @ WVU. For more information, please contact researchrepository@mail.wvu.edu.
} 


\title{
The Health Sciences and Technology Academy (HSTA):
}

A Case Study of the Community Impact of a $9^{\text {th }}$ Through $12^{\text {th }}$ Grade After School Pipeline Program

\section{Catherine Morton-McSwain}

\author{
Dissertation Submitted to the \\ College of Education and Human Services \\ At West Virginia University \\ in partial fulfillment of the requirements for the degree of \\ Doctor of Education in \\ Curriculum \& Instruction
}

\begin{abstract}
James Rye, Ph.D. Chair
Elizabeth Dooley, Ed.D.

Micah Fierstein, Ed. D.

Patricia Obenauf, Ed. D.

Samuel Stack, Ph. D.
\end{abstract}

College of Education and Human Services

Morgantown, WV

2013

Keywords: After-School, Community Impact, Pipeline Program, High School, Community Members, Stake Holder, Community Engagement

Copyright 2013 Catherine Morton-McSwain 


\section{ABSTRACT \\ The Health Sciences and Technology Academy (HSTA): A Case Study of the Community Impact of a $9^{\text {th }}$ Through $12^{\text {th }}$ Grade After School Pipeline Program}

\section{Catherine Morton-McSwain}

This is a qualitative case study designed to examine the viewpoints community members have about the after-school Health Sciences Technology Academy (HSTA) pipeline program for students in grades nine through twelve. The program is designed to foster success and improve the college going rate of under-represented students or what one colleague described as "kids on the bubble." There is little existing literature that examines community impact from the outside or gives voice to community members.

Health Sciences and Technology Academy (HSTA) has been in existence for 19 years in 26 of the 55 counties in West Virginia. It requires a four year commitment to the program which meets weekly during the school year. Students must complete 75 hours of community service over the course of the four years. In addition, students must complete yearly community research projects that address community issues and then present their findings at both local and state symposia. Upon completion students receive a tuition waiver to any state college.

The focus of the study was to capture and evaluate the community perceptions of the impact by interviewing 42 participants over the nine month period of this study. Additionally, extant data and documents as well as participant-observer observations and notes were examined, coded and compared for similarities and differences and served as a form of data triangulation.

The participants identified four categories of impact that were supported by extant and participant-observer data. Those categories were: Education, Community Service, Family and Community \& State. Subtopics under each category defined the categories in detail. For instance, Education subtopics were: college graduation rate, influence on local school systems, enhanced teacher training, and community education. Study implications indicate a recommendation for re-instituting the teacher graduate program and implementation of a community impact evaluation component to the existing community-club evaluations. 
HSTA: A Case Study

\section{Dedication}

First and most importantly, I would like to dedicate this work to all of the strong women in my life who served as role models, coaches, and inspirations. I shall start with my family. My mother who taught me to be tenacious, my aunties, Mayme and Ruth, who taught me to be strong, kind, independent, and inquisitive, my sisters who expect me to be nothing less than successful and are my friends and cheering team, and my granddaughters who are the light of my life and inspire me to set an example.

I have had the privelege of working with or being a student of several intelligent, powerful women. Dr. Ann Chester, has taken me under her wing and provides a daily model of how to get results with grace, strength, and compassion, Dr. Elizabeth Dooley, who sets the bar for professionalism, success and leadership, and Dr. Patricia Obenauf, who, with her quiet strength and wisdom always pushed me to "keep seeking".

Secondly, I want to dedicate this work to my sons who have always believed in me even when I didn't believe in myself, my grandson who is a shining star, my brother who knows me best, my wonderful husband who picked up the pieces and held things together when I wasn't there, and who is my best friend, and most of all my father, because he would expect nothing less. 
HSTA: A Case Study

\section{Acknowledgements}

I wish to acknowledge West Virginia University College of Education and Human Services for the support and encouragement to complete this effort. The college's vision and progressive nature opened many avenues and doors that provided me with an education that is well rounded and perhaps even more importantly relevant in the $21^{\text {st }}$ Century.

This research could not have occurred had it not been for the support of the HSTA program and more specifically, the people that participated in or contributed to this study. Their enthusiasm, patience, and participation were what kept me plodding along throughout the study. I would especially like to acknowledge the Community Research Associates, Field Sites, Central Administration staff and teachers who were always so willing to discuss, review, and hunt for information or documents alongside of me.

My sister Suzie was my editor, sounding board and grammarian who patiently read and reread my changes.

Last, but most importantly, I want to acknowledge my dissertation committee. Their strong, patient, support kept me going and got me through this. I can't find the words to express the gratitude I have for each of you and for all of the wisdom, knowledge and guidance that you have given during this journey. Jim Rye provided the foundation of my graduate school journey many long years ago and has been the lynch pin that has kept this effort together and seen it to fruition. His guidance and leadership have been priceless and for that I will be forever grateful. 


\section{TABLE OF CONTENTS}

Dedication .........................................................................II

Acknowledgements ............................................................ IV

Appendices A-Y ............................................................... IX

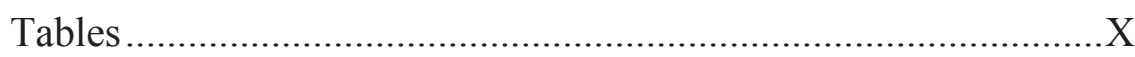

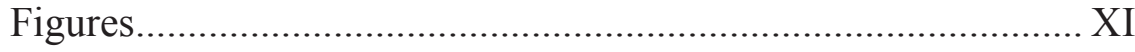

Abbreviations ............................................................................ XI

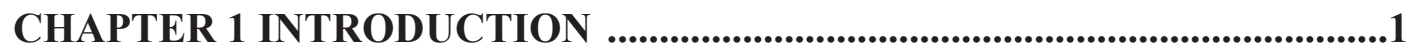

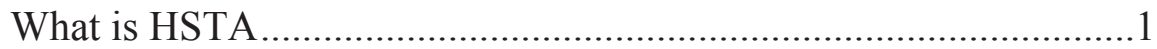

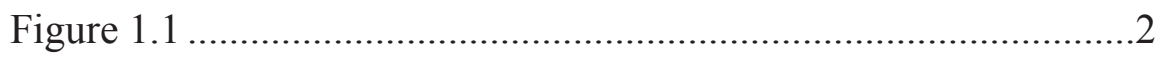

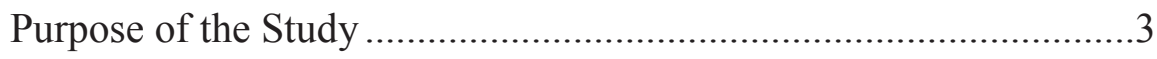

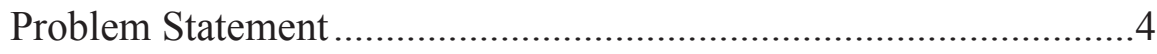

Figure 1.2 Concept Map of Knowledge Dissemination ...................5

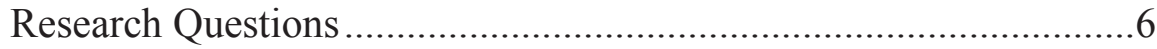

Significance of the Study ..................................................... 7

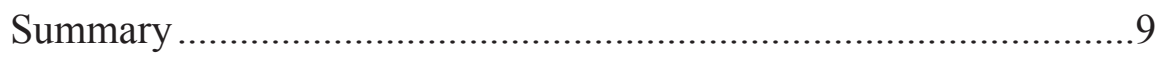

CHAPTER 2 REVIEW OF LITERATURE .....................................................11

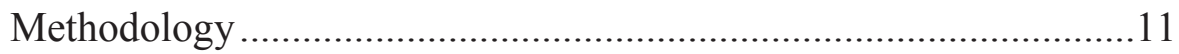

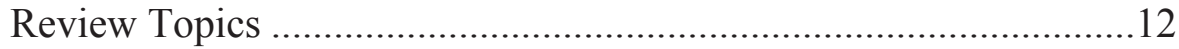

After School Programs for Secondary School Students ...................12

Community Impact of After-School Programs ...............................19

Examination of Existing Literature Written About HSTA ...............25

Figure 2.1 Joint Governing Board Workshop Questions..................29

Cited HSTA Literature................................................................ 30

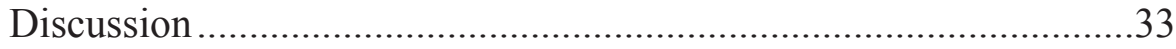

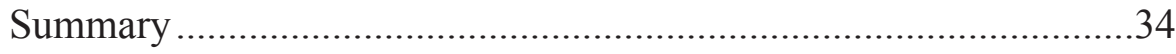

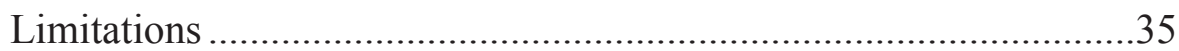

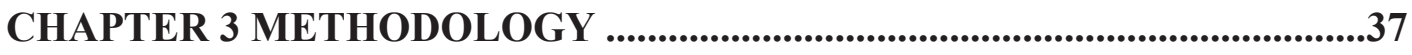

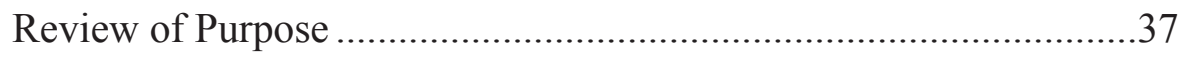

Research Questions Restated ................................................37

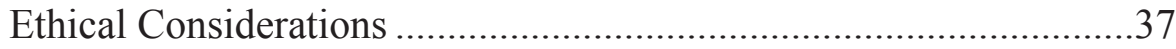




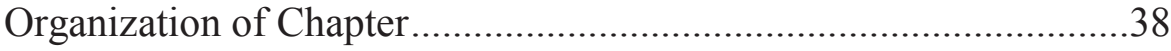

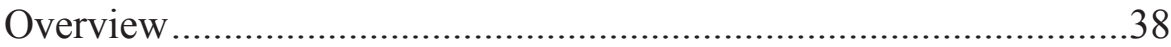

Regions Where Study was Conducted .............................................39

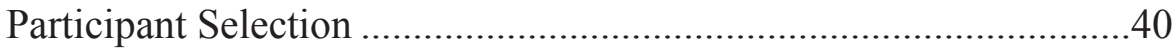

Figure 3.1 Participant Codes..............................................................4 41

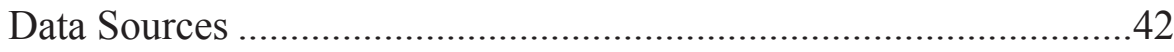

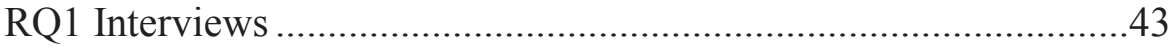

How Participants Are Interviewed...............................................43

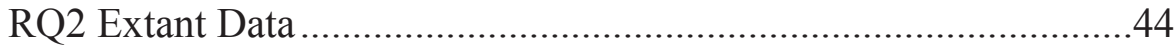

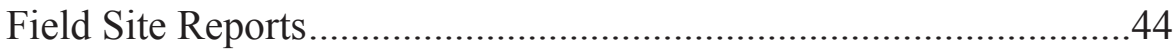

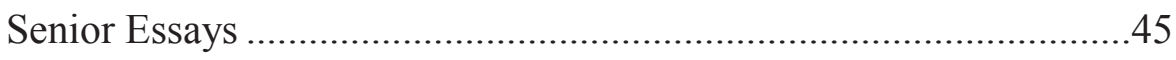

Community Club Evaluations .........................................................45

Student Project Abstracts \& Titles.................................................45

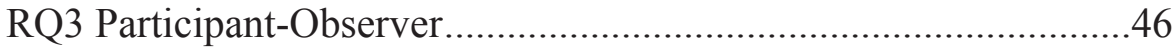

Personal Calendar \& Papers................................................................46

Essays \& Vignettes ...............................................................46

Research Journal ........................................................................46

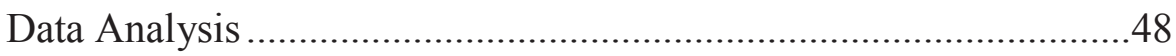

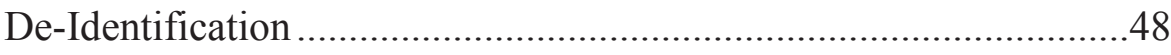

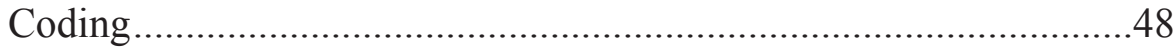

Table 3.1 Data Sources \& Programs for Coding .............................49

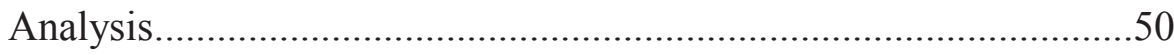

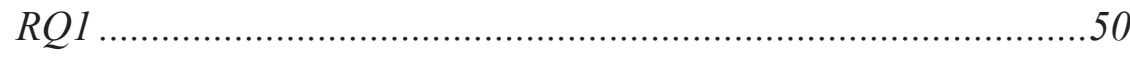

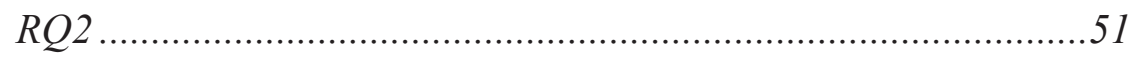

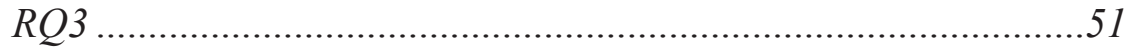

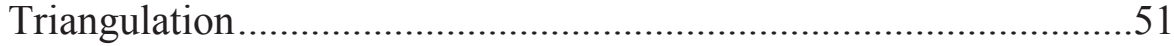

Figure 3.2 Convergence of Evidence.............................................52

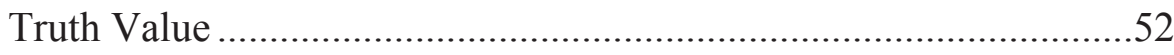

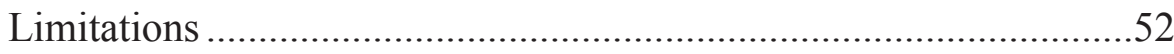

CHAPTER 4 FINDINGS AND DISCUSSION .......................................................54

Review of Research Questions ....................................................55

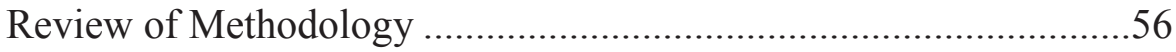

The Interview Process ...................................................................58 


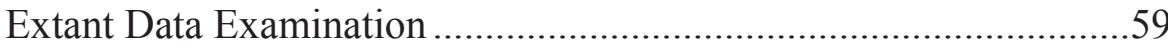

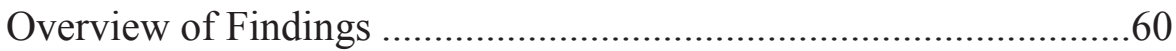

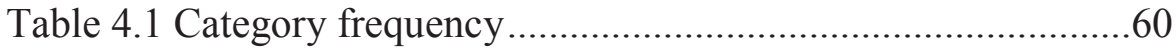

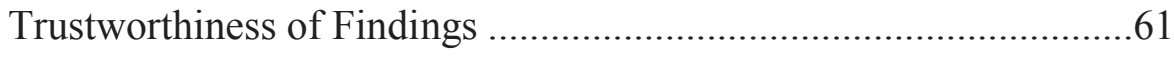

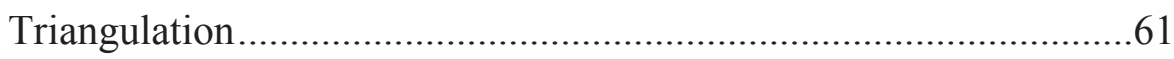

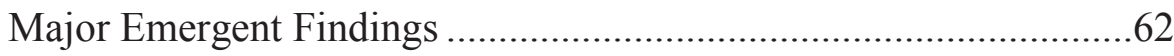

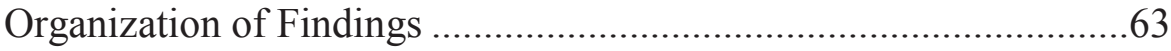

Figure 4.1 Organization of Findings \& Discussion ..........................63

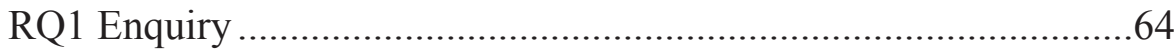

Table 4.2 Lists of Inductive Closed Codes .....................................65

Figure 4.2 Percentage of Category Strength ....................................67

Figure 4.3 Sample Note Card...........................................................68

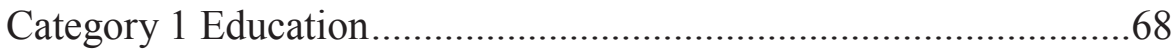

Figure 4.4 Education Subtopics ..................................................69

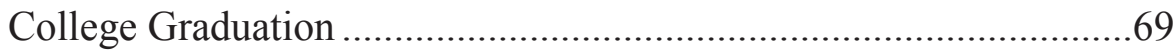

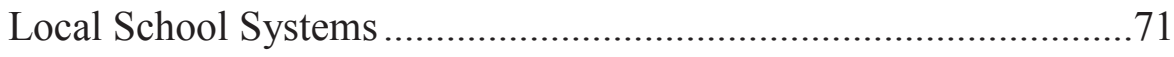

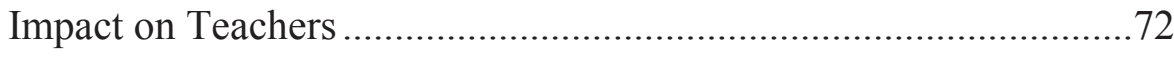

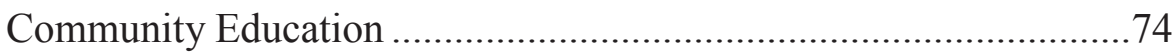

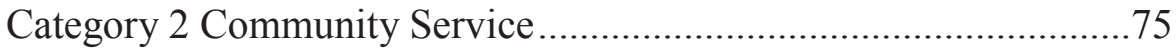

Figure 4.5 Community Service Subtopics .....................................76

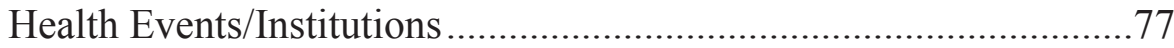

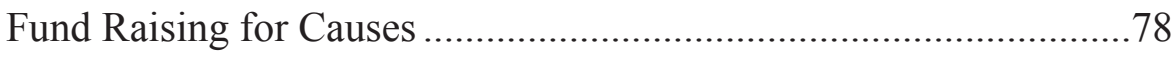

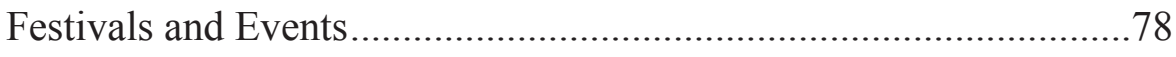

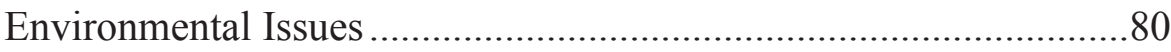

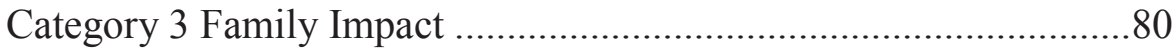

Figure 4.6 Family \& Subtopics.................................................. 81

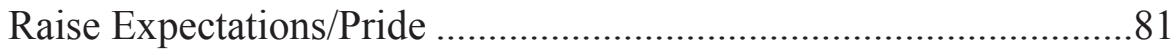

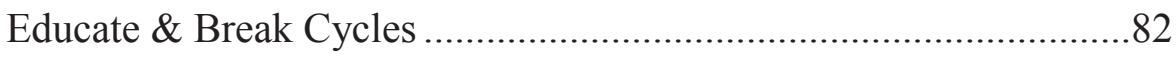

Category 4 Benefits to Community \& State ......................................84

Figure 4.7 Community \& State Subtopics ........................................84

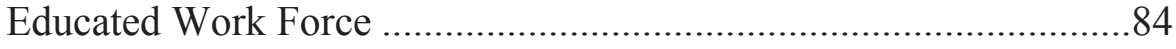

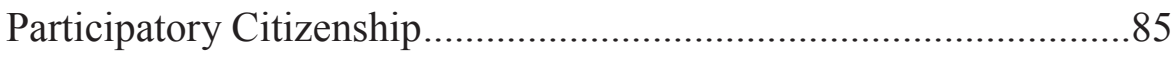

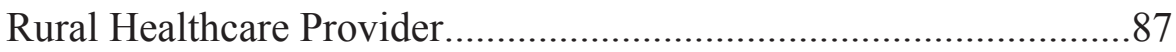


Increase Tax Base \& Remain in the State.......................................8

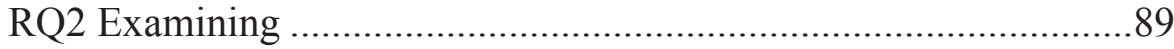

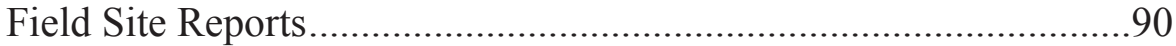

Figure 4.8 Topic Frequency from Field Site Reports .......................90

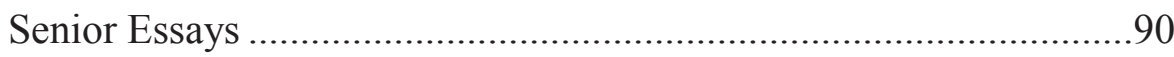

Figure 4.9 Topic Frequency from Essays .......................................91

Student Projects List \& Abstracts .................................................91

Community Club Evaluations .......................................................92

Figure 4.10 Results of Community Club Evaluations .....................92

Category 1 Community Service ....................................................93

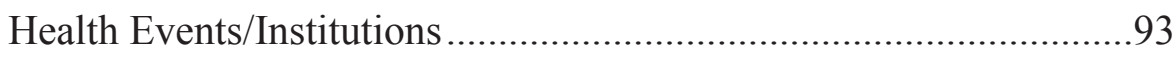

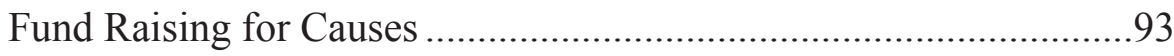

Festivals \& Local Events ............................................................94

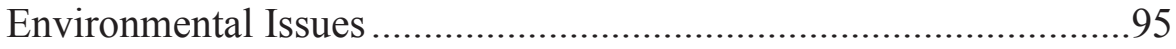

Category 2 Community \& State ....................................................96

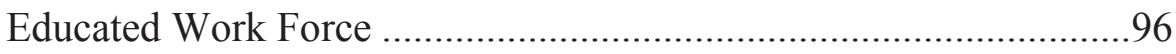

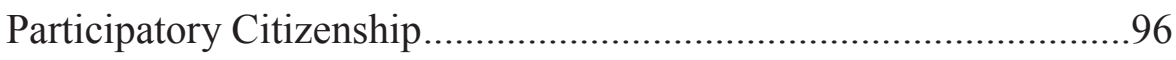

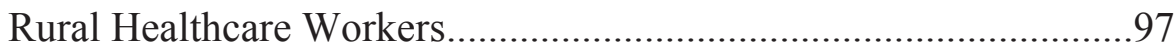

Increase Tax Base \& Remain In State ............................................98

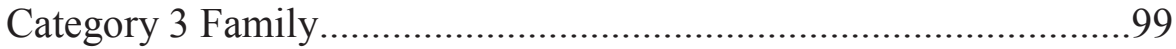

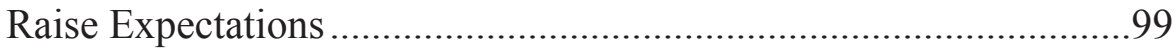

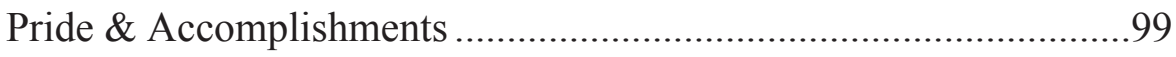

Educate \& Break Cycles ........................................................... 100

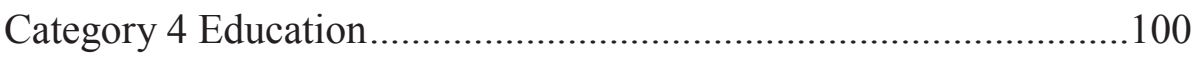

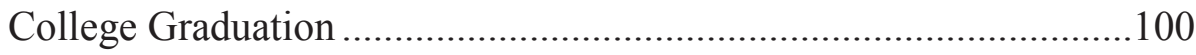

Impact Local School Systems .....................................................101

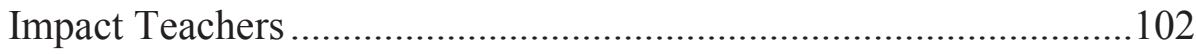

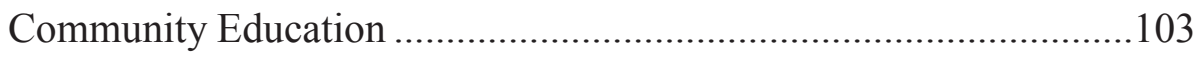

Additional Topic: Summer Institute ..........................................104

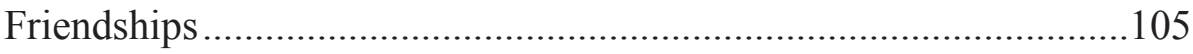

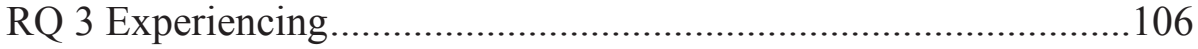

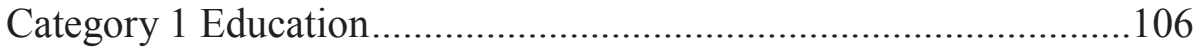

College Graduation ............................................................. 106 


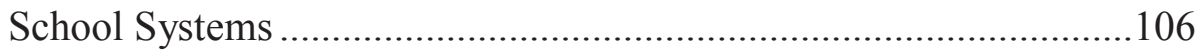

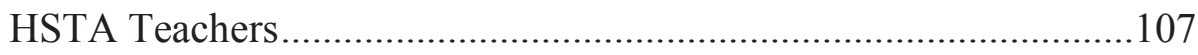

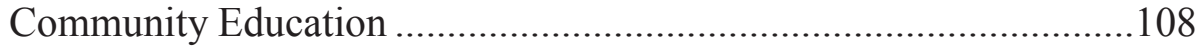

Category 2 Community Service.........................................................111

Fund Raising for Causes ..............................................................111

Festivals \& Local Events ................................................................112

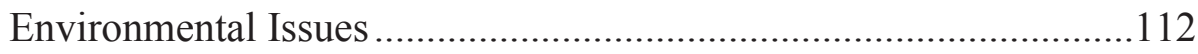

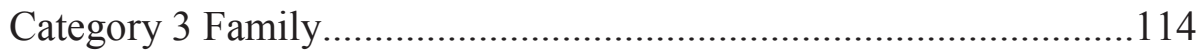

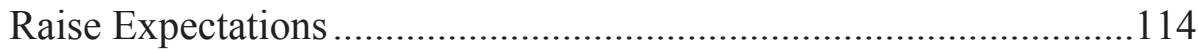

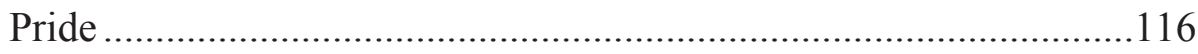

Category 4 Community/State..........................................................117

Educated Work Force ……………………………………..............117

Participatory Citizenship.................................................................118

Rural Healthcare Workers...............................................................118

Tax Base \& Remain in the State ..........................................................119

Peer Review ……………………………………………….......119

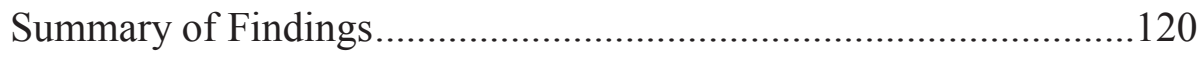

Comparison of Urban/Rural............................................................120

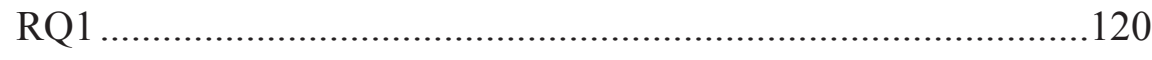

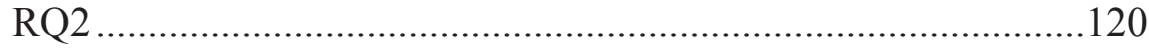

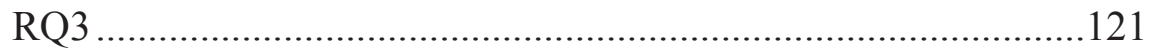

\section{CHAPTER 5 SUMMARY THROUGH RECOMMENDATIONS .........................124}

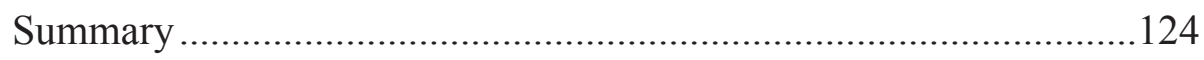

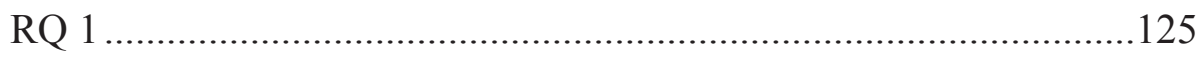

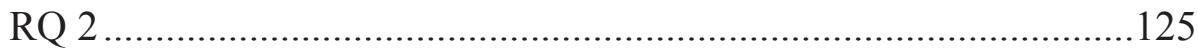

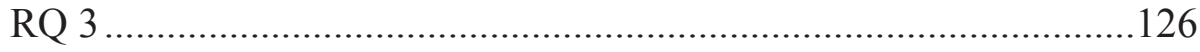

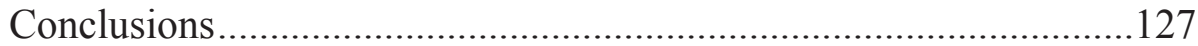

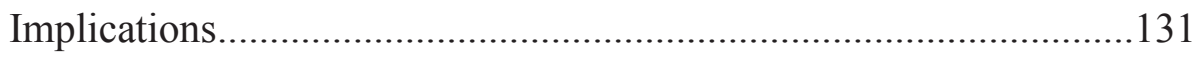

Recommendations for Research .......................................................135

References ................................................................................................136

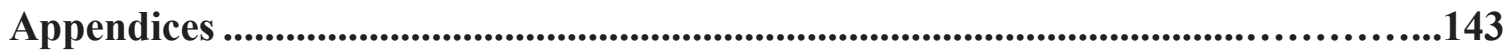

Appendix HSTA Structure..............................................................143

Appendix B HSTA Publication ..........................................................144 
Appendix C HSTA Demographics .....................................................147

Appendix D Legislative Budget Line Item .........................................148

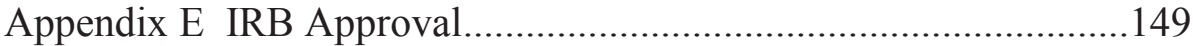

Appendix F HSTA District Map....................................................150

Appendix G Interview Question Prompts...........................................151

Appendix H FSC Report...............................................................152

Appendix I Daytimer Events ............................................................154

Appendix J Reflection Guide.........................................................155

Appendix K Logic Model ...........................................................156

Appendix L IRB Letter ..................................................................157

Appendix M Consent Dialog ……………………………….........158

Appendix N Redacted Member Check ………………………............159

Appendix O Student Essay …………………………………….........160

Appendix P Student Project Topics ...................................................162

Appendix Q Peer Comments ................................................................163

Appendix R Community Service Fund Raiser.....................................164

Appendix S Hometown Heroes .........................................................165

Appendix T 2012 Brochure …………………………………….......166

Appendix U Teacher poster from National Presentation...................167

Appendix V Teacher Published co-authored ......................................168

Appendix W Student Project List Health focus..................................169

Appendix X HSTA Mission Statement...............................................170

Appendix Y MultiFest Photo ...........................................................171

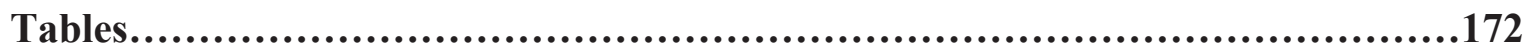

Table 3.1 Data Source \& Coding ..........................................................49

Table 4.1 Coded Data ……………………………………………....60

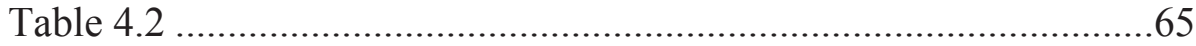

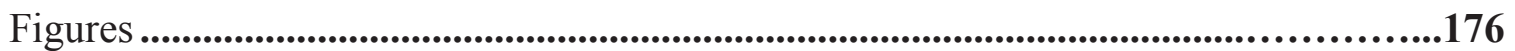

Figure 1.1 Pipeline Progression Titles ................................................

Figure 1.2 Dissemination of Knowledge ………………...................6

Figure 2.1 JGB Pre/Post Questions.....................................................29 
Figure 3.1 Participant Coding Key ...................................................41

Figure 3.2 Convergence of Evidence Diagram....................................53

Figure 4.1 Organization of Findings and Discussion..........................63

Figure 4.2 Percentage of Category Strength .......................................67

Figure 4.3 Sample of Coded Note Card ...............................................68

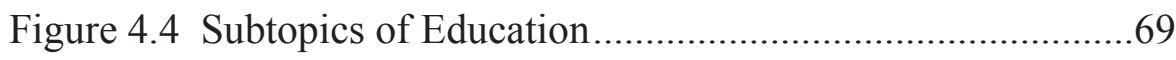

Figure 4.5 Subtopics of Community Service .......................................76

Figure 4.6 Subtopics of Family ..........................................................

Figure 4.7 Subtopics of Community \& State .......................................84

Figure 4.8 FSC Topic Frequency Percentages...................................90

Figure 4.9 Essay Topic Frequency Percentages ................................90

Figure 4.10 Community Club Evaluation ...........................................91 
HSTA: A Case Study

\author{
Abbreviations \\ HSTA Terms \\ CAIRN-Community Appalachian Investigative Research Network \\ CC-Community Club \\ CRA-Community Research Associate \\ FSC-Field Site Coordinator \\ HSTA-Health Sciences Technology Academy \\ JGB-Joint Governing Board \\ LGB-Local Governing Board
}

Other

CBPR-Community Based Participatory Research

NIH-National Institutes of Health

STEM-Science Technology Engineering Math 
HSTA: A CASE STUDY

\section{CHAPTER ONE}

\section{INTRODUCTION}

This is a qualitative case study designed to examine the viewpoints community members have about the after-school Health Sciences Technology Academy (HSTA) pipeline program for students in grades nine through twelve. The program is designed to foster success and improve the college going rate of under-represented students or what one colleague described as "kids on the bubble."

There are numerous articles about the activities and successes of HSTA that span the course of its nineteen years (Bardwell, et al., 2009; Rye, 1998). It is not surprising that all the articles examine components of how and what the program has done from the side of academia. It is vital to the success and the ability to obtain, justify, and maintain funding for the continuation of the program.

This case study examines the proverbial "other side of the coin". It provides a chance for the community's voice to be heard by revealing what community members believe to be the effects of the program in their communities.

\section{What is HSTA?}

HSTA began 19 years ago to prepare under-represented West Virginia high school students for health care careers (Bardwell et al., 2009; Rye, 1998). HSTA data tells us that since 1994 this program has provided a phenomenally successful academic enrichment and professional mentorship program in math and health sciences to low-income, minority, rural, and first-generation college-bound ninth through twelfth grade high school students throughout West Virginia. The program has grown from 44 students and 
HSTA: A Case Study

nine teachers in two pilot counties in 1994 to approximately 800 current high school students and 80 teachers from 26 counties in West Virginia today.

HSTA began as a way to address the rural health care provider shortage in the state. HSTA targets students who can’t afford college and don't have the resources and experiences available to guide them on how to prepare for and attend an institution of higher learning. The HSTA program actively recruits African American, disadvantaged, first-generation college, and rural students. The target population is successfully matriculating through the pipeline. There are no formal terms to describe HSTA students as they move along the continuum. I have defined the various levels for this research to provide clarity.

Figure 1.1. Student Pipeline Progression Levels and Names

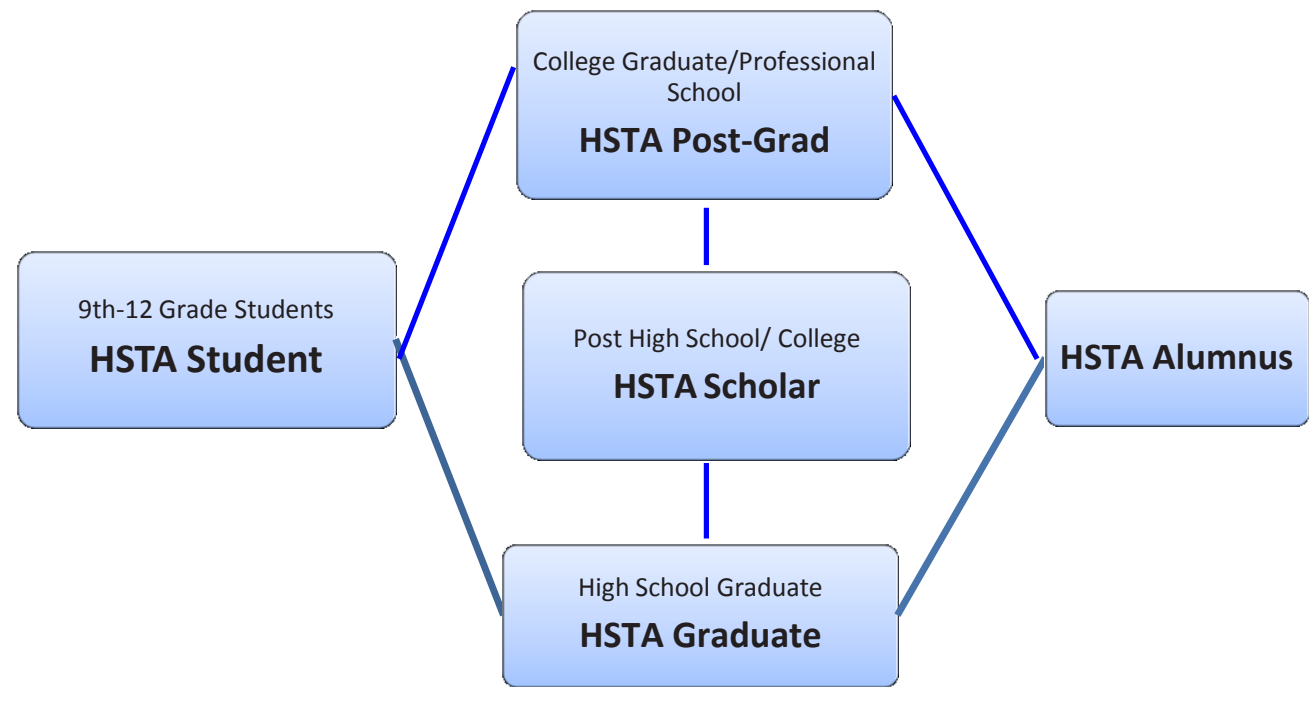

During their first four years in HSTA, students participate in after-school club meetings where they experience rigorous but fun activities that are designed to improve their math and science skills. Students are required to complete an annual research project focused on community issues and must present and disseminate their findings at a yearly symposium. 
HSTA: A Case Study

Summer Academies are held on college campuses and all HSTA students must attend two as part of the requirement of program completion before graduating from high school. These academies are grade appropriate and build upon the community club mission while immersing students in the college experience. Students meet and make life-long friends from across the state while they are challenged to learn and master new opportunities. HSTA is a program that reaches out to ninth through twelfth grade under-represented West Virginia students and follows them to college and toward professional school to help them prepare for health care careers (Bardwell, et al. 2009; Rye, 1998).

HSTA teachers are the key to delivering the programs. A strong professional development component provides the opportunities for teachers to build skills and gain knowledge they can use in their HSTA clubs as well as their classrooms (Rye, 1998). Each year teachers are expected to attend one of the Summer Academies the week before the students arrive to work with the college faculty and learn the material. The following week with faculty assistance, teachers lead the instruction with the students attending camp.

HSTA students are improving health in their own communities as they learn in their HSTA clubs (Branch, et al., 2009). The HSTA infrastructure, with its community leadership focus has access to hard to reach populations. Students complete yearly science research projects mentored and led by teachers and often partnered with scientists. The projects provide a perfect venue to address community health issues and are a way to improve health literacy and healthy lifestyles on a community level (see Appendix A).

\section{Problem Statement}

To date there has been no study of the community impact of the HSTA program as perceived by the community. There have been journal articles, 39 in all (see Appendix B) 
HSTA: A Case Study

published about activities, successes, and components of HSTA throughout the years which have touched on the community impact but not formally studied it. I have so often said that HSTA is a story that needs to be told. It is an example of a large (800 students) community-owned program that is changing the very face of the communities. How the community views the change is fully unexplored.

The journal articles on HSTA tell us of change and impact from the perspective of academia. There is little measure from the other half of the equation which is the community. When examining this literature the absence of the voice of the community is apparent.

To further illustrate this point I am including the following excerpt from a manuscript in which the HSTA CRAs coauthored and submitted for publication. This article addresses the Community Based Participatory Research focus of the HSTA program and its impact on community health literacy. The CRAs focus much of their attention on listening to the community and their needs so they can better guide the research of the students in the program. Unfortunately that is as far as it has been taken. It is evident that even the most recent articles focus on the target population, the students, and does not look at the broader community impact.

It is realistic to anticipate considerable transfer of health care relevant knowledge in a limited health care domain to the CRAs as they are highly motivated, experienced and intelligent science teachers, only lacking a formal training in health care. They can be expected to have the learning skills, potential for critical thinking and motivation to acquire equivalent knowledge to their university specialist counterpart. Thus, it is reasonable to anticipate that the CRAs will not only understand and be able to use concepts (as illustrated in the example of a concept map (Figure 1.2) but be able to develop and expand each topic area into 
its own concept map, with an ability to self-select and self-direct further in depth learning in conjunction with experts in each field.

The CRA role as a high level community health science teacher, in a CRA network of 4 individuals is the key linchpin to the overall program. Each CRA manages activities at approximately 20 HSTA clubs and is in daily and weekly contact with the individual HSTA club teachers. These teachers, once educated in health, use club activities to excite students with science, in health care, and become role models for striving to meld culture and science. It is with these students that the real family learning starts. To be a teacher is a powerful incentive to lean concepts to be shared amongst the adolescents. It will be the ability of HSTA mentors and mentees to provide an informal, unstructured discovery and learning process to families. This is where the success or failure of this strategy will take place.

Figure 1.2. Concept map CRAs, teachers and students use to share knowledge

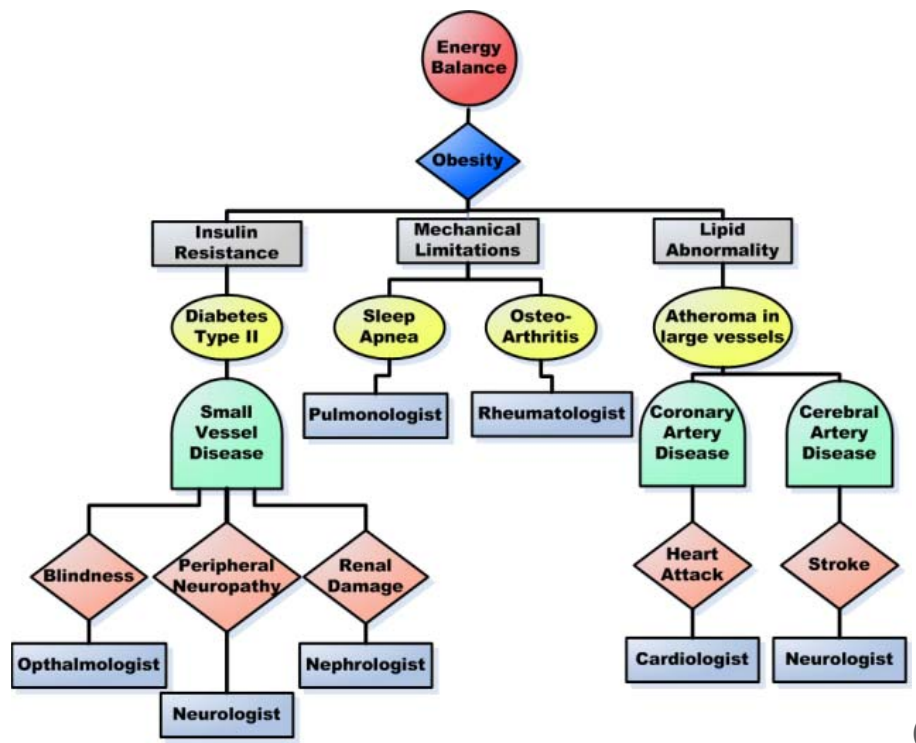

(Branch, et al. 2011, para.9.2) 
HSTA: A Case Study

I included the excerpt to demonstrate the role of community and to emphasize the absence of consideration for the voice to the community. The article addresses how essential the sharing of information is to success but neglects to include how the community would measure the success. The example serves to illustrate a need for this study.

\section{Research Questions}

The research questions are simple and direct. Perhaps the most difficult task of the researcher is to design good questions, research questions that will direct the looking and the thinking enough but not too much (Stake, 1995). I pilot tested my abilities to conduct interviews using a set of research questions designed to elicit the participants' opinions on the impact of HSTA. The pilot test was conducted in areas not included in this case study. It became evident early on that I needed to clarify during the interview what the participants defined as community while they were discussing their perceptions of the impact of HSTA. I found that participants assumed I knew what they meant by community. However, they could define community broadly such as the teaching field, the state as a whole, or narrowly such as their neighborhood or specific club.

- Research Question \#1: How do various stakeholders or community members perceive the impact of the HSTA program on the community?

- Research Question \#2: What do extant data sources (community club evaluations, Field Site reports, student project abstracts, and senior essays) used for HSTA program evaluation say about the impact of HSTA on the community?

- Research Question \#3: As a participant-observer, what are the investigator's perceptions of the impact of HSTA on the community? 


\section{Purpose of the Study}

The purpose of this qualitative case study is to examine the broader impact that the HSTA program has on the community by giving voice to the community through interviews. I examined the HSTA program through the lens of a descriptive case study. I looked at how various stakeholders and community members perceive the impact of the HSTA program on the community. I have categorized the participants as either stakeholders or community members. Stakeholders are defined as those people involved with the program such as HSTA teachers, local governing board members, field site coordinators, graduates, and parents of graduates. Community members are participants that have no direct association with the program. Their views in relation to the different constructs of their roles provide an insight into the extended effect of a pipeline program whose mission is to increase the college going rate and interest in health science careers of a demographic that typically does not attend college.

\section{Significance of the Study}

No study to date has formally explored the stakeholder and community member perspective and perception of the HSTA program outside the obvious impact of educating students. This case study has been designed to address the community impact as evaluated by community members. It can serve as a resource that sheds light on the beliefs that the community has as to the results that HSTA has had on the community. It can serve to enlighten others by providing a data set that can be considered henceforth when evaluating effects of the program. Likewise, the case study is a measure that can corroborate archival data using a missing perspective to complete an important piece of the evaluative picture.

Historically, HSTA has had a robust evaluative component that consists of an outside evaluator who conducts pre and post evaluations of the various components of the program. The 
HSTA: A Case Study

evaluations are designed to measure the specific segments such as the community club programs and summer academies as well as the program as a whole. Results are used to guide and improve areas of need to make HSTA stronger. It is vital to the success of the program. This case study addresses the inadvertent omission of the voice of the community by providing an important evaluative piece which is the community's perceptions of the impact of the program. The case study can serve as a reference when applying for future grants and awards that often require evidence of a measure of community value.

To date, 1,714 students have graduated as high school senior from the HSTA program. The HSTA college going rate is $96 \%$, nearly twice that of the general West Virginia collegegoing rate of 58\% (WV Report Card, 2012). The students are able to succeed in college and graduate at higher rates than the general college-going population ( $92 \%$ versus $55.5 \%)$. They choose science and math careers at a higher rate $(49 \%)$ than the general college population (38\%). Of the approximately 533 HSTA students who have had time to graduate from college, 354 have completed a four-year degree, 184 in health and science majors (52\%); 62 have completed a master's degree, 22 in health sciences majors (35\%); 60 have completed a two-year degree (83\% in health and sciences); 19 have completed a Ph.D. or other terminal degree; 10 have completed an M.D.; and two have completed a Doctor of Osteopathic Medicine degree. Of the remainder, 745 are still pursuing undergraduate degrees, 360 in health sciences majors (48\%); 95 are pursuing graduate degrees, 55 in health sciences majors (58\%); and two are pursuing a second bachelor's degree. (HSTA Program Database, 2012)

The difference between potential earnings without the HSTA program and expected earnings of the student after participation in the program is on average $\$ 30,000$ annually. Assuming the student works for 30 years, this will provide each student in excess of $\$ 900,000$ 
HSTA: A Case Study

additional earnings more than that of parents over the course of his or her career. This positively impacts the economics of the state because $92 \%$ of the students remain in West Virginia (see Appendix C).

The goal of HSTA is to nurture the ambitions of talented students who, for economic or other reasons, might not ordinarily achieve these career goals. This is documented and measured by the program with the view of the results coming from within the program. Success has not been measured from the view point of the community.

College faculty, high school teachers, and other professionals engaged in delivering this program have produced articles and findings in several different journals over the years (see Appendix B). HSTA has a longitudinal base of research both quantitative and qualitative, which covers the various components of the program from the community club based meetings that occur during the school year to the summer campus institutes (see Appendix C). Yearly, HSTA maintains and updates an extensive database of students and graduates. It has analyzed its monetary impact on the state income and return on investment (Chester \& Dooley, 2011). Most recently, a study indicates that HSTA students, when compared to students of similar demographics, score significantly higher on the West Virginia state achievement tests (Smith, 2011). HSTA is unique because, although housed in a research institution, it remains community based.

\section{Summary}

In summary, the main purpose of this qualitative case study is to examine the community perception of the impact of HSTA through interviews of stakeholders and community members, archival data and participant observer documents and experiences, to thus, provide an evaluative perspective that was missing. I examined how the perceived impact is constructed and conveyed 
HSTA: A Case Study

by community members from the interviews. I compared it to the HSTA archival data and reports and my personal experiences as a participant-observer. This case study provides unique and useful findings for a topic not yet formally explored and concludes with implications for policy and practice as well as recommendations for further research. 
HSTA: A Case Study

\section{CHAPTER TWO}

\section{REVIEW OF THE LITERATURE}

As a former HSTA teacher and member of the administrative team for 18 years of the program, I have often remarked that the story of HSTA and its impact is a critical educational story. To date there exist 39 articles written about various aspects of the program but none have addressed the impact as it is perceived in the communities in which it exists.

This review examined the body of literature written about the influences of after- school programs and sought to determine if the literature explored the impact on the communities where they are located. It focused on findings and results of after- school enrichment programs for secondary and elementary students, studies that measured community impact, and an examination of the existing articles about HSTA.

The sources for the literature review were found in the databases at the WVU libraries. These were the main sources of information with Academic Complete, ERIC, EBSCO, and JSTOR databases, the ones upon which I most heavily relied. I searched electronic dissertation abstracts at the WVU libraries. I performed keyword searches and also dug deeper into the sources of some of the most relevant literature cited looking for examples that applied to my study.

Keyword searches included the following words:

- Case study

- Secondary after-school programs

- Secondary after-school education

- Secondary after-school centers

- Program evaluation 
HSTA: A Case Study

- Community impact

- Measuring community impact

- Stakeholder evaluation of impact

- Community engagement

- Broader impact

Google Scholar was a quick resource and much easier to navigate than the library databases. The major drawback of using Google Scholar was trying to obtain the full article which often required payment, but this is where the West Virginia University database became invaluable. PubMed Central, a National Institutes of Health, free archive of biomedical and life research, and Science.Gov were also useful sites.

\section{Review Topics}

The literature review is presented in four topics: after school programs for secondary school students, community impact of after-school programs, examination of existing literature written about HSTA, and cited HSTA literature. Knowledge of existing studies examining stakeholders' and community members' beliefs of the broader impacts of programs would be useful in this case study's design and analysis.

\section{After school programs for secondary school students.}

This review topic was chosen to provide a comparison to programs that were secondary after- school programs like HSTA. The need for examination of similar programs was important in allowing a closer look of what were effective practices and commonalities to the HSTA program. There are few secondary after- school programs and even fewer programs that are designed to increase college-going rate and success. HSTA is a pipeline program and unique to West Virginia. 
HSTA: A Case Study

There was limited research on secondary after- school enrichment programs. The majority of the research focused on elementary and middle school programs which are much more prevalent due to the need for providing safe, supervised venues for this vulnerable age group. "There are few studies of the effects of specific after-school programs, and those that exist have found highly inconsistent outcomes" (Fashola, 1998, p.3 ). More often than not, articles discussing secondary after-school programs measured the effectiveness of the program to meet the goals set forth in grants. These goals addressed the success of the program as it pertained to the issues such as the students and did not look beyond the targeted population. It is the watershed or the ripple effect of the program and how it is viewed by the community that lies unexplored.

The most similar programs to HSTA are those from the U.S. Department of Education like TRIO, (a term coined to describe federal programs that began in the 1960's which are educational opportunity programs). Initially TRIO included UPWARD Bound, Talent Search, and Special Services for Disadvantaged Students, now known as Student Support Services. Today TRIO is comprised of seven programs that target various issues which have had their own successes. Of those seven, TRIO's Upward Bound Math and Science Initiative that began in 1990, allow a closer time frame for comparison to HSTA which started in 1994. The uniqueness of HSTA is that it is addressing the needs of a state with a critically, medically, underserved population. Most importantly, it is community led. TRIO programs are federal and do not have the local input and buy-in that drives the HSTA program.

Upward Bound is a program that develops skills and promotes success for underrepresented students by strengthening math and science knowledge needed to succeed in college. It provides college campus experiences that the students would otherwise not have. 
HSTA: A Case Study

Upward Bound serves high school students from low-income families and high school students from families in which neither parent holds a bachelor's degree. The goal of Upward Bound is to increase the rate at which participants complete secondary education and enroll in and graduate from institutions of post-secondary education. (Ed. Gov, retrieved 9/5/2011).

HSTA has the infrastructure designed for community leadership. It differs greatly from Upward Bound in that HSTA provides tuition waivers to any in-state college upon successful completion of the program. It also tracks students throughout college and after graduation keeping record of where they reside and the careers they have chosen. This is not the case for UPWARD Bound where students complete the program during their senior year in high school and go on to attend college on their own. A study of 48 Upward Bound students who were freshmen in college had mixed results (Laws, 1999). There were no statistically significant differences between the mean GPA and dropout rate of Upward Bound students when compared to a control group. The expectations were that Upward Bound students would have a higher GPA and a lower dropout rate. It did find that Upward Bound has a strong English component but the math and science programs were not effective in improving skills and abilities. The study did not look at community impact nor did it seek input of the impact from the students, families or communities.

Another TRIO program, Talent Search, is for seventh and eighth grade bright and gifted students and provides them with accelerated curriculum and encourages them to take advanced courses in high school. The largest component of the program is the Summer Camp where Talent Search students take courses and reside on a college campus. Students, who entered Talent Search and participated, took more advanced placement courses in high school, were more likely involved in their Student Government or some other leadership role, and received 
HSTA: A Case Study

more academic awards or honors while in high school (Brody \& Mills, 2005). Students and parents alike were surveyed and asked their perceptions of the impact of the program. Parents of Talent Search participants noted that the benefits of participating in Talent Search included learning about their child's abilities, increasing their child's educational opportunities, and expanding their child's thinking about careers and college. Unfortunately, parents were not clear or aware of the other benefits of participation in the program (Jarosewich \& Stocking, 2003). The response was significantly indicative that the program was having the intended academic effect and the community recognized it. The community is defined in this survey as the parents and students themselves who were Talent Search students. The program did not explore the impact on the community or the perceptions of the community at large. "As Talent Search continues to develop new ways to serve the needs of advanced learners, it is important that they continue to embrace the legacy that all of their efforts should be research based" (Jarosewich and Stocking, 2003, p. 149).

Through Expanded Learning Opportunities (ELOs), youth often have opportunities related to potential college majors and careers that typically are not explored during the traditional school day (Harris, Deschenes, and Wallace, 2011). The Harvard Family Research Project sponsored the brief written for the National Conference of State Legislators in 2011, and it continued with the following bullets of wisdom.

- Allowing for flexibility in recognition of the fact that older youth often have other responsibilities, including work and family obligations.

- Employing staff who can form strong relationships with youth participants and demonstrate that they care about them.

- Offering a safe and nurturing environment that creates a sense of community. 
- Providing opportunities for intentional and meaningful peer interaction (Harris et al., 2011, para. 8).

The Harvard Family Research Project Brief bulleted points are found to be guiding principles in other programs that nurture students regardless of the target age of the population. These are among the tenets of the HSTA program. The brief had no mention of measuring impact. The overriding themes in the brief, however, show similarity of characteristics needed for programs to successfully improve the college-going rate of students.

An article by Haggis, Sims-Gould, Winters, Gutteridge \& McKay (2013), looked at measuring sustained impact of community based physical activity interventions. They didn't measure impact but rather discussed what an impact measure should include. They postulate that health promotion research contributes to sustained impact. "That measure should include and acknowledge the interplay between social, environmental and political systems of influence" (2013 from the abstract). They also state that there needs to be a theoretical and methodological integration that should have a social-ecological approach, be participatory action oriented, and should be conducted by an enthusiastic interdisciplinary team.

Hatch (2012), wrote there was a need for a programmatic investigation of high impact practices. In particular he examined successful college engagement programs and student success. This essay argued that despite having a high impact or good practices that are shown to have a high impact on student engagement levels, there was need for a more systematic investigation of the practices. He believed a structural and collective investigation instead of topical one, was needed for a deeper understanding of student and community engagement.

Davis, et al. (2011), explored research based and other literature to find what it said about young peoples' perspectives of community and engagement. It went on to discuss what types of 
HSTA: A Case Study

student groups were involved in community engagement and how the schools could use this information to promote more involvement. It did not measure impact or broader impact but looked for patterns to promote increased student participation.

Knowledge and Excellence in Mathematics, Equilibrium, and Technology (KEMET) Academy targets African-American students enrolled in the under-resourced Black Belt region of Alabama schools. This intervention pilot targeted the academic skill development of KEMET Academy participants in the following areas: reading comprehension and literacy; mathematics; computing and science; visual arts; emotional and mental health, and finally, physical health and fitness (Davis, et al., 2011). The study was relatively small with 48 subjects in seventh and eighth grades, and the subjects were followed through the five years of the program. It was similar to HSTA in that it targeted at-risk youth and provided community and campus experiences enriched and mentored by caring adults, with the following goals:

- Increase the number of children from Alabama's under-resourced schools who pursue post-secondary education or training;

- Raise the number of under-represented minorities pursuing careers perceived as non-traditional; and

- Improve the likelihood that these students will return to their home communities and contribute to the communities' sustainability and growth (Davis, et al., 2011, para. 8).

The article lists the successful strategies that it encourages other programs to embrace to allow dissemination of the program. KEMET addresses many of the same issues HSTA faces and in a somewhat similar fashion. It is a smaller program in scope and duration but similar in 
HSTA: A Case Study

its results. There was no mention of impact measurement in this article. It would have provided a possible comparison and insight into the results of a similar program had there been one.

Not an after school enrichment program, but an interesting and fairly standard program in many West Virginia high schools today, is a credit recovery program. In an article about such a pilot credit recovery program at a large Midwestern high school, students who had failed a course were given the opportunity to recover the credit. This program did not measure the impact from the students but did note that students participating were on target to graduate with their class where before the credit recovery, they were not. It also noted that a strong factor in the program was being selected to participate. "If a teacher felt a student could succeed, then perhaps the student had greater confidence in his/her own abilities - a type of self-efficacy" (Franco, \& Patel, 2011, p. 25). The sample size was small, n.10, and the results may not transfer so successfully to a larger study. It is noted that the community impact or student impact were not measured. In a program so critical to the successful graduation of students who would most likely drop out, a study of the belief of impact held by the community would be fascinating.

This leads into the following study which examined how a university partnership with a middle school changed a community. "While still in its early stages, the University Assisted Community Schools (UACS) at Pond Gap shows how collaborative partnerships between local schools and universities can tap available resources while working alongside the community at large" (Lester, Kronick, and Benson, 2012, p. 25 ). This study discusses the need to be responsive to the needs of the community and be flexible enough to remain relevant. It is successful because it remains democratic and encourages and nurtures community ownership and democratic participation. It can serve as a model to respond to impact because to be able to allow the community to drive the program, it must have input from a community that is 
HSTA: A Case Study

experiencing the impact whether implied or spoken. This program at the Pond Gap Elementary school is new and not measuring community impact but has similar driving themes and mantra that mirror HSTA.

The elementary afterschool program LA's BEST was created in 1988 to address the lack of adult supervision of children after school. "Today the program serves 28,000 thousand students ages 5-12 and provides education enrichment and recreation in the city of Los Angeles, (www.lasbest.org accessed 9/12/2012). "Student engagement not only influences outcomes within the LA's BEST program but has an effect on advancing the important benefits of individuals graduating from high school, going on to college, and making positive contributions in their own lives and to society at large" (Sanger \& Heckman, 2011, p. 77). The program, which has been in existence for 24 years, is now beginning to study the long-term impact on the lives of its students. "LA's BEST is currently tracking alumnae to discover to what extent engagement in its programs led to different patterns of course selection in postsecondary education and jobs or careers later in life" (Sanger \& Heckman, 2011, p. 77). This study too, looked at the impact on the target audience, the students.

The literature on secondary enrichment programs is small, and the examples I chose to review that were elementary were chosen because of their similarity to components of the HSTA program. A common theme in the literature regardless of the target age group was the sparse attention to measuring community impact.

\section{Community impact of after- school programs}

The second topic of the literature review examined articles that were measuring community impact of programs. It was during this phase of the review that it became evident that the overwhelming majority of impact studies measured impact from the viewpoint of the 
HSTA: A Case Study

program from those within the program outwardly or "inside-out" (Falk \& Needham, 2011, p. 1) which too often, weakly or completely neglected to give voice to the community. "Most research in support of these assertions, however is limited in scope and 'inside-out' in approach" (Falk, \& Needham, 2011, p. 1). It is the norm for programs to report impact from the inside-out and rare that impact is measured from the voice of those in the community. It stands to reason that it is logical to have leaders of programs looking for impact as they designed it to occur. It is not unusual that a program would have assumed that the audience for which the impact was intended would recognize and name the impact as it was experienced, but it is unusual for a program to look beyond the audience and seek community perspective of impact. Their study measured the community impact of a science museum using surveys and phone interviews. “Almost every adult community member surveyed who had previously visited the Science Center agreed that their visits to this institution resulted in an increase in their science and technology knowledge" (Falk \& Needham, p. 9).

Being able to document evidence of impact demonstrates that organizations and programs are making a difference and or accomplishing something positive. "The results of a program must ultimately change people's attitudes or behavior or benefit society in other ways" (Diem, 2002, abstract). Most research in support of these assertions, however, is limited in scope and evaluate benefit using the "inside-out" in approach. "In other words, data demonstrates that a self-selected population has benefited from such experiences, but little research has used the "outside-in" approach to demonstrate that large numbers of the general public have benefited" (Falk \& Needham, 2011, p. 2). Labeling the phenomenon of the method most commonly used was a clarifying moment to me. The phrase "outside-in" brought into focus how the interviews of stakeholders can close a gap in evaluation and provide a piece of the missing picture. The 
HSTA: A Case Study

HSTA case study brings the outside perception of impact in to the discussion by providing a means in which community members can explain their views on the broader impact of the 18 year old program.

Through Health Sciences and Technology Academy, West Virginia families who have never had educational opportunities have greater access to higher education. Health Sciences and Technology Academy leaders are afforded numerous otherwise unavailable opportunities for professional development though Health Sciences and Technology Academy board retreats and workshops. Teachers network with scientists and faculty members across the state in innovative ways. These collaborations help students acquire advanced skills in science and math while nurturing their interest in related careers. Faculty members are able to conduct research in authentic environments. As a result, community-based problems such as obesity are addressed locally. Above all, students are able to form learning communities with other students from counties across the state (Chester, \& Dooley, 2011, p. 95).

The measured impact of the HSTA program looks at the success as to how it met the goals of the land grant university. It details the outreach and involvement with the community and the HSTA teachers when it speaks about retreats, workshops and professional development. It explains how HSTA teachers and students working with scientists increase career awareness, improve academic skills, and address health issues that affect communities. It accurately describes the impacts and has data to back it up. It does not look at the perspective and beliefs of the community as to what they perceive to be the impacts.

Chester \& Dooley describe the economic impact of HSTA. 
HSTA: A Case Study

Although West Virginia University founded Health Sciences and Technology Academy, the State of West Virginia recognizes the effectiveness of the Academy and funds Health Sciences and Technology Academy annually at about $75 \%$ of its costs. A study of the first 231 Health Sciences and Technology Academy graduates comparing their earning power to that of their highest earning parent revealed an increased earning power of approximately $\$ 26,000$ annually. Because $92 \%$ of these students stay in West Virginia to work, this increased earning power is directly benefiting the communities. If this figure is multiplied by a 30 -year career with the additional earning power, every dollar invested in the program by the State is returned in tax revenue to the State at a rate of $\$ 2.60$.

The effort has garnered: $\$ 11,887,425$ in state funding, $\$ 3,781,850$ in federal grants, $\$ 5,499,904$ in foundation grants, $\$ 544,344$ in individual donations, for a total of $\$ 21,713,523$ over the past 15 years. In addition, the cost of student loans to Academy students for higher education is significantly reduced by the tuition and fee waiver they are eligible for throughout undergraduate, health professions, and graduate school at West Virginia University and other colleges (Chester, \& Dooley, 2011, pp. 94-95).

The numbers speak for themselves; however, the above information is not well disseminated or known even to those who should be most interested: the state legislators who provide $\$ 1,525,000.00$ in funding each year for HSTA for the last five years (see Appendix D). The "inside-out" approach is not unique to HSTA but is the standard by which programs measure and evaluate. Literature is plentiful that measures programs impacts and most of them are heavily measured in this manner. It is a natural flow of program development and 
HSTA: A Case Study

assessment to do so. It seems logical that those who evaluate are those who are implementing the program. Likewise, it stands to reason that the articles about such impacts are written by academia and come from that perspective. It is often difficult to get the community impact measured and evaluated from the standpoint of the community unless an infrastructure and trust is established with the community and they feel safe and invested in the program.

"Traditionally, the criticism of evaluation in Extension has been that evaluators have simply reported on the number and demographics of the people who participated" (Gentry-Van Laanen \& Nies, 1995, para. 2).

This is standard for many programs, but fortunately HSTA, leadership saw the need to document and evaluate all components from the beginning and could measure community impact albeit "inside-out". HSTA has examined the economic impact, college success rate, health career impact, and the rate at which students remain in the state after graduation. It has closely examined the end results that benefit societal conditions through social, economic, civic, or environmental improvement. This is not the case for Extension programs. "In general, Extension programs which utilize program evaluation in the form of outcome studies do not document impact by collecting real evidence of behavior change and/or greater end results that benefit societal conditions through social, economic, civic, or environmental improvement" (Workman, 2010, p. 22, 23).

I found that several of the articles called for a more in-depth examination of stakeholder perspective or outside-in analysis, while researching for literature that examined community impact.

First Year Experiences of GPA and retention showed that despite some limitations, the results suggest a quality program focused on enhancing the first 
HSTA: A Case Study

year student experience can have a meaningful positive effect on both GPA and retention. Future analyses should include a complete examination of the survey results from both faculty and students to better understand this FYE program from the diverse perspectives of these important stakeholders (Jamelske,2009, p. 390). A commentary written about the following article recognizes the use of and need for participant feedback and its ability to encourage ownership and even activism extolling the need for feedback but only from the participants' view. "Because our interviews with participants show that report back increases environmental health literacy and stimulates personal and civic action, disseminating these methods has public health impact” (Brown, Brody, Morello-Frosh, Tovar, Zota, Rudel. 2011, p. 193).

A California program that was designed to improve the science literacy of the community, was cognizant of the importance of evaluation and feedback from the target audience. It trained the staff how to elicit and discuss the feedback from the community. The Community Based Participatory Research CBE's standing with community members and elected officials was strengthened because they brought science to the community. The research was empowering for residents who brought their results to public hearings. It offered good leadership development by training CBE staff in research methods and interpretation and giving residents opportunities to discuss and testify about results (Adams, et al., 2011, p. 329).

Lastly, an article written in 1998 measured the perceptions of parents of college freshmen students who were in the Upward Bound program and attending the University of North Carolina at Chapel Hill. "Clearly, these parents perceived the University of North Carolina at Chapel Hill (UNC-CH) program as having a substantial impact not only on their children's academic 
HSTA: A Case Study

development but also on their social and emotional development" (Zulli and Frierson, 1998, p. 370).

\section{Examination of existing literature written about HSTA.}

The third topic of the literature review examined the existing HSTA literature for evidence of impact evaluation from a community aspect. The fourth topic under this category emerged when I noticed 17 articles were cited by others, and I became curious as to why the articles were cited in hopes of discovering more literature that addressed community impact as measured from the community perspective.

The body of HSTA articles can serve as a statement of impact. These articles generally fall into one or more of the following themes: HSTA program development; HSTA student research projects; HSTA teacher professional development; HSTA students as community researchers. Additionally, there are articles about the success of the program at various stages the success the program has had in helping to address the shortage of rural healthcare workers. Broader impacts are implied.

Existing documentation and quantitative data indicates that HSTA has a broad community impact, but there have been few articles written that address this in detail with a perspective that considers the community experience. Articles about HSTA are written for scholarly publication and address a research or project initiative. Community impact is mentioned in articles and implied often for the reader to infer but has not been the focus of study. During the project described in an article, it states that "friends of HSTA students came in from neighboring towns to use the community walking trail” (Rye, O'Hara-Tompkins, McClure, Aleshire, 2008, p. 45). The ripple effect of the project is inferred but not measured. Articles addressing community wellness activities initiated by HSTA students do give some attention to it 
HSTA: A Case Study

but again do not look specifically at measuring the impact from any other view than from "inside-out". An article which I co- authored discussed how HSTA students worked with the town council to map out and mark two separate mile-long routes for walking through a small town to encourage citizens to get active. This was how students addressed their initial findings after discovering the leading cause of death in their county was cardiovascular disease (Bardwell, Hyde, Lewis, Morton-McSwain, Rye, and Simoyi, 2001). The article does not measure impact or look at the usage of the walking routes after the project was built.

Another article by Rye set forth conditions that asked teachers to complete additional professional development on electronic concept mapping and to provide in-service session on project software (Inspiration ${ }^{\mathrm{TM}}$ ) and applications they developed to other HSTA teachers as well as colleagues at their school of employment as a requirement to receive the training and the site licenses (Rye, 2001). I was a part of this study and was required to submit an attendance sheet and short summary of the in-service after it was given. The in-service was attended by 28 faculty members and administrators. I did not get formal feedback from those attending but did note that during the course of the school year after the in-service, several teachers who chose to use the software contacted me for support.

An article written addressing the training of HSTA teachers and staff in multicultural awareness discusses the perceived impact of sensitivity to cultures other than our own and the ability it may have to encourage students to pursue careers in science and health.

When teachers model inclusiveness and multicultural awareness in their approach to students, they are modeling open-mindedness, which entices innovation. This approach is true to the nature of science. Innovation leads to new insights and problem solving. This process of scientific investigation captures student interest 
HSTA: A Case Study

and generates enthusiasm for some students to pursue college degrees and careers in the sciences and science teaching (Bardwell \& Kincaid, 2000, p. 35).

The article goes on to discuss the science project topics chosen by HSTA students and how the knowledge from these projects is exposing families to change. "Through completion of these projects, students devise solutions that can be implemented in their schools and communities, and promote informal education about healthy lifestyles for the future" (Bardwell \& Kincaid, 2000, p. 35).

Similar to the previously mentioned article, one authored by Dooley and Bardwell studied multiculturalism and the effect it has to encourage underrepresented HSTA students to study and pursue health care careers. It focused on practices which impact the success of the HSTA program in terms of multiculturalism (Dooley, \& Bardwell, 2000).

A HSTA article discussing the use of pedometers by classroom teachers with their students points out that the use of the pedometers can address childhood obesity. It implies that the knowledge gained about energy balance will become skills that carry over into everyday life choices and thus will impact the health of those involved. "Pedometers and associated resources on human energy balance are important tools that science teachers can employ in helping schools respond to the national call to prevent childhood obesity" (Rye, Zizzi, Vitullo, and Tompkins, 2005, p. 529).

Recent articles on HSTA students conducting Community Based Participatory Research (CBPR) state the benefits include not only the translation of knowledge to influence community lifestyle behavior but also the creation of a pipeline of new biomedical scientists for the future (Chester \& Branch 2009, p. 352). The focus of a sister article discussed the nearly untapped opportunity of having adolescents (HSTA students) conduct CPBR and serve as the conduits of 
HSTA: A Case Study

knowledge translation to family and friends (Bardwell, et al., 2009). I co-authored two other articles on the same subject which details the student training and the research findings on diabetes. The articles assume the readers infer the larger long range family and community impact (Bardwell, et al., 2009, Branch, et al., 2011). There is a ripple effect that radiates out because of the actions of the program, and it is affecting the families and communities. It is vitally important to know what these effects are and how they are valued by the communities. It is an issue of empowerment and cooperation. Giving a voice to all, measuring effectiveness from many perspectives such as "inside-out" and "outside-in", allows ownership that will help steer the mission of HSTA. Studying the broader impact also validates the effectiveness of the activity beyond the target audience.

The following is an example of how it did steer the mission of HSTA (see Figure 2.1). In November of 2011, the HSTA Joint Governing Board convened a state- wide meeting at Stonewall Jackson Resort. The objective of the retreat was to provide professional development for the all state and local board members and employees other than teachers, who had just completed their own professional development. It was a meeting designed to address consistency, fairness, and policy implementation. All regions had an officer or officers who attended. All field staff and central administration were present. The two day meeting was extremely productive. It was the first time in six years that the community leadership from across the state had been together. The community members led the discussions and provided insight, valuable information and solutions for issues. The attendees had completed rigorous training, felt unified, developed a new mission statement and were ready to take their ideas and enthusiasm back to their communities. This is an example of a principle of community engagement. It is an example of the impact of a program when the 'outside' leads the inside. 
Figure 2.1. Joint Governing Board workshop pre/post questions, 2011.

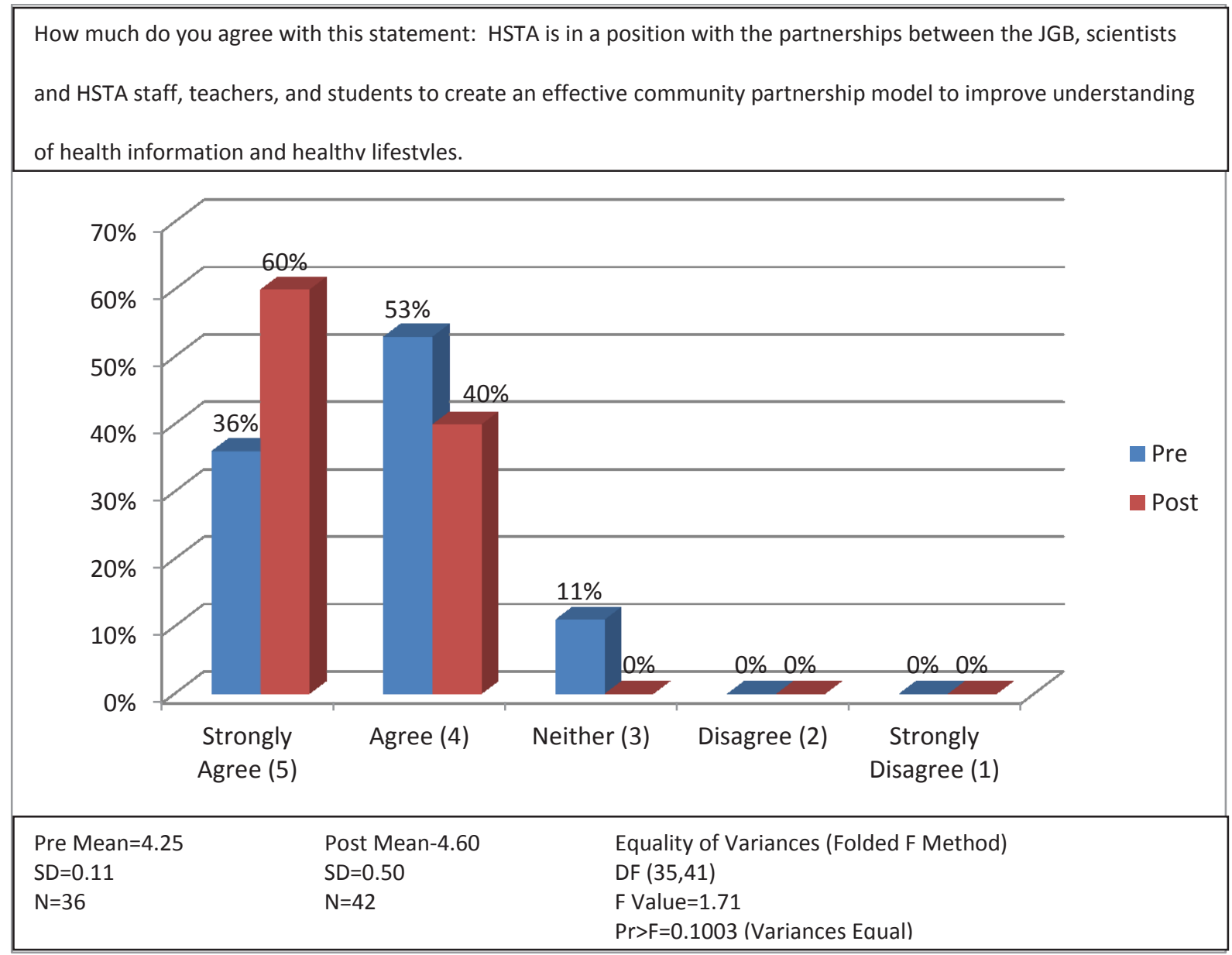

The most detailed article that discussed the community impact of HSTA is one of the more recent which appeared in the Journal of Higher Education Outreach and Engagement (Chester, \& Dooley, 2011). Excerpts from it can be found under the previous topic. The article discusses the impact on faculty, youth, economy, society, students, and the state as a whole but doesn't specifically look at a community impact from a community perspective. It is not a common or frequent way of measurement. It is one that I would normally think a social scientist would study. It is also the subject I would defer to an expert. It stands to reason that people normally measure what they do and thus gives understanding as to why most programs measure impact from the "inside-out" (Falk \& Needham, 2011, p. 2). As a classroom teacher for 25 years, 
HSTA: A Case Study

I measured my teaching effectiveness by how well my students learned. It was something I could measure---grades-- and see immediately. If students weren't mastering subject material, then I would adjust my methods for re-teach or revise what I had believed to be their level of base knowledge. This is another example of "inside-out" and how it can be used to formatively evaluate programs and progress.

The topic of Dr. Feon Smith's 2011 dissertation was about the impact HSTA had on the state achievement scores. Her research study was to determine if students who participated in HSTA showed an increased level of performance on the math and reading/language arts sections of the West Virginia Educational Standards Test 2 (WESTEST 2) than students who were not in the program. She matched comparison groups by socioeconomic status, first generation college, and race and had equal numbers in each study category. Her results show that when the 168 HSTA students were compared to 168 students who were not HSTA students, HSTA students scored significantly higher on the math and reading/ language arts portions of the test (Smith, 2012). The impact is not lost on the reader, especially when discovering the effect that HSTA has on narrowing the gap between white and culturally diverse students. Her study does not include a community perspective but, like other HSTA literature, measures the outcomes of the program.

\section{Cited HSTA literature}

The fourth topic was an examination of the HSTA literature and how others used it in their scholarly publications. It was important to understand the benefit others found in the existing HSTA literature, and to do that I began a search for what articles and how many times they were cited. Exploring the use of the articles for others implied value from the aspect of the community of academic authors. 
HSTA: A Case Study

Seventeen of the 39 articles or $44 \%$ have been cited. The most frequently cited article was about technology integration and was published in The Journal of Technology and Teacher Education in 2001. It was written by a doctoral student whose job it was to train HSTA teachers about best practices for technology use in the classroom and HSTA clubs. It was cited 38 times (Nisan-Nelson, 2001).

The second most cited article by Zizzi, Rye, Vitullo, O’Hara-Tompkins,2009 presented Appalachian youth conducting research interventions using pedometers. It was cited 24 times

One of the earliest articles written has been cited 20 times. Authored by Rye \& Chester, it appeared in Academic Medicine in 1998 and discussed the HSTA program and its mission to "grow" West Virginia health care providers targeting underrepresented youth (Rye \& Chester, 1998)

Interestingly, the remaining articles are cited eight or fewer times. Two of the three articles cited eight times are written about the same events but examine different phenomena. In 2001, Bardwell, Hyde, Lewis, Morton-McSwain, Rye \& Simoyi, wrote about HSTA student projects that addressed community issues. The other article by the same authors discussed the how partnerships were used to promote teacher professional development and inquiry learning. (Bardwell, et al, 1999) The third article written in 1998 was published in Rural Educator and presents findings about a teacher professional development program offered by HSTA. The program allowed HSTA teachers to obtain a Masters' Degree in Secondary Education with an emphasis in science for little cost to the participant. While in existence, the program helped 26 teachers from across the state further their education (Rye, 1998). 
HSTA: A Case Study

Cited seven times, was the article explaining how the pre-college enrichment program, HSTA, maximized success in post-secondary education for underserved students. It was published in 2000 in Academic Medicine (McKendall, Simoyi, Chester \& Rye, 2000).

The two articles cited six times each were published seven years apart and illustrate a change in program emphasis. The 2001 article that appears in The Journal of Science Education and Technology, discusses HSTA teachers' use of electronic concept mapping (Rye, 2001). I was part of the cohort trained to use Inspiration ${ }^{\mathrm{TM}}$ software. We were then tasked with taking our skills back to our schools and holding staff professional development. Upon completion of the training, the school was awarded 30 site licenses. Hind sight begs to wonder what pre and post evaluations from the community, in this case non HSTA teachers, would have revealed. The second article written in 2009, presents how HSTA students and teachers trained in and conducting community based participatory research (CBPR) is an effective model of a pipeline for future researchers (Chester \& Branch, 2009). CBPR was the "'catch phrase" in academia as it became known as an effective way to conduct research. Allowing adolescents to conduct real, relevant to them, research that required ethics certification and handling of sensitive information was almost unthinkable.

Two articles were cited five times each. The first one was another publication written about CBPR as a spinoff from the CBPR one mentioned above (Bardwell, Branch, Buch, Cecchetti, Chester, et al, 2009). The second article published in 1997 explains how rigorously training teachers to improve lab skills and nutrition knowledge carries back to the club (Rye, 1997).

There were four articles cited four times. The first one explains the findings from the CBPR obesity and diabetes project (Bardwell, et al, 2009). The following three were written on 
HSTA: A Case Study

the topics of dietary kilocalorie, science and math instruction (Rye,1999), Science, health and technology applications to use for authentic science instruction (Rye, Bardwell, \& Hu, 1999) and how pedometers and human energy balance can be integrated into meaningful science instruction (Rye, \& Smolski, 2007).

The last three articles were each cited twice. The first added to the work published on pedometer activities for learners (Rye, Richards, Mauk, Waterworth, \& Poling, Cool, 2007). The second and third articles describe the HSTA program as it was just beginning to grow (Bock, 1996) and the role mentors play in increasing student interest in medicine (Dooley and Bardwell, 2000).

There have been eleven HSTA teachers of whom I was one, co-author six of the publications. The opportunity arose while in the masters' program and was an extension of what we were doing. It is highly unusual for classroom teachers to be published in peer review journals and the opportunity to do so was an incentive to many of the HSTA teachers.

\section{Discussion}

The term nonobviousness is used to mean secondary considerations when relating to the presence of an unexpected property (Merriam Webster Dictionary, accessed $8 / 24$ ). I believe this is the diplomatic way of saying "it was right under your nose". I can't help but feel that way when I read the literature, especially the literature written about HSTA. The nonobviousness of the community impact was often omitted. It was known, but perhaps not named. It was subtle but strong. It is an issue to be studied and explored. It is not the standard consideration of evaluation but one that from here on out needs to be included. Articles with a likeness to HSTA or that mentioned impact were examined as was what impact was being measured. Those that 
HSTA: A Case Study

did mention impact referred to the stakeholder and did not examine community perceptions or beliefs.

After school programs for secondary students are much fewer in numbers than those for younger students. A factor of maturity and ability to fend for oneself is a contributing reason. Secondary school students are often involved in or have available to them sports, drama, band, and numerous other school- related extra-curricular activities that are not as prevalent in elementary and middle schools. Additionally, many secondary students chose to work part-time to provide spending money and help out with family expenses.

It also stands to reason that adding a measurement of community impact requires money and manpower. Funds for evaluation are budgeted to be most effective and pointed. If programs are new, impact measurement may not be a consideration and evaluation may be formative to help strengthen and validate the goals and objectives. Programs that have been in existence longer may not have considered measuring the impact from the view and beliefs of the targeted populations and communities.

\section{Summary}

The ripple effect of the HSTA program has spread out to reach areas or populations far removed from the lives of students and families. The influence has been measured as to the focus of the program goals, but the community beliefs have not been explored or documented. There is little literature about secondary after-school programs. The bulk of the literature is written about elementary and middle school programs. There is ample literature about measuring community impact of programs, but the bulk of it measures the impact from the perspective of the program out, "inside-out." Few are written from the perspective of the community, "outside-in". The HSTA literature is rich in publications with a total of 39. Eleven 
HSTA: A Case Study

articles have been published with community impact mentioned or have examined community impact, but most often the community impact in the HSTA articles is implied. None measure community perspective. This tends to be the norm in all the reviewed literature.

\section{Limitations}

One of the limitations in the current literature is most of the after- school programs that are evaluated are for elementary students (Cooper and Valentine, 2001). Few secondary afterschool enrichment programs exist. Those that do have done little if any studies to evaluate the community impact of the program. Additionally, the intent of the evaluations is to determine if the programs are meeting the delineated goals and objectives as set forth in the design and rely heavily on this data to measure the success of the programs.

This review was also limited by the lack of literature with a focus on community impact of after-school enrichment programs. It is logical that the research would pertain to the effectiveness at meeting the primary goals for which the program was designed and implemented. This lends itself to the "inside-out" view and is very evident in the literature. Again, it is vital to funding and support to be able to measure the efficacy of the programs to meet the goals and objectives for which it was designed.

Often, as is the case with HSTA, the focus of the articles became the rate of success and effectiveness of which the activity described had met its goals. The ripple effect that resulted from meeting those initial goals is often unexplored due to the simple truth that the need for documentation and analysis pertain to the primary goals, and meeting measurable, primary goals is essential to funding and sustaining a program. When the effects on and views of the communities are recognized and included, they tend to be mentioned but are not the focus of study. "HSTA has had a large impact on the economy, graduation rates and number of health 
HSTA: A Case Study

care providers serving the state of West Virginia"(Chester \& Dooley, 2011, p. 97). A need for this case study exists because substantial, long-reaching community effects and influences have spread to reach areas or populations far removed from the original audiences. 
HSTA: A Case Study

\section{CHAPTER 3}

\section{METHODOLOGY}

\section{Review of Purpose}

The purpose of this study is to examine the perceptions and views of stakeholders and community members regarding the community impact of HSTA. In this chapter I will discuss how this was achieved. Specifically this study addresses a need to examine and explore the issue that is missing from the current HSTA research. To date, very little of the research conducted on HSTA or by HSTA has looked at the impact of HSTA from the viewpoint of the community or “outside-in” (Falk \& Needham, 2011).

\section{Research Questions Restated}

Research Question \#1: What do various stakeholders or community members perceive as being the impact of HSTA on the community?

Research Question \#2: What do extant data sources (community club evaluations, Field Site reports, student project abstracts, and senior essays) used for HSTA program evaluation say about the impact of HSTA on the community?

Research Question \#3: As a participant-observer what do personal calendars, research journal, and papers, reveal are the investigator's perceptions of the impact of HSTA on the community?

Ethical considerations. This study was ruled exempt by the West Virginia University Internal Review Board (IRB Tracking \# H-23994) as there is no protected personal information gathered, and all participants are over the age of 18 years (see Appendix E). 
HSTA: A Case Study

\section{Organization of Chapter}

This chapter is divided into six subtopics, the first of which is an overview of the methodology in which I discuss the components of case studies and why this is a descriptive study. The second section of the study discusses the criteria used for selection of the regions chosen to participate. The third section addresses participant selection and describes the rationale for the criteria for selection of the study participants and how they were chosen. The fourth section, data sources, describes the sources of data and the methods I used to collect them. The fifth section, data analysis, describes the specific procedures that were used for analysis of the data collected during the course of the study. The sixth and final section titled validity and trustworthiness describes the strategies utilized to ensure the validity of the data and trustworthiness of the research.

\section{Overview}

This is a case study. Hays points out that "case study entities are known for being unique in their content and character", (Hays, 2004, p. 218). According to Yin (1994), "Case studies should be used in research when "how" and "why" questions are being posed, when the investigator has little control over events, and when the focus is on a contemporary phenomenon within some real-life context" (p. 1).

This case study of the communities' perceptions of the impact of HSTA fits the latter which is “a contemporary phenomenon within a real-life context" (Yin, p. 1).

Case studies can be used to explore, describe, or explain. Case studies can be used to "explain the causal links in real-life interventions that are too complex for the survey or experimental strategies. Case studies can "illustrate certain topics within an evaluation, again within a descriptive mode- - even from a journalistic 
HSTA: A Case Study

perspective. Case studies can "explore those situations in which the intervention being evaluated has no clear, single set of outcomes and case studies can serve as a form of "meta-evaluation - a study of an evaluation study, (Yin, 1994, p. 15).

For the purposes of this study, a descriptive case study methodology is a better overall design. "What makes case study methodology particularly effective as a type of empirical inquiry is that it investigates a contemporary phenomenon within its real-life context, especially when the boundaries between phenomenon and context are not clearly evident" (Yin 1994, p. 13).

This is particularly true for my study, “... which seeks to identity the implicit beliefs of community impact, a concept that may be quietly woven into the lives of the participants' experiences in a way that cannot be clearly separated and defined" (Yin, 1994, p. 14).

\section{Regions Where Study was Conducted}

HSTA recently divided the state into three districts, and I used these as the foundation for which of the 26 regions to include in the study. The state is divided into the North East, Central, and Southern districts (Appendix F). An equal number (12) of stakeholders from each category plus community members at large were interviewed from each district totaling 42 interviews, (Figure 3.1). I chose to match one rural and one urban region for each category of participant using the list provided to me by the Field Sites. For the purposes of this study I define urban as a region that had a town with a population of more than 15,000 people. It is my experience that each region has its own unique qualities but when HSTA regions are discussed they are commonly described as urban and rural. I was curious to see if there were substantial differences in responses when comparing the two. The regions chosen in each district are those that have been in existence the longest and have no less than 4 HSTA clubs in the attempt to 
HSTA: A Case Study

minimize a variable. The breakdown of districts is as follows. The North East District urban region is Ohio-Marshall which has had active HSTA clubs (5) for 18 years, and the more rural region of Mountain HSTA which has had 9 clubs for 16 years and consists of Barbour, Taylor, Preston, and Tucker counties. The Central District urban region is Kanawha which is an original HSTA region with 9 clubs. Kanawha has had a program for 19 years, and it is paired with the more rural region in the Central District of Webster-Braxton which has had 4 clubs for 18 years. This region is the smallest of the samplings. It is my home region but it does reflect the other rural regions in the Central District. The Southern District urban region is Raleigh, with 7 clubs and a 16 year old program. It is paired with the more rural region of McDowell, which also has 7 clubs and is the other original HSTA region with 19 years. HSTA started in two regions in 1994 and those regions were Kanawha and McDowell counties which, as stated above are included in the study and are in the Central and Southern districts respectively. I believe the sample is a good representation of the program.

\section{Participant Selection}

A key group of stakeholders in the study included Field Site coordinators from each HSTA district. To identify the remainder of the stakeholders which are defined as parents, graduates and teachers and all of the 12 at large community members, the Field Site coordinators were asked to submit names of four to six possible interviewees from each category of stakeholders and community members. Field Sites were instructed to identify persons they knew were still living in the communities and who they thought might be interested in being interviewed for my research. I believe the Field Site coordinators have the strongest community presence and are more qualified to recommend interviewees. They are vital to the success of HSTA; they are the tie that binds the community to campus and are a cornerstone of the 
program. They provide another level of valid community input. This strategy was employed as a protective measure against interviewee selection bias by the investigator and to provide a small bank of extra people to contact in case the need arose. The Field Sites were extremely cooperative and helpful. Most of the Field Site coordinators provided phone numbers and e-mail addresses in addition to the names of potential participants.

Figure 3.1 shows the districts and the codes used to de-identify participants.

Figure 3.1. Participant Coding by District, Position, Rural or Urban as Defined by Study

\begin{tabular}{|c|c|c|c|}
\hline Position & North East & Central & Southern \\
\hline \multirow[t]{2}{*}{ Local Governing Bd. Members } & N $1 \mathrm{~L}$ & C 2 L & S $3 \mathrm{~L}$ \\
\hline & $\mathrm{N} 4 \mathrm{~L}$ & C $5 \mathrm{~L}$ & S $6 \mathrm{~L}$ \\
\hline \multirow[t]{2}{*}{ Field Site Coordinators } & $\mathrm{N} 1 \mathrm{~F}$ & $\mathrm{C} 2 \mathrm{~F}$ & S $3 \mathrm{~F}$ \\
\hline & $\mathrm{N} 4 \mathrm{~F}$ & C $5 \mathrm{~F}$ & S 6 F \\
\hline \multirow{2}{*}{ Teachers } & $\mathrm{N} 1 \mathrm{~T}$ & $\mathrm{C} 2 \mathrm{~T}$ & S $3 \mathrm{~T}$ \\
\hline & $\mathrm{N} 4 \mathrm{~T}$ & C $5 \mathrm{~T}$ & S $6 \mathrm{~T}$ \\
\hline \multirow[t]{2}{*}{ HSTA Graduates } & $\mathrm{N} 1 \mathrm{H}$ & $\mathrm{C} 2 \mathrm{H}$ & $\mathrm{S} 3 \mathrm{H}$ \\
\hline & $\mathrm{N} 4 \mathrm{H}$ & $\mathrm{C} 5 \mathrm{H}$ & $\mathrm{S} 6 \mathrm{H}$ \\
\hline \multirow[t]{2}{*}{ Parents of Graduates } & N 1 P & C 2 P & S 3 P \\
\hline & $\mathrm{N} 4 \mathrm{P}$ & C $5 \mathrm{P}$ & S $6 \mathrm{P}$ \\
\hline \multirow[t]{4}{*}{ Community Members } & $\mathrm{N} 1 \mathrm{C}$ & $\mathrm{C} 2 \mathrm{C}$ & S $3 \mathrm{C}$ \\
\hline & $\mathrm{N} 4 \mathrm{C}$ & C 5 C & S 6 C \\
\hline & $\mathrm{N} 11 \mathrm{C}$ & $\mathrm{C} 22 \mathrm{C}$ & S33 C \\
\hline & N44 C & $\mathrm{C} 55 \mathrm{C}$ & S66 C \\
\hline
\end{tabular}

Key: $\mathbf{N}, \mathbf{C}, \mathbf{S}=$ North East, Central, or Southern Districts;

\#s 1, 2, 3, 11, 22, 33, denote rural $<15,000$ population of any one town,

\#s $\mathbf{4}, \mathbf{5}, \mathbf{6}, \mathbf{4 4}, \mathbf{5 5}, \mathbf{6 6}$, denotes urban $>15,000$ of any one town

$\mathbf{L}, \mathbf{F}, \mathbf{T}, \mathbf{H}, \mathbf{P}, \mathbf{C}$ denotes position in the community.

$\mathbf{L}=$ Local Governing Board member

$\mathbf{F}=$ Field Site Coordinator

$\mathbf{T}=$ Teachers

$\mathbf{H}=$ HSTA Graduates

$\mathbf{P}=$ Parents of Graduates

$\mathbf{C}=$ Community members at large

Note. The code N 1 L identifies the participant as from the Northern District, rural area and as an LGB member. 
HSTA: A Case Study

\section{Data Sources}

Qualitative research is inquiry in which the researcher collects data by interacting with selected persons. It describes and analyzes the individuals' thoughts, beliefs, and perceptions of a phenomenon (McMillan \& Schumacher, 2006). A qualitative method was a good choice for this type of research because it allowed me to listen to the views and beliefs of the research participants while focusing on the context from which they experienced the impacts. Because the interviews were about personal perceptions and beliefs of a relatively small number of participants, $\mathrm{N}=42$, the study used a case study design which lent itself easily to qualitative research. I had three categories of data sources. Participant interviews were used to address RQ 1. Extant data, which consisted of seven years of Field Site reports, four years of senior essays, five years of student project titles, three years of project abstracts; and three questions from community club evaluations were used to answer RQ 2. Lastly, participant-observer data which consisted of: reflections and observations kept in my research journal during interviews and data analysis, five years of personal calendars, notes, plus three vignettes I jotted down as I worked as Education Coordinator for HSTA, and five essays written when I was a teacher in the masters' program were examined to answer RQ 3.

Before I began gathering data, I practiced conducting interviews with a few volunteers who were not a part of this study and who were from regions that are not included in the study. The purpose was to try out the questions and my ability to interview. The answers of the first two volunteers were mostly about the effects of HSTA on students or individuals such as the opportunity to attend college. While teasing out more details and repeating to the volunteers what they had described, I discovered that community was being lost in the haste to give the answer and community meant several things depending upon who I was interviewing. My 
HSTA: A Case Study

observation motivated me to ask how community was defined in the context of their answer to impact. When I asked the participants to think about how they would describe community first, and then discuss how HSTA has had an impact on community, I got answers that were more focused on community.

RQ 1. Participant interviews. Interviews of course, were a source of qualitative data. In all, I conducted 42 interviews with stake holders and community members at large. Interviews were conducted over the telephone or in person. Sixteen interviews or $38 \%$ were conducted in person with the remaining 26 or $72 \%$ being conducted over the phone.

How were the participants interviewed? I conducted interviews in person, and by telephone. As the researcher it is my job to consider the voice and perspective of the participants. I added my impressions and observations while interviewing and kept them in my research journal. Everyone I contacted agreed to be interviewed. There were 2 contacts that did not have working phone numbers. These two people were replaced by moving down the list of additional suggested interviewees.

I found that when approached to participate, people were eager and glad to get to share their impressions and beliefs about HSTA. I made several phone calls where the call went to message and as I was leaving a message, the participants would answer the phone and agree to participate. This happened on $67 \%$ of the calls I made that went to voice message. I made calls to arrange and conduct interviews on Sunday afternoons. This time worked well as I caught many people at home preparing for the work week ahead. Phone interviews usually lasted about 15 to 25 minutes. Face to face interviews were approximately 30 to 40 minutes. Interviews were informal in nature. I purposely left the questions open and asked for other issues and items the participant wished to discuss and share but rarely got information other than those they believed 
to be causing an impact on the community (see Appendix G). All interviews were transcribed and returned to the participants via e-mail for comments or corrections or they were read to the participant over the phone to check accuracy. This completed a member check for a level of truth value. Four transcribed member checks resulted in clarifications or changes. In all four of the instances the changes required adding additional information that the participant recalled after the interview. These were the major changes resulting from member checks.

RQ 2. Extant Data. Extant data and reports that have been gathered by the program and various supervisors of HSTA such as the Director, Program Manager, the Community Research Associates, and the Education Coordinators over the years and are maintained as part of the HSTA data base, was examined. This data spans over 19 years and was gathered using of both formative and summative instruments which includes but is not limited to Field Site reports, spreadsheets of student project topics, records of community events, survey instruments, questionnaires, interviews, observations, focus groups and pre-post tests. The archival data was examined from the last seven years or less. Specifically these documents were used: Field Site reports, senior essays, community club evaluations and student project title and abstracts.

Field Site reports. Field Site reports are submitted 5 times a year and are the summary compilation of the two previous months of club activities and regional issues each field site and local board have addressed. They are based largely on the monthly club activity reports submitted by teachers. These reports document student and club activities performed in the communities. They were a rich source of data and documented many instances of community impact such as events and volunteer opportunities, I examined and open coded seven years of Field Site reports (Appendix H). 
HSTA: A Case Study

Senior essays. Senior essays are written by students who compete for a scholarship set up in memory of a former HSTA student who was tragically murdered. The essays topic is "What HSTA Means to Me". Often the essays reveal community volunteer experiences and project work that was not listed in other documentation. I examined four years of student essays for a total of 43. All essays were de-identified, labeled, and open coded following the previous format.

Community club evaluations. Next I looked at the yearly community evaluations which are conducted each spring. Community club evaluations are completed by current students and teachers to evaluate the effectiveness of the community component of HSTA. Taken after the community HSTA clubs have presented their yearly research projects, it paints a vivid picture of which components and clubs are strong and which need the most attention. I expected this data to be a good measure of community impact since it documented the perceptions of teachers and students concerning their community club component and the community research project of the HSTA experience. I reviewed five years of the community club evaluations and did not find a question measuring impact. For the 2012 HSTA year, three questions were added to measure student and teacher perception of community impact, and I included them.

Student project abstracts and titles. I examined the documents that listed the titles of each of the student projects spanning the last five years looking for evidence of community impact. I sorted them into categories and then cross referenced them as some of the events could fit into more than one category. Next, I examined the three years of project abstracts that were available and matched them with the corresponding years of the titles of the projects. These lists have been valuable in determining the types of projects completed and are a solid indication of the health and environmental issues students were addressing in the communities. The projects 
HSTA: A Case Study

were de-identified, labeled and open-coded in the same manner as the other data to allow for ease of matching and identification of events that were district or region specific.

RQ 3. Participant-Observer data. I have an eighteen year history with HSTA. I have always enjoyed journaling events or occurrences to capture the moment or mood of the event. Most of my personal works are outside the realm of work and thus there were only a few that were applicable to HSTA.

Personal calendars and papers. Another source of data is notes spanning the seven years I was the Education Coordinator for HSTA that I kept in my daily planner calendars. I have done this since becoming employed full time with HSTA in 2004. I used the daily planners from the last five years as a source of data. These are valuable as I noted events and issues that are related to all areas of HSTA as they pertained to my work in HSTA as an education coordinator and addressed student, club and community issues. Although these are brief and sometimes cryptic they were bell ringers and jogged my memory as to pertinent events applicable to the study. I placed identifiers or labels to the items from the calendars using the same system as the interviews so I could easily match them to the district from which they came. There were 17 items from the daily planners that provided events that pertained to community impact (see Appendix I).

Essays and vignettes. Personal essays and vignettes used for assignments while working on my masters' degree or to share with leadership were examined for subject matter that could illustrate community impact. There were three vignettes that were useful in this study.

Research journal. Although not a true source of data to code, I used a research journal in which I kept my personal notes and observations. 
HSTA: A Case Study

This corroboration of the evidence provides multiple measures of the same phenomenon. Pragmatic validation [of qualitative research] means that the perspective presented is judged by its relevance to use by those to whom it is presented: their perspective and actions joined to the [researcher's] perspective and actions (Patton, 1990, p. 485).

As a participant-observer I kept a journal of events, interpretations and happenings as I

conducted interviews and reviewed extant data. I used a reflection guide (see Appendix J), that I kept taped in the front of the journal to guide my thinking. This simple but useful journal of observations and perceptions jotted down as I interviewed and while I examined the qualitative and existing quantitative data, allowed me to quickly find references I made to information as well as understand the context in which it was gathered and/or examined. (see Appendix I). The journal served as a way to document the chain of evidence and data providing validity to the research, and frankly helped me remember more of the detail and context in which I examined evidence. My notes and interpretations are redacted and labeled following the format I used for the interviews to make for easier matching and pairing to participant interview and my penned interpretations during that specific interview.

The logic model for my research plan (see Appendix K) graphically shows the data sources I used and provides another way to look at the research sources and plan I followed. According to Stake, methodological triangulation, using multiple approaches within a single study to validate findings is the most recognized (1995, p. 114). Triangulation and validity, (truth value) will be discussed further in chapter four. 
HSTA: A Case Study

\section{Data Analysis}

The following is a discussion of the procedures I followed to de-identify, code, and analyzed the data. It is broken down into steps for ease of use, replication, and understanding.

De-identification. The de-identification/label guide for the participant interviews can be found in figure 3.1. Interviews were de-identified and given a label for organization. The label system was used to protect participants. For example, N1P stands for (N) Northern district, (1) Rural population, and the role is $(\mathrm{P})$ for parent. All interviews were transcribed by me. I conducted member checks by returning a copy of the transcript to the participants via e-mail for comments and corrections or read them back to the participants over the phone. Any name that appears in dialogs and quotes inserted throughout the case study are pseudonyms. This was to make sure discussions during interviews would not inadvertently name someone who could be easily identified.

All types of documents used in this study were de-identified and labeled such as the participant interviews, field site reports, community evaluations, senior essays, and student project titles and abstracts. I de-identified and then labeled every piece of data using this system so I could examine and match them easily to look for patterns that were not only global but might be specific to a district, region or county and also to keep them in an orderly, filed, fashion. For instance, the extant data examined was from all regions of HSTA and was given labels by source, region, date if appropriate, and year meaning the community evaluations for Braxton Webster would appear as CE/BW/2007. Likewise, a field site report was labeled as FS/BW/Feb2007.

Coding. I conducted open-coding on each category of data separately. I used the Microsoft Word find button. The program counts the frequencies of all the identified words or 
HSTA: A Case Study

phrases in the document. For example, I ran a search on each document for volunteer, service, help, share, community, impact, festival, fair, assist, help, improve and change. "Analysis begins with identification of the themes emerging from the raw data, a process sometimes referred to as “open coding” (Strauss and Corbin, 1990, p. 47). Using the computer to start coding was a good beginning. However, most helpful to me in working with all documents was the old fashioned method of coding. I printed and reviewed each document and manually highlighted items that I believed were an impact. This allowed me to tangibly review and revisit the documents often and with ease. Then I put the impacts from both the word search program and my manual coding on color-coded note cards. Next, I listed the categories and put them into an excel sheet, before moving on to the next source of data and documents.

Table 3.1 shows the order of coding. All interviews, which comprised data source number one, were open-coded before moving on to data source number two, extant data, and then finally to data source number three, participant-observer documents.

Table 3.1. Data sources and types of programs used in coding and sorting

\begin{tabular}{|c|c|c|c|c|}
\hline Data source & Microsoft WS & Manual coding & Note cards & Excel \\
\hline 1. Interviews & Yes & Yes & Yes & Yes \\
\hline 2. Extant data & Yes & Yes & Yes & Yes \\
\hline Except c/c evals & No & Yes & Yes & Yes \\
\hline 3. Parti/observer & No & Yes & Yes & Yes \\
\hline
\end{tabular}

c/c stands for community club evaluations

I open-coding and sorted the interviews following the method stated above. I then opencoded the extant data such as field site reports, senior essays and student projects. The nature of the other documents in extant data was not conducive to using Microsoft word sort such as the community club evaluations. They were coded manually. The participant-observer items did not 
HSTA: A Case Study

lend themselves to Microsoft word search either. The few items in the participant-observer documents were hand coded.

Analysis. Open coded categories were broad and diverse in range from intrinsic such as serving as an inspiration and motivation for others, to economic such as employment of graduates who pay taxes. The open-coding resulted in over 550 documents being examined the most of which included the 42 interviews, 473 field site reports, and the 43 essays.

$\boldsymbol{R Q}$ 1. I wanted to give voice to the community and allow it to lead the study. I purposely set aside the open-coded extant and participant-observer data and began with the interviews to determine categories of impact. I took all lists that identified impact and grouped them by similarity into topic categories or performed closed-coding. For example, from the interviews there were noted events of volunteering at an annual health fair and blood drive. One participant noted volunteering at a local nursing home. These were first open-coded as two separate impact areas-community health events and community health/long term. These broad patterns however collapsed into more distinct categories when they were close-coded. I coded the semi-structured interviews noting participant perceptions from interview notes, which helped identify categories and themes via inductive analysis. Then the topics were compared to my perceptions of the impact since I am an embedded participant-observer who has been in various roles as a HSTA employee for 18 of the 19 years it has been in existence. I was a HSTA teacher for 10 years, was employed as HSTA education coordinator for seven years, and most recently was appointed Assistant Director. As such, I bring a unique perspective as a participantobserver. 
HSTA: A Case Study

$\boldsymbol{R Q} 2$. I found the extant data was a much larger set and thus more detailed than the interview data. After open-coding, the data was close-coded and it too collapsed into four distinct categories similar in nature but not in frequency. For example one Field Site described HSTA students volunteering to assist the Red Cross with the blood drive. Looking across the seven years of this Field Site's reports showed the dates and number of years HSTA students had assisted the Red Cross with this event. Examination of a senior essay from the same region discussed the blood drive too.

$\boldsymbol{R Q}$ 3. There was very little data to draw from for this question when compared to the previous two. Calendar notes and vignettes were the data that jogged my memory and helped fill in blanks that weren't written in such detail. Looking up the original essay or event to review what I was trying to describe refreshed memories.

\section{Triangulation}

A case study is known as a triangulated research strategy. According to Patton there are 4 types of data triangulation of which the one best suiting this case study is Data Source. Data source is defined as the researcher looking for the data to remain the same in different contexts. I strove for internal validity by pattern matching. "Analysis will lend itself to looking for reoccurring or similar responses found in the interviews by examining them first as open, where

all responses are examined, and then closed which will allow patterns, if they exist, to immerge" (Patton, 2002, p. 49).

Triangulation also occurred using multiple sources of evidence "However, the most important advantage presented by using multiple sources of evidence is the development of converging lines of inquiry, a process of triangulation and corroboration..." (Yin, 2009, p. 115). 
HSTA: A Case Study

Figure 3.2. Convergence of Evidence

\section{RQ 1 \\ Interviews}

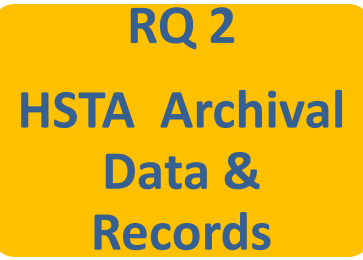

\section{Broader}

\section{Impact}

RQ 3

Participant

Observer

\section{Truth Value}

Truth value will exist if the data measured can support the theory, which is that the community perception of HSTA has a broad impact on the community beyond its role as a pipeline program. Case studies rely on analytic generalizations. "In analytical generalization, the investigator is striving to generalize a particular set of results to some broader theory, which is the objective of this study" (Yin, 2009, p. 43). Lastly, I addressed trustworthiness by following and adhering to a research protocol and simple careful coding so that if in the future the case study were repeated, the investigator would find similar results.

Data triangulation alleviates the potential problems of construct validity. "Multiple sources of evidence provide multiple measures of the same phenomenon" (Yin, 2009 p. 116)

\section{Limitations}

It is through my eyes and interpretations of accounts from interviews, extant data, and participant-observer experiences and artifacts that the case study unfolded. I know that bias exists and as such, is a limitation but I also am keenly aware of addressing the bias. 
HSTA: A Case Study

"Triangulating information from interviews, sources, data, and persons will help negate but not alleviate the bias" (Novick, 1993, p. 50). It is a fact and must be accepted that a participantobserver conducting research, will have bias.

It is also an assumption that those interviewed will be self-selected by agreeing to participate and thus be biased. Likewise others who may not have such a kind view or experience of HSTA will perhaps refuse to interview to avoid the discomfort of being seen as negative. If an interviewee is uninterested they may not answer the interview questions truthfully and this could skew the results. Since the districts of HSTA span the state it did cause difficulty for conducting face to face interviews. This was addressed by opting for phone interviews and contacting participants via e-mail or phone to schedule interviews. When possible transcripts were e-mailed or if not the transcript was read over the phone to perform a member check. The threat of understanding the participants' definition of community is addressed by asking the participant to think about community and then ask them what they perceive as the impact of HSTA on the community. The body of literature available on HSTA which discusses community impact or implies that HSTA has a broader community impact beyond the students is small and thus is reason to complete this study. Additionally and most importantly is there is no literature or study of community perception of impact and this study will address the lack of information. 
HSTA: A Case Study

\section{CHAPTER FOUR}

\section{FINDINGS AND DISCUSSION}

The purpose of this chapter is to report the findings of a qualitative case study conducted in HSTA regions across the state of West Virginia during the spring and summer, January through August of 2012. It contains descriptions, analyses, and discussion of the findings from data collected on an informal after-school pipeline program that prepares under-represented, underserved students for college and careers in health and STEM careers. This is a case study of how communities construct and perceive the impact HSTA has had on the community. Using informal interviews as my principle source of data, I investigate how aspects and meanings of impact might be discovered in the perceptions, experiences, and words of various community members. I demonstrate how these aspects of community impact might be divided into thematic categories, organizing the data to illustrate each category according to the levels of certainty within that category. The reason for this approach is to develop a few key issues, which, according to Stake, (1995), is an approach "not for the purpose of generalizing beyond the case but for understanding the complexity of the case" (p. 123).

Categories that emerged from the interviews guided the search through extant and participant-observer data. I employed data triangulation to ascertain if such data from RQ 2 and RQ 3 strengthened the emergent categories. Closed coding of the extant data such as the senior essays and field site reports helped to support the coding of the interviews and strengthen the labels of the subtopics. 
HSTA: A Case Study

\section{Review of Research Questions}

RQ1: What do Various Stakeholders or Community Members Perceive as Being the Impact of HSTA on the Community?

This question addresses the perceptions of community members have as to the impact of

a $9^{\text {th }}$ through $12^{\text {th }}$ grade after school program. This was the foundation for the case study. There were four categories that emanated from the interviews.

RQ2: What do Extant Data Sources (community club evaluations, Field Site reports, student project abstracts, and senior essays) Say About the Impact of HSTA on the Community?

This question addresses the search for existing data that can corroborate or refute the perceived impacts community members have reported. The same four categories emerged from the extant data but with a difference in frequency.

RQ3: As a Participant Observer, (HSTA teacher and now Education Coordinator), What are the Investigator's Perceptions of the Impact of HSTA on the Community?

This question emerged as I was interviewing and keeping my research journal. I have a long 18 year history with HSTA and my memories were frequently jogged when interviewing primary stakeholders because I was often involved with or knew of the activities and events which were being reported. Now in its nineteenth year of operation, HSTA played a huge role in shaping my views, pedagogy, and education. It profoundly changed the way I taught and learned. Through answering this research question, I wanted to achieve a greater understanding of what my views were and how they compared to the views of those from the "outside- in" or from the community (Falk and Needham, 2011, p. 1). 
HSTA: A Case Study

\section{Review of Methodology}

During the year 2012, Spring and Summer semesters, I conducted a descriptive, interpretive case study of an after school program, (HSTA), designed to increase the college going rate of under-represented students and encourage them to pursue careers in the health sciences. As a professional who became a HSTA teacher in the program in its second year, (1995), and one who has been extremely and profoundly changed by it, I bring a longitudinal perspective from within.

For RQ 1, I interviewed 42 participants and produced transcriptions of each interview. I instituted member checking by asking participants to review and comment as needed on the transcript from each of their interviews. For RQ 2, I utilized used five years of archival program data, one year of a community club evaluation, seven years of Field Site reports, five years of student project abstracts, and four years of student senior essays. For RQ 3, I used the last five years of personal calendars and notes taken during daily work activities with HSTA as I served as Education Coordinator 2004-2012, and notes, papers and essays I completed during my course work and employment as a HSTA teacher, 1995-2004. These contained memos and observations from all 26 counties that HSTA serves. Additionally, I kept a research journal that documented my perceptions, impressions, and thoughts as I conducted interviews, combed through the extant data, and worked the case study. Notes in my research journal also came from informal discussions between HSTA teachers and staff which I recorded in my journal and referred to when analyzing data. Analysis of the data led to interpretations based on categories and themes that emerged during the coding and analysis process described in Chapter Three. The findings are presented as narratives interspersed with commentary and discussion. The emerging categories were a result of interviews, extant and participant observer data. One form 
HSTA: A Case Study

of triangulation occurred when interview categories and subtopics were compared using RQ 2, extant data and RQ 3, participant-observer experiences. "Data-gathering techniques could be subsumed adequately under three major headings...experiencing, enquiring, and examining," (Wolcott, 2009, p. 81). I found this extremely helpful when organizing my findings and as I developed the format for this chapter.

The following is how the items used in discussion reflect the headings as described by Wolcott, (2009, p. 81). Enquiring is defined as seeking first-hand knowledge through interviews, and focus groups. This describes RQ 1 and the participant interviews. I interviewed 42 participants. Thirty were stakeholders and 12 were community members with no affiliation to HSTA. The participants were equal in numbers to represent rural and urban regions as defined by this study. Figure 3.1 illustrates the participants by group and district.

Examining, according to Wolcott (2009), was addressed with RQ 2 when I coded and used extant data from Field Site Coordinator bi-monthly reports, lists of HSTA student yearly research projects, essays written by HSTA seniors, student project abstracts and titles, and community club evaluations. There was an abundance of corroborative data coded from the above named sources.

RQ 3 is experiencing according to Wolcott's method (2009) and as the participant observer, I coded five years of personal calendars and reflections as the HSTA Education Coordinator, personal essays and papers that were assigned as part of course work as I matriculated though graduate school as a HSTA teacher and education coordinator, and personal reflections after each interview as kept in my research journal. I examined these documents in search of evidence to support or refute the categories and subtopics that emerged during the data 
HSTA: A Case Study

analysis process while remaining cognizant as to how those categories and themes relate back to the research questions and community impact.

\section{The Interview Process}

Thirty interviews were conducted with six participants each from the following categories, current HSTA teachers, HSTA graduates, HSTA parents, HSTA Field Site Coordinators, and HSTA Local Governing Board Members. Twelve at large community members were also interviewed for a total of 42 interviews. Interviews lasted from 15 to 45 minutes. Participation was voluntary and before the interviews began, the informed consent process was explained in detail. All participants understood the exempt status of the case study interviews, the de-identification of subjects, and were given the option not to participate. A copy of the letter (see Appendix L); the script I used for consistency when explaining the consent process (see Appendix M), and the IRB (see Appendix E), are included.

All interviews were taped and transcribed verbatim and verified by an independent editor. Additionally, all transcripts underwent a member check (see Appendix N) to allow participants to correct and verify content. "Member checks are a valid way to increase trustworthiness and provide another form of triangulation (Yin, 1994, p. 147). Four of the participants added comments and details to the interview transcripts via email. The additions were events or details that the participants wanted to share that didn't occur to them at the time of the interviews. All additions and clarifications were duly noted and recorded.

All names cited by participants have been changed when used in this chapter and throughout the case study to prevent identification. This is required and was done out of sensitivity to those people discussed or mentioned during interviews as many of the stories reveal personal and difficult situations that may cause embarrassment to the participant or person 
HSTA: A Case Study

named if identified. Additionally as another precaution, I changed the transcripts to remove the names of individuals about whom the interviewees spoke.

\section{Extant Data Examination}

Archival data was examined and coded. The archival documents consisted of student essays, (see Appendix O), Field Site reports (see Appendix H) and student research project topics and abstracts (see Appendix P).

Student essays are written by high school seniors wishing to compete for the Sara Spencer \$2000.00 scholarship. It is awarded each year in memory of a HSTA student who was tragically murdered in a drive by shooting. Regional HSTA governing boards judge their entrants and submit the best one to a Joint Governing Board committee on the state level. Not all 14 regions submit a contestant for the scholarship each year. I examined five years of essays spanning from 2008-2012 for a total of 43 documents. The essays provided a perspective from students who were in their last semester of the high school program at the time they were composed.

Field Site coordinator (FSC), reports are submitted every two months and include a monthly summary of club progress and activities in their regions. I examined six years of field site reports from 2006-2012 which totaled 473 documents. FSC reports were a rich source of data that supported and lent details to many of the events discussed by participants during interviews. They gave an insight into community club activities and the breadth of the projects the students were completing.

Student project topics are submitted each year and as the Education Coordinator and now Director of Community Research, I have had to examine the scope and issues of what the research addressed in addition to monitoring protocol. The students' research reflects timely 
HSTA: A Case Study

topics as well as a wide array of subjects. Projects are driven by student interest and their perception of community issues. I examined five years of student research project topics from 2008-2012 and although they numbered 2,100 topics they weren't necessarily useful for any category except community service. They didn't have any detail other than the region, student name, and title of the project. I matched the few that were mentioned in interviews with the year the project was presented. When interviewed, two of the graduate participants discussed using their community service as the foundation to expand their research projects and I found the project topics in these lists. Project abstracts weren't useful except to match them with titles of the projects.

\section{Overview of Findings}

Four major categories emerged from the data however the relative importance or frequency of each category differed between the interview and extant data sources.

The following table lists the principal categories that emerged from the inductive analysis of each of the largest data sources, in order of frequency.

Table 4.1.1. Category Frequency According to Data Source

\begin{tabular}{|l|l|l|l|l|}
\hline & RQ 1. Interviews & RQ 2. FSC Reports & RQ 2. Student & RQ 3. Particip- \\
1. & Education & Community Service & Community \& State & Education \\
\hline 2. & Community Service & Community \& State & Family & Community \& State \\
\hline 3. & Family & Education & Community Service & Family \\
\hline 4. & Community \& State & Family & Education & Community Service \\
\hline
\end{tabular}

RQ 2 had the most data points and the two leading sources are listed.

RQ 3 document numbers were small and were used with participant/observer experiences to corroborate findings. 
HSTA: A Case Study

Education was the strongest category identified by participants and the Participant-Observer. It was followed by community service which was the strongest category from extant data.

\section{Trustworthiness of Findings}

Triangulation. Data in this chapter is presented in a way to demonstrate how I attempted to add trustworthiness to the findings. I collected the data from multiple sources using several data collection methods. I triangulated data sources to ascertain the strength of the findings. I then triangulated findings by having three peers review the coded data and drafts of the report to provide different insights and perspectives, (see Appendix Q). I also asked two participants to review the report. All comments and suggestions were incorporated throughout.

Yin (1994) recommends having a draft of the report reviewed, not just by peers, "but also by the participants and informants in the case. "If the comments are especially helpful, the investigator may even want to publish them as part of the entire case study", (p. 144). This process of having participants review a draft of the report is referred to as member checking (Yin, 1994; Stake, 1995; Creswell, 2003; Wolcott, 2001). The comments from peer reviewers and participants and the impact they had on the analysis and reporting of this data is discussed at the end of this chapter.

The process of triangulation is useful even when an assumption is made that no objective truth exists. Any investigator can claim that it is normal and should be expected that participants will always have slightly different recollections of the same concept or event; however, according to Yin (1994), the procedure of triangulation of data "should help to identify the various perspectives which can then be represented in the case study report" (p. 146). Pattern matching, a form of triangulation (Patton, 2002), was completed using results of interview categories RQ 1, with results from extant RQ2, and participant-observer RQ3. Methodological 
HSTA: A Case Study

triangulation according to Stake, (1995) uses multiple approaches within a single study to validate findings (p. 114), such as interviews, observation and document review. Yin (2009) states that the use of multiple sources of evidence provided converging lines of inquiry and is a process of triangulation (p. 115).

Field Site reports from RQ 2, best supported the category of community service that emerged from RQ 1 adding truth value to the findings. Student essays added strength and truth value to the community \& state category from RQ 1. Lastly, participant-observer data best supported the RQ 1 category of education.

To complete an exemplary case study, I again refer to Yin as a guide. Yin, (1994), defined the components of such a study as:

- Is significant, or of public interest in that "the underlying issues are nationally important, either in theoretical terms or in policy or practical terms" (p. 147).

- Is complete, in which the boundaries of the case are made explicit and “exhaustive effort" was made "in collecting the relevant evidence" (p. 148).

- Considers alternative perspectives.

- Displays sufficient evidence. "The exemplary case study is one that judiciously and effectively presents the most compelling evidence so that the reader can reach an independent judgment regarding the merits of the analysis" (p. 150).

\section{Major Emergent Findings}

There were four strong categories that emerged from the data. They were: education, community service, family, \& community/state. The order of frequency of categories from the interviews was used throughout the discussions of findings for consistency. Of the 42 
HSTA: A Case Study

participants (interviewees), 36 discussed education and averaged three to five coded items on the topic. Twenty-four of the 42 participants cited community service as an impact and did so on average of one to three times. Twenty of the 42 participants discussed the impact on families and averaged one to three coded items. Fourteen of the 42 participants that mentioned community \& state averaged one coded item.

\section{Organization of Findings.}

Findings are organized and discussed by categories. Categories are presented in order of frequency of enumeration. Each category begins with the findings from coded interviews which determined the categories themselves. Interview data, RQ 1, enquiry, is presented and discussed for the category. Next, the extant data, RQ2, examining, is used to refute or support the findings and propound the evidence for this category. Lastly, the participant-observer data, RQ 3, experiencing, is given to discussion as it supports or refutes the category. Figure 4.1 is a diagram of the organization.

Figure 4.1. Organization of Findings and Discussions

\begin{tabular}{|l|l|l|l|}
\hline Emergent Category & RQ1 & RQ2 & RQ3 \\
\hline Category 1 & & & \\
\hline Subtopics of category 1 & & & \\
\hline Category 2 & & & \\
\hline Subtopics of category 2 & & & \\
\hline Category 3 & & & \\
\hline Subtopics of category 3 & & & \\
\hline Category 4 & & & \\
\hline Subtopics of category 4 & & & \\
\hline
\end{tabular}


HSTA: A Case Study

Figure 4.1. Order of presentation of findings. RQ1 is presented first discussing each emergent category from interviews. This order of presentation begins with Category 1 and is subsequently repeated for Category 2, 3, and 4, respectively. Then RQ2 is presented and each emergent category from this question. Finally, RQ3 is presented and follows the same format.

The findings are presented as emergent categories and each of the four categories had subtopics that more distinctly defined the categories. This chapter is organized simply and with the intent to allow the reader to maintain the thought and flow of the findings. First, each research question and emergent categories will be presented and discussed. For instance, RQ 1 examined community perceptions from interviews and discussed each category and sub-topic that fell under the category as illustrated by the first column of arrows. Next, RQ2, an examination of extant data, discussed each category and sub-topic that emerged under the category. RQ2 follows the same format of category and subtopics as illustrated by the second column of arrows. Lastly, RQ3, my findings and experiences as a participant-observer, are presented and examined. This is the $3^{\text {rd }}$ column of arrows in the series. It too follows the same format of category and subtopics. (See figure 4.1.) All categories and subtopics are listed and discussed in order of frequency.

\section{RQ 1: Enquiring}

Transcribed member checked interviews were coded using line-by-line in-vivo coding and were coded by subject. I coded using the Microsoft editing tool Find as word search program and then coded by hand. I used an "old school" technique of putting topics on color coded note cards that I could move and shuffle. I preferred the hand coding because I was much more engrossed with the documents. This case study lent itself to such a coding. Open-coding of the interviews resulted in 21 topics. Further culling reduced it to 11 topics that were sharing characteristics. 
Inductive coding, according to a guide published online by the South Alabama College of Education and accessed on 10/24/2013, are codes that are developed by the researcher as he or she examines the data. Additionally, the data can be described as co-occurring meaning it gets coded with more than one code as it is taken from the context of the interviews (Johnson, \& Christensen, 2007). This is how I coded my data and collapsed it as it fell into categories. Many of the codes fit into more than one category but a closer examination of the phrases and the context in which it was delivered assisted me in being able to broaden the final four categories and cover specifics under subtopics.

Table 4.2. Unordered Lists of Inductive Closed Codes from 317 Open Coded Items

\begin{tabular}{|c|c|c|c|}
\hline $\mathbf{1}^{\text {st }}$ Closed Coding & $2^{\text {nd }}$ Closed Coding & $3^{\text {rd }}$ Closed Coding & Final Codes \\
\hline Education & $\wedge=\}$ Education & ${ }^{\wedge}$ Education & Education \\
\hline College graduation & $\wedge=$ College graduation & $\wedge \sim$ Family health & $\begin{array}{l}\text { Community } \\
\text { Service }\end{array}$ \\
\hline High school graduation & $\wedge$ \}High school graduation & ${ }^{\wedge}+$ Health careers & Family \\
\hline Pro-active citizen & $+\sim$ Pro-active citizen & ${ }^{\wedge}$ Teachers & Community State \\
\hline Health issues/educate & $\wedge+\sim$ Health issues & $\left.{ }^{\wedge}\right\}$ Influence peers & \\
\hline Return to the community & $+=$ Return to the community & $\wedge *+$ Economic & \\
\hline $\begin{array}{l}\text { Family/health literacy/ } \\
\text { economic }\end{array}$ & $\begin{array}{l}\wedge \sim+\text { Family/health literacy/ } \\
\text { economic }\end{array}$ & $\begin{array}{l}\text { *Community Service } \\
\wedge *+\text { Economic }\end{array}$ & \\
\hline Volunteer/causes/helping & $*+$ Volunteer & $\begin{array}{l}\text { *Fund raising/health } \\
\text { events/ballgames }\end{array}$ & \\
\hline Health fairs/blood drives & *Health fairs/ballgames & $\sim^{*}$ Involved families & \\
\hline $\begin{array}{l}\text { Make more money/prevent } \\
\text { brain drain }\end{array}$ & $+=$ State improvement & $\begin{array}{l}\sim \text { Family } \\
\wedge \text { Family health }\end{array}$ & \\
\hline $\begin{array}{l}\text { Help family live better } \\
\text { Improve neighbors }\end{array}$ & $\sim^{*}$ Help families/neighbors & $\begin{array}{l}+ \text { Stay in state/community } \\
\wedge *+\text { Economic }\end{array}$ & \\
\hline
\end{tabular}


HSTA: A Case Study

\begin{tabular}{|c|c|c|c|}
\hline Health careers jobs & $\wedge_{+}+=$Health careers & & \\
\hline Science teachers chemists & $\wedge_{+}=$Science careers & & \\
\hline $\begin{array}{l}\text { Rural health care providers. } \\
\text { PT, Dr, RN,EMT }\end{array}$ & $\wedge+$ Rural health care providers & & \\
\hline $\begin{array}{l}\text { Influence peers/set example } \\
\text { for others at school }\end{array}$ & $\left.{ }^{\wedge}=*\right\}$ Influence peers & & \\
\hline Teachers trained/model & $\wedge=$ HSTA teachers improved & & \\
\hline $\begin{array}{l}\text { Break out of poverty/help } \\
\text { family live better }\end{array}$ & $\wedge \sim+$ Break out of poverty & & \\
\hline $\begin{array}{l}\text { Adults participate in } \\
\text { comm/on boards, volunteer/ }\end{array}$ & $\sim^{*+C i t i z e n s h i p}$ & & \\
\hline $\begin{array}{l}\text { HSTA walking trails, parks, } \\
\text { pamphlets }\end{array}$ & $\begin{array}{l}\wedge+=\text { HSTA improves } \\
\text { community }\end{array}$ & & \\
\hline $1^{\text {st }}$ to graduate $\mathrm{HS}$, college & $\wedge^{\wedge} \sim=1^{\text {st }}$ to graduate & & \\
\hline $\begin{array}{l}\text { Leave home/return } \\
\text { educated/contribute }\end{array}$ & $\wedge \sim+$ Attend college & & \\
\hline
\end{tabular}

Key: ${ }^{\wedge}$ Education; Family; * Community service; + Community/state; = School, $\}$ Friends

I completed open coding by listing all words and phrases that implied or stated impact.

There were 317 items resulting from open coding. After completing the first closed coding I had

21 categories. I re-examined the categories and this time I cross referenced them using six

symbols according to what I had seen emerge as six reoccurring themes. This is column two and is labeled second closed coding. The third closed coding resulted in reducing the categories to 11 in number. When I began analysis trying to use the 11 categories they just weren't making sense and were too restrictive. Reexamination of the third closed coding resulted in the final four categories which seemed to work well if I took the most frequently mentioned topics that were under them and made them sub-topics. This is how I organized the findings. 
HSTA: A Case Study

Peer evaluation (see "Trustworthiness of Findings" above) of the same data was very similar but more compact and clustered. I attribute the differences, although slight, to my hesitancy to be too restrictive. Closed-coding ultimately resulted in the topics from interviews being reduced to four thematic categories that were strongly prevalent in all interviews. They were, in order of frequency, education, community service, family, and community/state resources. It is important to understand that all four categories are closely intertwined. The subtopics were identified to better define the nature of the category. Reading through the excerpts, it is easy to see how closely tied each of the subtopics are across the categories.

Figure 4.2 illustrates the percentages of perceived impact. An explanation of how I arrived at the percentages follows.

Figure 4.2. Percentages of Perceived Impact According to Interviews

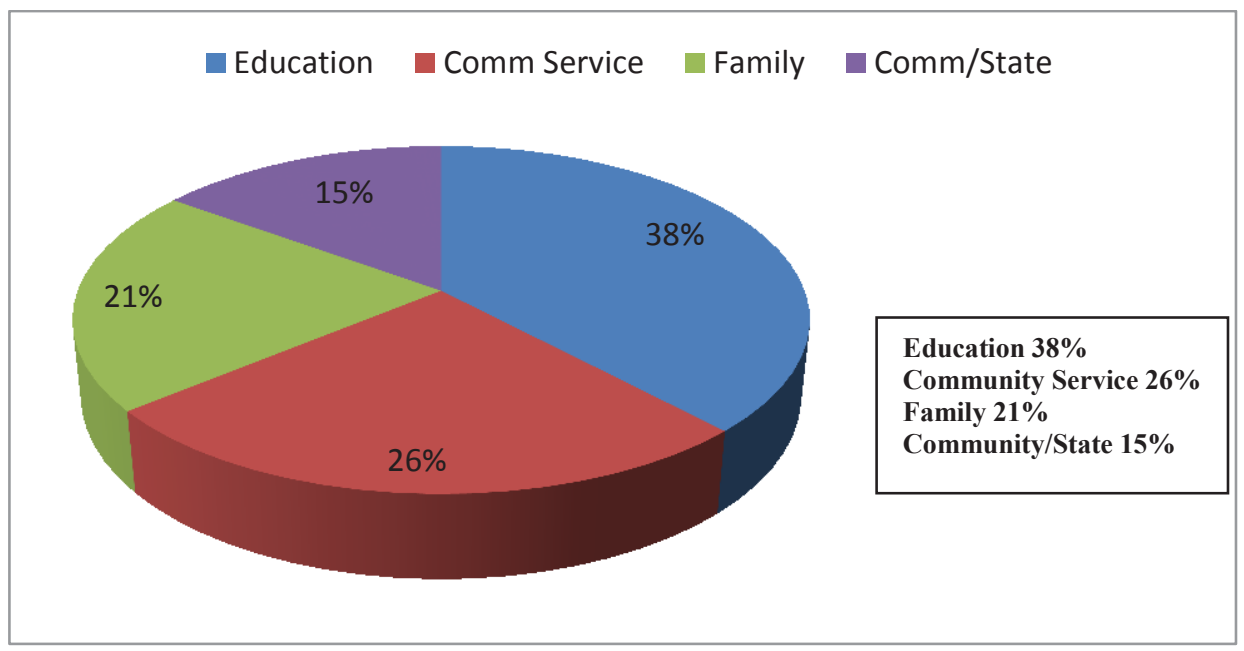

The percentages were calculated by simply looking through the interview note cards and counting how many of the 42 participants had mentioned each of the four specific category(s), community service, community/state, education, and family. Figure 4.3 is an example of a coded note card. 
HSTA: A Case Study

Figure 4.3. Sample of a Coded Participant Note Card

\begin{tabular}{|llll|}
\hline \multicolumn{3}{|c|}{ Participant Code: C2P } \\
Comm. Ser. & Comm/ St. & Education & Family \\
\hline Blood Drive & & Graduate/BS & $1^{\text {st }}$ in Family \\
River Clean up & Grad school & Proud \\
& & Teacher Ed & \\
& & College Waiver \\
\hline
\end{tabular}

Information from this card was entered into the excel sheet under the appropriate category once for the three different categories because it shows participant $\mathrm{C} 2 \mathrm{P}$, discussed three of the four categories during the interview. To come up with the percentages, I gave each category listed only one point regardless of the number of examples that the participant gave under each category. The final results showed 36 of the 42 participants discussed education, 24 of the 42 interviews discussed community service, 20 of the 42 interviews also spoke about family impact and 14 of the 42 interviews included community and or state impact. Participant C2P did not discuss anything that would be coded in community/state as seen in figure 4.3. I added each of category columns together which totaled 94 and then divided each category total by 94 to get the percentages. Therefore, 38 percent (36/94) of the impact is attributed to education, 26 percent (24/94) is attributed to community service, family comprised $21 \%$, and $15 \%$ went to community and state.

\section{Category 1: Education}

Education is a broad category, but for the purpose of this study it will be defined by the impact as perceived by the participants. The most frequently mentioned community impact of HSTA was education. Thirty-six of the 42 people interviewed said education is what came to mind when thinking of HSTA. Participants had many examples and stories pertaining to the 
HSTA: A Case Study

category of education. They ranged from personal success stories to experiences they had witnessed. The category was divided into subtopics as participant examples fell under similar subject matter and these subtopics are presented and discussed. There were four principle subtopics of impact that emerged under education. They were in order of frequency: college graduation, local school systems, teacher training, and community education.

Figure 4. 4. Subtopics as They Relate to Education as an Impact

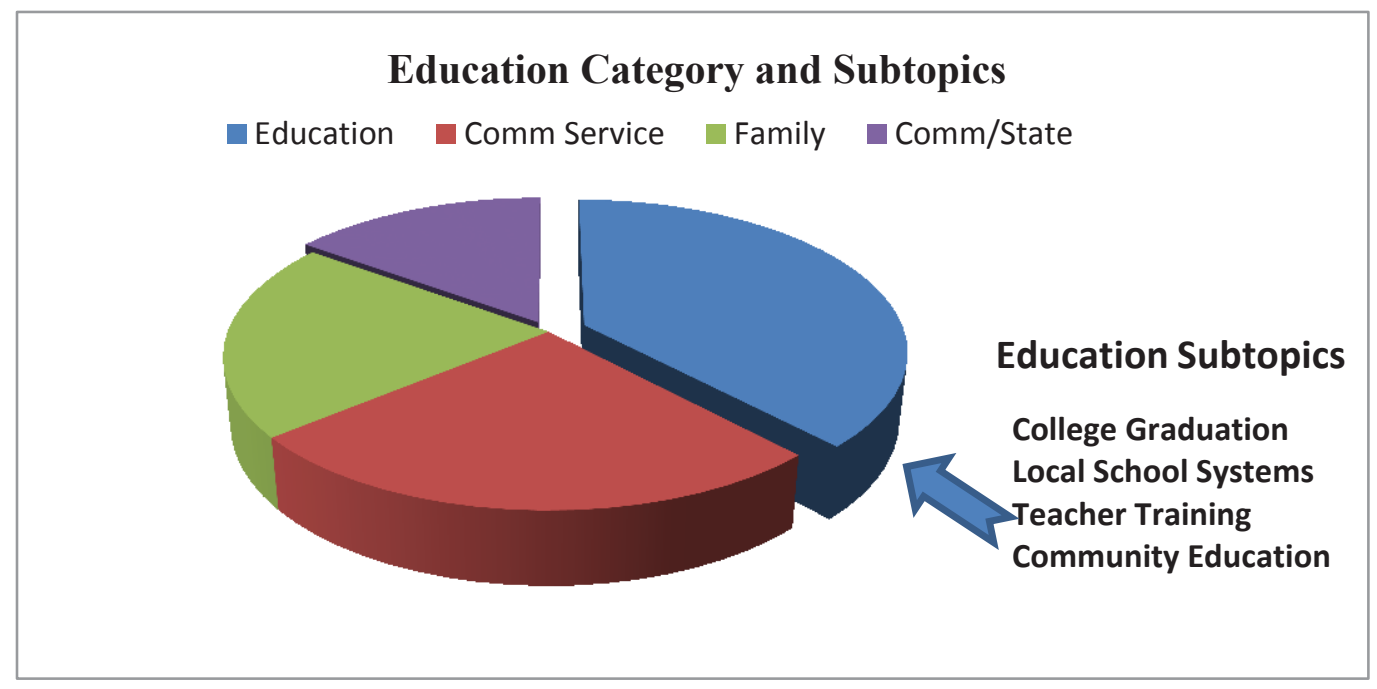

College graduation. Interviews were full of stories and examples of how important college graduation and obtaining a college degree were for the participants. It was the first thing mentioned in many interviews and is the primary fact that is associated with HSTA. It is not surprising that stakeholders mentioned college graduation, but the community at large also saw the impact as just as important.

Jeremy, a HSTA graduate spoke of his experience:

A classmate once told me she couldn't ever imagine me becoming a pharmacist. I was just a small town, country boy. With the help from the HSTA program I graduated and now work in our local pharmacy. It makes me smile. HSTA made my dream finally come true. 
HSTA: A Case Study

Ruby a HSTA teacher believes, "For many of my students, HSTA is the only access they have to college. They develop the skills and knowledge to be successful in college".

A field site coordinator replied:

HSTA has had a huge impact on the community in southern West Virginia. If not for HSTA many students would not have been able to attend college. Sure, some may have been eligible for financial aid, but would not have known how to go about applying for it. HSTA has changed lives in our community. With the many opportunities given to these students, it has broadened their lives and brought them out of a culture where you didn't leave your neighborhood only to go to school or the first of the month when you had to travel out of your local area to go to the grocery store for your monthly supply of goods.

Sherry, a community member shared this:

I have known Karry's family all my life. Her mom and dad was raised on welfare. They had three kids and are raising them the same. It is a vicious cycle. Neither one of them ever worked. Karry, the oldest, will graduate as an x-ray technician this spring. That is the kind of impact HSTA has. She is showing them they can have a better life.

College tuition waivers are a huge incentive for students and families. It has provided a means to finance an education. The overriding good here is that students who attend college graduate and return to their communities, (HSTA college graduate database 2012). The HSTA student, now a college graduate, brings their experiences home and with them, and the expectations of a better life. Often they become the leader in the family and the catalyst for other 
HSTA: A Case Study

family members to improve their lifestyle. The community sees the graduate as a productive member of the workforce and an asset to their areas.

Local school systems. Participants felt that HSTA's influence on the local school systems was substantial. Many of them saw it as being two fold in that students influenced peers who weren't in HSTA and that the teachers involved in HSTA were better educators because of the opportunities available to them.

A teacher revealed: "I learned new pedagogy and changed how I normally taught. HSTA gave me the self-confidence to practice what I had learned. I saw a remarkable difference in my students."

It is easy to overlook the impact the HSTA program has on local schools and school systems in the 26 counties in which the program exists. Many of the HSTA students would not have gone on to college without the program as evidenced by interviews and student senior essays which could be interpreted to mean that those school systems would have lower numbers of high school graduates attending college. This is a statistic that is measured and used to help evaluate the effectiveness of the West Virginia school system (see Appendix C).

When interviewed, a HSTA teacher explained the impact on the local school system this way: It is a watershed effect. HSTA students are normally the students that are under the radar and so are their friends. I have witnessed time and again, HSTA students encourage their non-HSTA student friends to plan for college and help them through FASFA, or meet deadlines, or apply to attend college. It is especially powerful and influential when a male student can balance sports, and academics and HSTA. Boys in our culture tend to see success in school as nerdy. When our HSTA boys challenge that through their actions, they really chip away 
HSTA: A Case Study

at the stereotype. The HSTA kids are clearing the path and leading others to a better future.

I was somewhat surprised to find that the study participants other than teachers saw the effect that HSTA students have on the school community and believed it to be a large impact. One might expect teachers to discuss the impact the program has on their teaching and training which they did, but community members frequently spoke of the example the HSTA students set and the path they blazed to college. The HSTA students had a ripple effect on others, and the community at large saw its impact.

A community member summed it up this way:

Kids in HSTA show their classmates what hard work and determination can do.

You just don’t expect a lot of these kids to go any further than high school if that.

They are living proof of what it takes to get ready for college.

A local governing board member shared this insight, "Every spring I see the graduating top twenty seniors published in the local paper and a whole lot of them are HSTA students. That is a heck of a role model for all of their friends."

Impact on teachers. Teachers shared changes they had experienced and had seen in their fellow HSTA teachers as a result of the program.

A HSTA teacher explained the impact HSTA has had on her teaching as follows:

I taught and thought differently after becoming a HSTA teacher. We were exposed to so many new and novel ideas and activities that it changed the way I approached my job. The core of HSTA teachers became great friends, but more importantly we shared activities we were using in our clubs and classrooms. As HSTA teachers, we had the cutting edge equipment, the latest training and tools in 
HSTA: A Case Study

technology, and the best practices modeled for us to learn and use. What was important also was that it prodded many of the other teachers in our schools to change what they were doing. Students in their classes were clamoring for activities and science like we were doing. To this day, I try to keep the fun in learning in everything we do.

Another HSTA teacher shared this additional experience when she emailed the following as an addition to her member check:

I have been a HSTA teacher for five years, and during that time, I have grown in ways I did not expect. This is my last year of teaching and my advice is to take advantage of all of the programs HSTA offers - you never know where it will lead! For instance, I am currently participating in an on-line fellowship on inquiry-based learning with the American Physiology Society, an opportunity that was available to me because I am a HSTA teacher. In addition, through the HSTA summer programs, I have learned how to teach multiculturalism and write grants (and with those skills, (I have won two!) and I have updated my laboratory research skills through WV-INBRE.

However, what I have enjoyed most of all is collaborating with my HSTA teacher colleagues and the professors I met during HSTA programs; one of these professors recently accepted my invitation to be a guest speaker at my school. I have also enjoyed getting to know a small group of students very well and watching them grow and mature as people, as learners, and as scientists. Finally, I particularly appreciated the freedom and flexibility to use materials and do activities that I did not have the time or funding to do within my regular 
HSTA: A Case Study

classroom setting. And with each of these experiences, I twisted and tweaked them and then incorporated them into my classroom as well.

Community education. Community education is a strong emphasis for the HSTA program because educating the community on the health issues affecting them is the first step in bringing about change. This is just the tip of the iceberg when addressing community education because it also includes the more subtle nuisances of informal education that occurs when students share or include their family members, extended family members, and peers as subjects in their research projects.

A Field Site spoke about how projects can be used to educate the community. HSTA student projects have been a part of many outreach programs. Over the years, families, peers, church groups, and neighbors were brought in to be involved in projects such as diabetes, fitness, eating healthy, drug prevention, genetic studies, tobacco prevention, and anti-bullying just to name a few.

A HSTA teacher said:

HSTA has had a tremendous impact on the community through awareness of health issues. Students have been able to connect their symposium projects to their community and families' lives. Each student's family has supported the health initiatives such as diabetes awareness, metabolic disease, and genetics.

Last year this teacher said she had six students in her club test a student designed nutritional intervention which was exchanging white bread for wheat bread by using their families as participants. The students served as coaches and conducted the interventions for a nine week period at which time they analyzed compliance and efficacy of the dietary change. 
HSTA: A Case Study

A parent shared this story:

I have learned how to read food labels. I have cooked all my life, and I had Home Ec (economics) in high school and I never was taught any of that stuff. Part of Robby's project was to list everything in our cupboard that had saturated fat and high fructose corn syrup. Lordy, the only thing we found without it was oatmeal! It sure has made me a better shopper.

A HSTA graduate relayed the following:

Our project was to see if a dietary intervention would decrease weight. My group focused on substituting water for soda. That was the only change our family members were to make for six weeks. I think there were 18 people in our study at the beginning. We had five people drop out of the study. I think the big thing that everyone at the symposium learned from us was that it is hard to make changes, but that small changes can make a difference.

The excerpts and discussions from the interviews paint a picture of the scope of educational impacts as perceived by the community. Participants who shared memories of projects and activities were animated and didn't hesitate to name students or participants. There was a sense of accomplishment and ownership in their statements whether implied or spoken.

\section{Category 2: Community Service}

There are four subtopics within the category of community service that emerged from the interviews with participants. They are health events /institutions, fund raising for causes, festivals and local events, and environmental activities. Figure 4.5, shows the category and subtopics. 
Figure 4.5. Community Service Category and Subtopics

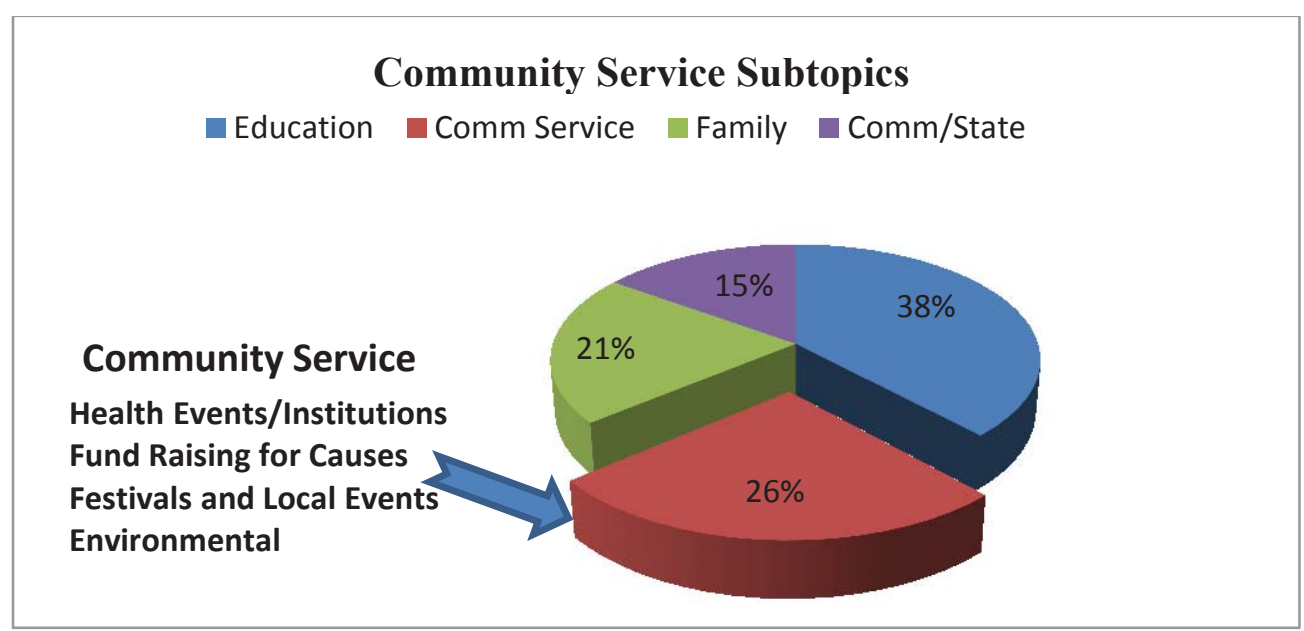

Community service activities were the second most frequently reported community impact indicated in interviews. Twenty-four people interviewed discussed the impact of community service. Field site reports were a rich source of community service documentation. Field Site reports noted large and extensive community service activities for which students volunteer. To a lesser degree, the senior essays spoke of them. Lastly, some community service events were noted in my calendars, but since this was not my focus as Education Coordinator, I did not have many on my radar.

The major subtopics of Community service that emerged from interviews were health events such as volunteering at hospital, nursing homes; fund raising causes such as cancer, diabetes, heart disease, and the local fire department; community festivals and local events like running a HSTA booth teaching about diabetes; environmental causes such as clean streams, adopt a highway or tree planting; and service at after-school and community events such as, concession stand worker for little league, field clean up or serving at banquets and dinners. All HSTA students must complete a minimum of 75 documented hours of community service by the end of their senior year in high school as part of their completion requirements. 
HSTA: A Case Study

Health events/institutions. HSTA has encouraged students to complete community service hours with a focus on health. This is not always possible depending upon the region and its local resources, but it is encouraged. Health events and working at institutions such as nursing homes was the most frequently cited community service event.

A community member who is a county health nurse spoke of her experience. "We hold a blood drive every year and the HSTA students are the ones we rely on to always help us. They are courteous, kind and willing to go that extra mile."

A teacher shared this story:

Our club adopted the local nursing home for our project. We decided that just once a year at Christmas was not enough to make a difference. The kids divided into teams and decided that doing something four times a year would be manageable. One group delivered magazines and books, and another group spent a Sunday and sang gospel songs. Surprisingly, the kids liked visiting more than I imagined. They played checkers or read or played cards with those that were able.

Pam, a community member spoke of the help given at the animal shelter. "The HSTA kids help us get the community to donate cleaning supplies, and food. We always need volunteers. They help us run the dog beauty pageant and the car wash we do for fund raisers."

Another teacher talked about her students work with the local hospice: "Our club has been volunteering and working with our county hospice for the last four years. Hospice has been able to count on my kids. They really have a deep commitment with this program." 
HSTA: A Case Study

Fund raising for causes. HSTA students were praised for their attitude and dependability especially when they were mentioned concerning fund raising events. A HSTA Graduate shared her experience:

My grandmother had cancer and I felt helpless. She was the rock of our family. Our Field Site coordinator was the county chair for the Relay for Life. She encouraged us all to help her, and for me it was a welcome outlet and way that I believed I could do something. It was so emotional. Grandma came, and that was the only relay she got to participate in. I will cherish that lap my sisters, mom, and I got to take with her for the rest of my life. Today I help chair the Relay and I do it in memory of Grandma.

Donna, a community member, sent this example to me as an addition to her member check: I forgot to mention that the HSTA kids are the ones who helped me raise money for the Betty Puskar Breast Care Center. We held a walk-a-thon and the HSTA students brought in over $\$ 1,000.00$. They were there the day of the walk and helped register, man water stations, as well as walk.

It is noteworthy to mention that the students, who often work at health events or with institutions, as mentioned in the previous category, also often help raise money. Pam spoke of that in her interview about the animal shelter in the example above.

Over the years, HSTA students have championed many causes, but one cause that is most wide spread is fund raising for the Cancer Society. Cancer in one form or another has touched each and every West Virginian and our HSTA students are no exception.

Festivals and events. One interviewee told me that she rarely attended a community function, whether it was a festival or little league event, that did not have HSTA students serving 
HSTA: A Case Study

as volunteers. This was quite a testament from the rural community member. She said she had noticed several years ago when attending her son's little league football game that the announcers thanked the volunteers and made it a point to commend the HSTA students who volunteered to run chains and work the concession stand all season long. It was then that she started looking for them at other events.

Oglebay Fest in Ohio County is another example of how students assist community organizations. The HSTA students and Field Site set up a booth to inform kids about HSTA and teach a fun science activity. After one long day at the booth, HSTA student Laura, now a scholar, said she could become a teacher. She knew she wanted to make youngsters see science was fun: "I wanted to share my love of science with all of those cute little kids. I remember hating science class because it was just another textbook. When the kids came to our booth, I was helping them to see science suddenly become magical."

A teacher spoke about how the HSTA students were the group that volunteered to work the county elementary basketball tournaments every year:

I contract to run all the school fairs and events and the HSTA students are the ones I can count on time and again. They helped with every phase of organizing and running our school's first tri-county wrestling meet. They helped set up and organize the county social studies and science fairs. It is great to know that I can count on them.

Another teacher was proud of how his students had always worked a local festival since the club was established 15 years ago. He stated that his students usually worked 14 hour days and even the students that have completed their 75 hour requirement liked to participate. 
HSTA: A Case Study

Environmental issues. Students as well as teachers are quick to volunteer to improve their environments. Several HSTA schools have recycling programs because HSTA students organized them, collect the items and arrange to get them to the centers.

A teacher described her club's highway project:

We adopted a two mile long section of the highway that runs in front of the school. We spend one Saturday every other month picking up trash. The students really are proud of how much cleaner and how nice the area looks. It doesn't hurt that they have the Department of Highways sign that identifies this area as HSTA's.

Another teacher discussed his club's project:

The students chose a project three years ago that tested the healthiness of the river and its tributaries. When they learned that some of the streams dumping into the river were contaminated, they joined the local Lion's club that had adopted the river and attended the work days to clean up the streams. They still participate as a club in the spring and fall cleaning days.

One parent spoke about her daughter starting a recycling program at the school. She and her husband helped to haul the cans to the recycling plant. Her daughter's club joined the effort and the money they made was donated to the animal shelter.

\section{Category 3: Family Impact}

The impact on families was a category that was mentioned by parents of HSTA students and by others that were interviewed. Twenty people interviewed spoke in some way about how HSTA not only had an impact on the student but also the family of the student. 
HSTA: A Case Study

Figure 4.6. Family as a Category of Impact and Subtopics

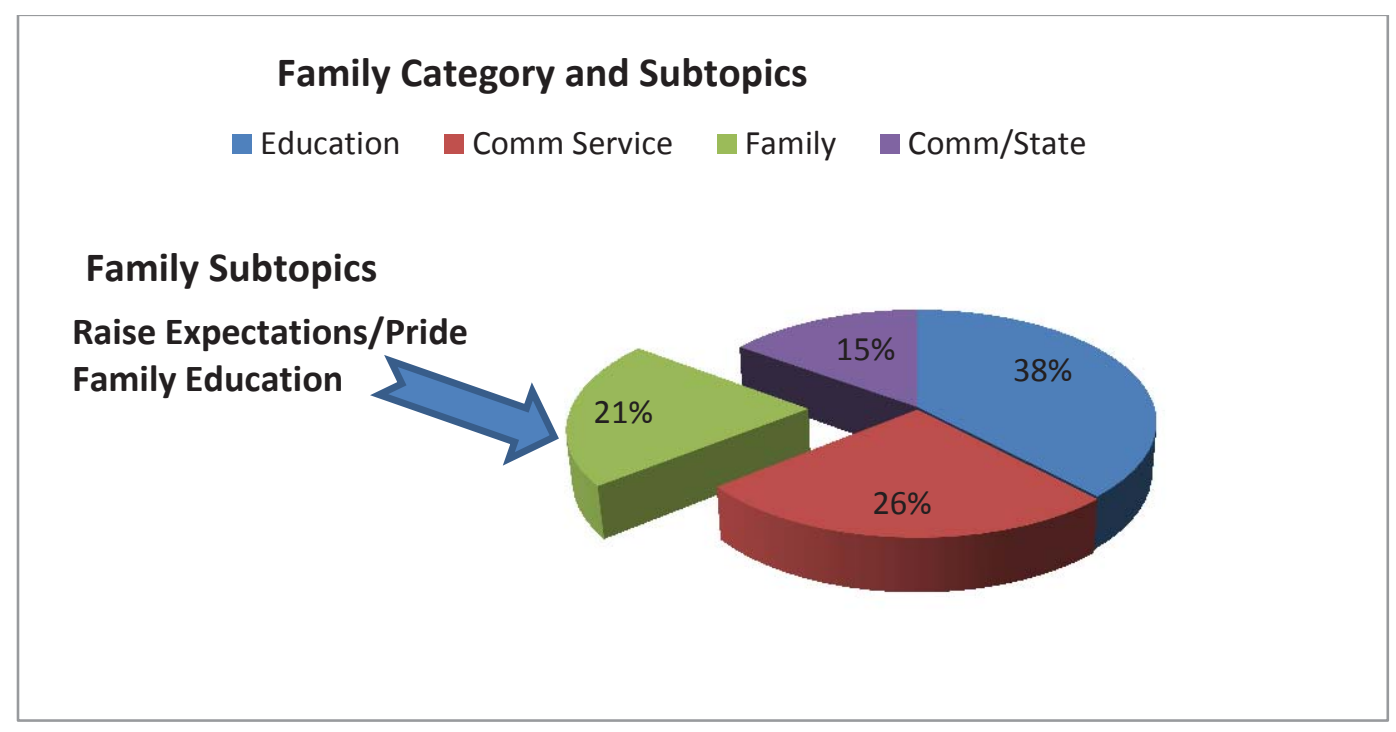

Appalachia is known for its close knit family ties and it is not uncommon to find several generations of the same family living in the area settled by their ancestors some of whom trace back to the revolutionary war. It came as a surprise to me to find how open and candid participants were when discussing their family's inability to afford college, lack of education or socio-economic status. It indicated a level of familial trust especially knowing how reserved many people are, and considering I had never met most of the participants. "Participants reported that family members usually deal with family problems internally and that sometimes second-degree relatives, such as aunts, uncles, or grandparents, are included in the process." (Coyne, Demian-Popescu, Friend, 2006, para. 25). Their only tie to me was that I was the Education Coordinator for the HSTA program.

Raise expectations \& pride. Raised expectations and pride is a category that is a theme throughout the interviews. It is evidenced in the eyes and facial expressions of the participants if not mentioned outright. Community members and stakeholders were proud of the accomplishments of their HSTA students and delighted that so many of them returned to their communities. Family and community expectations are voiced and spoken with pride. 
HSTA: A Case Study

A HSTA graduate spoke very emotionally when she told me this:

My family did not have the financial stability to pay for college expenses. My older brother and sisters never had the chance to go to college. Our mother always wanted us to further our education. She has worked at the same place for 20 years and her income is less than $\$ 15,000.00$. Because of HSTA, I will graduate from college in the spring. My whole family is coming to graduation.

JoAnn, a teacher told me:

I have students return to the community to live and work locally and that makes me very proud to have been a part of the process. It is also neat to see how proud their families are and how much they (the HSTA student) help their families.

A HSTA parent shared this:

Words can't express the pride and joy we feel knowing we have a college graduate in our family. Sherry is the reason I went back to school. She is the model for me, her mother. I never would have tried if she hadn't gone to college first. I just wouldn't know where to begin.

Laura, a HSTA parent said this:

My husband didn't finish high school and that is as far as I got. Do you know that our daughter and son are the only two people in our entire family, and it's a big one, that have graduated from college? We're so proud we could bust a gut! We tell everybody about HSTA.

Educate \& break cycles. I included education as a family sub topic because it was frequently mentioned in the interviews as an impact on the individual families. Like all of the other subtopics it is not clean and clear but is intertwined and woven throughout the evidence. 
HSTA: A Case Study

A graduate interviewed mentioned how her projects and research changed their family's thinking on lifestyle issues. She returned this in her member check:

My research project the last two years I was in our club focused on diabetes prevention. All four of my grandparents have diabetes. My family is all overweight except my youngest sister. My project was to educate our church group on how to identify all processed foods we were eating and to cut out one. Our family took up the challenge too. We chose to switch to wheat bread. We still eat wheat bread but it took a while to get used to it. The next year we cut back on soda pop. That was the hardest but it had the biggest effect.

Rose, a HSTA teacher, wrote to me and added this to her interview member check:

Throughout my time with HSTA, I have seen first-hand the importance of HSTA and community relationships. Both help to build a sense of family. They ensure students have someone looking out for them and keeping them on the right track. Through HSTA and the community, students are given the structure and support that allows them to succeed. Many of our HSTA graduates have returned home to work and live, and are paying it forward by volunteering with HSTA.

Joe, a HSTA parent shared this: "I've learned more stuff about health and how to improve my health since my daughter has been in HSTA than I had in all the thirty-nine years of my life."

It is noteworthy that two of the three previous quotes also discuss health literacy. This is a goal of the students' yearly community research projects "However, research shows that many adults find health information hard to understand" (Torpy, Bruke, Golub, 2011, p. 1158). 
HSTA: A Case Study

Students able to translate findings into easily understandable and relative dialog make this possible.

\section{Category 4: Benefits to Community and State}

Fourteen people interviewed discussed the broad benefits to community and state which became the fourth category. This category broke out into four subtopics. They are discussed below.

Figure 4.7. Community \& State Subtopics

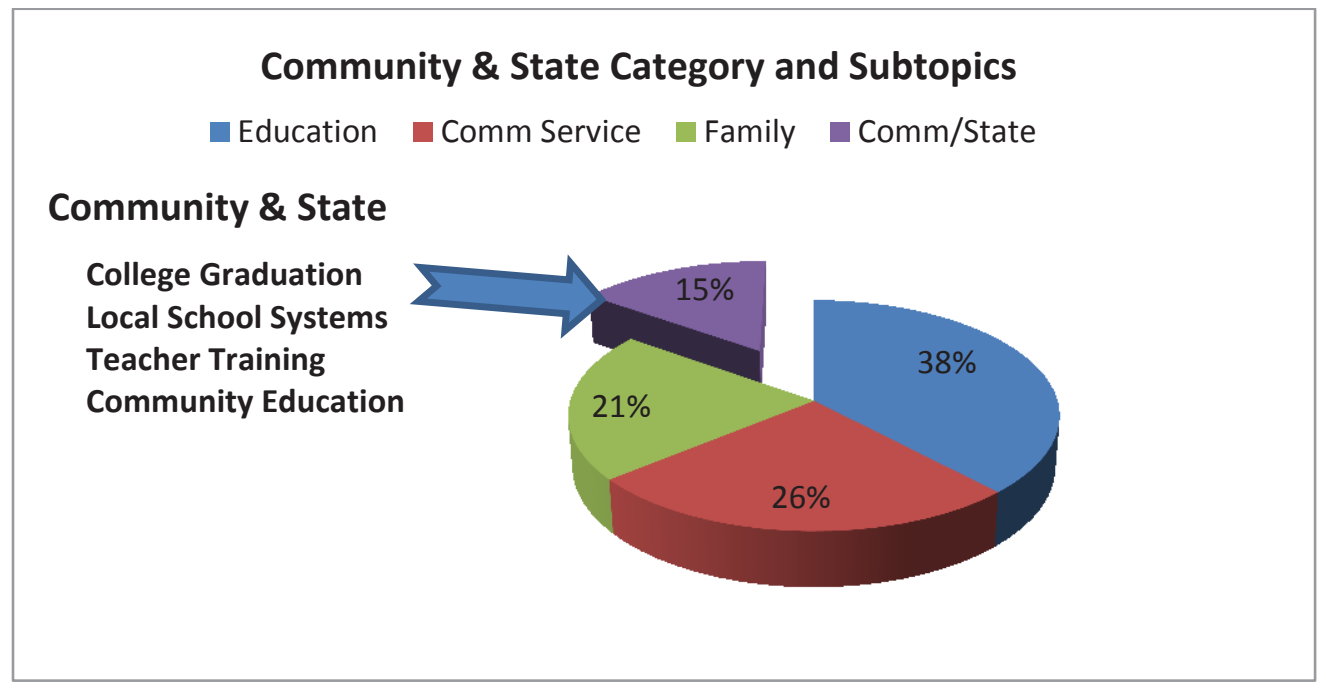

Educated work force. In today's global economy, an educated work force is vital to keeping and maintaining a competitive edge. West Virginia, like so many other rural states, has suffered a brain drain. Badenhausen, (2009) reports that:

A recent study by Payscale.com found that $72 \%$ of WVU graduates who had been out of school for at least five years had left the state. That was the highest rate of any top public university in the country and in the state with the lowest college graduation rate: Only $16 \%$ of West Virginia residents have a college degree (para. 7). 
HSTA: A Case Study

A more recent study from 2011 just released, however, shows that of the 115,730 students who graduated from college in West Virginia in the last 10 years, $48.1 \%$ of them were working in West Virginia, (wvutoday.wvu.edu, accessed 4/2013).

Sarah, a community member shared her experience about HSTA college graduates who elected to stay in the state:

Our school health clinic nurses are HSTA graduates. I just think that is wonderful. I really didn’t know a lot about HSTA until I began teaching with Travis who is also a HSTA graduate. I had all of these kids in high school. They were bright for sure and I know this sounds awful, but they weren't the ones I expected to be able to go to college. They went, graduated, and now live and work at home. It is so nice to see that. My kids are older, but they left the state after graduation.

Toby, a HSTA graduate explained it this way: "I want to live and work in West Virginia. My family is real close. When I graduated, I knew where I wanted to spend the rest of my life. My education lets me do that."

Randy, a former legislator shared this with me:

Our new high school principal is a HSTA graduate. We have an MD in the county that is a HSTA graduate. The EMT who took my mother to the hospital was a HSTA graduate. I know there are more but those come to my mind first.

Participatory citizenship. Participatory citizenship takes on many forms in the documentation and is wide in its scope and variety. Participant interviews show it ranges from being an officer on the home-town little league program to serving on the county health committee. What is exciting to me is the change I personally have seen over the eighteen years I 
HSTA: A Case Study

have been in this program. Time and time again I witness the same phenomena. Students, the quiet, accepting, invisible students, gain skills, self-confidence, and hope, develop into strong, compassionate leaders. These leaders go on to college, graduate and return home to work. They become the participants in civic organizations and involved in their children's lives. They do not settle for the standard in which many of them were raised but now bring their non-participatory parents with them as participatory grandparents. There were two instances during the interviews where HSTA graduates discussed this.

Grace, a HSTA graduate shared the change she has seen in her father:

My dad never went to anything I was involved in when I was in school. Neither did my grandpa when he was living. They didn't feel comfortable and wouldn't go no matter how much I begged them to. My dad goes to all of my daughter's soccer meets now. I like to think it is because I have helped him see it isn't so bad.

A field site coordinator relates in an interview:

One success story is Lilly, who grew up in abject poverty. She was a quiet, petite, and tiny little girl who by third grade, was responsible for getting her younger brothers to and from school. No one ever expected much from little Lilly. Her dad didn't hold a steady job, and her mom was an alcoholic. Lilly was bright and sweet, but it seemed to most that she had just too much to overcome. I had pressed her, no really hounded her, to apply for HSTA and she did. Today Lilly is an RN working in her local health clinic and serves on the local HSTA governing board. Lilly has broken the bonds of poverty, is happily married and has a little girl that looks just like her. 
HSTA: A Case Study

Randy, a community member also spoke of this: "The county little league football and baseball programs are chaired by a HSTA graduate who is a physical therapist. She worked with me after my surgery".

Rural healthcare providers. HSTA was a program originally designed to address the critical shortage of rural health care providers. This remains a major focus among what are now expanded companion objectives of increasing the number of STEM (Science, Technology, Engineering and Math) graduates.

Beth, a community member had a lot to say about HSTA but shared this in particular about the rural health care providers:

As far as impact, I believe that HSTA has quite a large impact. Several students who were once HSTA students are now employed by our local hospital and work as well in doctors' offices and clinics. They serve our friends and neighbors by taking care of their health care needs and by being upstanding citizens and role models to others.

Lynn, a HSTA graduate believes:

In the past, our local hospital struggled to find healthcare providers. Today, I am one of eight HSTA grads who returned home and work in our hospital. We are physical therapy assistants, x-ray technicians, nurses, billing clerks, and an MD. That is an impact.

A field site shared this: "Our school health clinic is staffed by two nurses who are HSTA graduates and our local pharmacist although from a different HSTA region is our pharmacist." 
HSTA: A Case Study

The mission of HSTA was and still is to provide a rural healthcare workforce. It is evidenced that the communities are aware of this and can often name several HSTA graduates who work at clinics they visit.

Increased tax base \&remain in the state. Participants discussed the importance of local students being able to obtain an education and skills that allowed them to return to their hometowns. They noted the higher standard of living and income available to the graduates that helped the local economy.

Benny, a Local Governing Board member, discussed this:

The graduates who return to the community have a huge economic impact. They pay taxes and spend money in our businesses. It is so gratifying to know I am a part of a program that allows kids who were more than likely destined to a lower standard of existing be able to be successful, use their talent, and move out of the grips of poverty.

Linda, a HSTA teacher related:

I have been a HSTA teacher for 13 years. I have students that have gone on to be physical therapists, physician assistants, teachers, and chemists. All but two live in the state and I can guarantee they make a lot more money than I do with the exception of the younger teachers. Seriously, so many of our students live a much better lifestyle.

Libby, a parent shared this:

My daughter graduated from college and moved back home to work. She lives two blocks from us. She teaches preschool. My two older kids didn't go to college. We never even considered it for them really. HSTA wasn't around then 
HSTA: A Case Study

and we just didn't know. There was no jobs here and my oldest son moved to North Carolina and his brother followed him after graduation. They have decent livings but they can't get work here.

Donna a teacher gave this example.

Our HSTA program has allowed some of our brightest and less fortunate students to get an education and be active members of the community. I remember these students barely hanging on the fringes of school and extra activities. Now they are the leaders and coaches for these programs. They got their education, returned home and are giving back in so many ways.

A community member shared this: "We need to keep our college graduates in West Virginia. The state can't afford to educate the best and then sit back and watch them leave. HSTA has a good track record of students who remain here."

How the community and state benefit from HSTA was an afterthought to me. My focus was mentoring students to success. As is often the case, the immediate pressing needs of life, consumed time and left little energy to consider the loftiness of what the program had to offer. It was not until much later that I even considered the long reaching benefits that come from student success. It is telling that the community members recognized this as an impact.

\section{RQ2: Examining}

Examination of extant data, RQ 2, revealed the same categories as RQ 1 however there was also another subject which was summer institute that emerged. It was not frequent enough for inclusion as a category but was sufficiently present in the data to warrant mentioning. It will be discussed at the end of this section. Even though RQ2 data revealed the same categories there 
HSTA: A Case Study

was a difference in topic frequency when comparing the coded Field Site reports and senior essay.

\section{Field Site Reports}

The 473 Field Site reports listed community service activities $63 \%$ percent of the time when compared to education at $11 \%$ percent (Figure 4.8). Community and state was reported in $21 \%$ percent and family only in $9 \%$ percent of the Field Site reports. Education as it emerged was not strong. I believe this is due to the nature of the Field Site report, the function of which is to report local governing board, club, and current student activities.

Figure 4.8. Percentages of Topic Frequency from 473 Field Site Reports

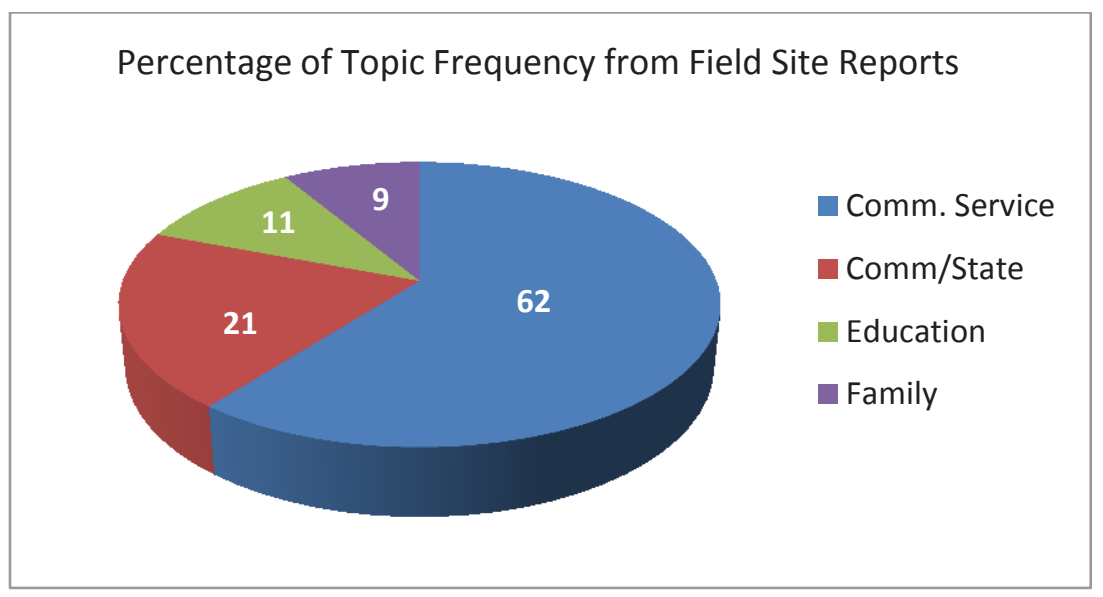

Field Site reports provided the clearest view into the activities of the community club component and the interests of students and teachers. It is important to note that several teachers have group community service activities each year, which is in addition to the individual student interests.

\section{Senior Essays}

Senior essay topic frequency of the 43 essays (Figure 4.9) revealed that they were more closely matched in percentage to results from RQ 1. Community and state had the highest frequency at $33 \%$. Family was next and was coded in $26 \%$ of the essays. Community service 
had a frequency of $21 \%$ and education was $19 \%$. The degree to which the four categories are supported by the essays is fairly even. The topic of the senior essay requires the student to describe what HSTA means to them. At the time the students are writing the essay they are almost assured of receiving the tuition waiver. The fact that the students felt strongly about the impact they could have or make on their community or state was evidenced by the high percentage. Second was family. Students discussed their pride, and what they expected to be their ability to help their families once they received their degrees. Community service and education were often discussed in relationship to building character and leadership. Figure 4.9 shows the frequency in percentages of extant data from this data source.

Figure 4.9. Percentage of Topic Frequency from 43 Essays

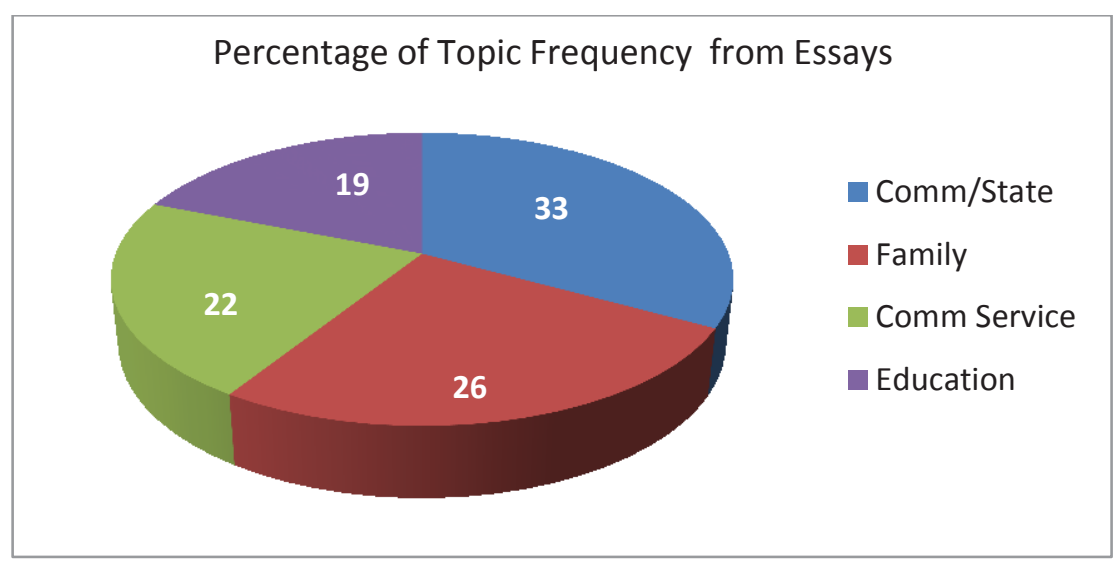

\section{Student Project Lists and Abstracts}

The 2100 titles of student project titles did not support any of the categories when coded. It was often difficult to tell what the project topic was just by the title. For example, "Frankenfats" probably referred to hydrogenated oil, and "Diabetes in Smokers vs. NonSmokers" really didn't fit the categories that had emerged. Community Research Associates, (CRAs), keep track of the number of health topics the students research each year and those numbers can be found in Appendix W. 
HSTA: A Case Study

\section{Community Club Evaluations}

Nineteen years of extensive evaluations of the many components of the HSTA program revealed there were no questions examining impact. To address this, the program evaluator added three in 2012. Examination of the three questions added to the annual community club evaluations to measure perceived impact of projects and community service as perceived by students and teachers showed that $89 \%$ felt that community service had an impact that was very to extremely important. Seventy-nine percent, believed the student research projects had a moderate to very high impact on the health of the community. When asked about the impact the research projects had on the health of HSTA families $77 \%$ rated it as moderate to very high.

Figure 4.10. Results of Community Club Evaluation Questions Addressing Impact

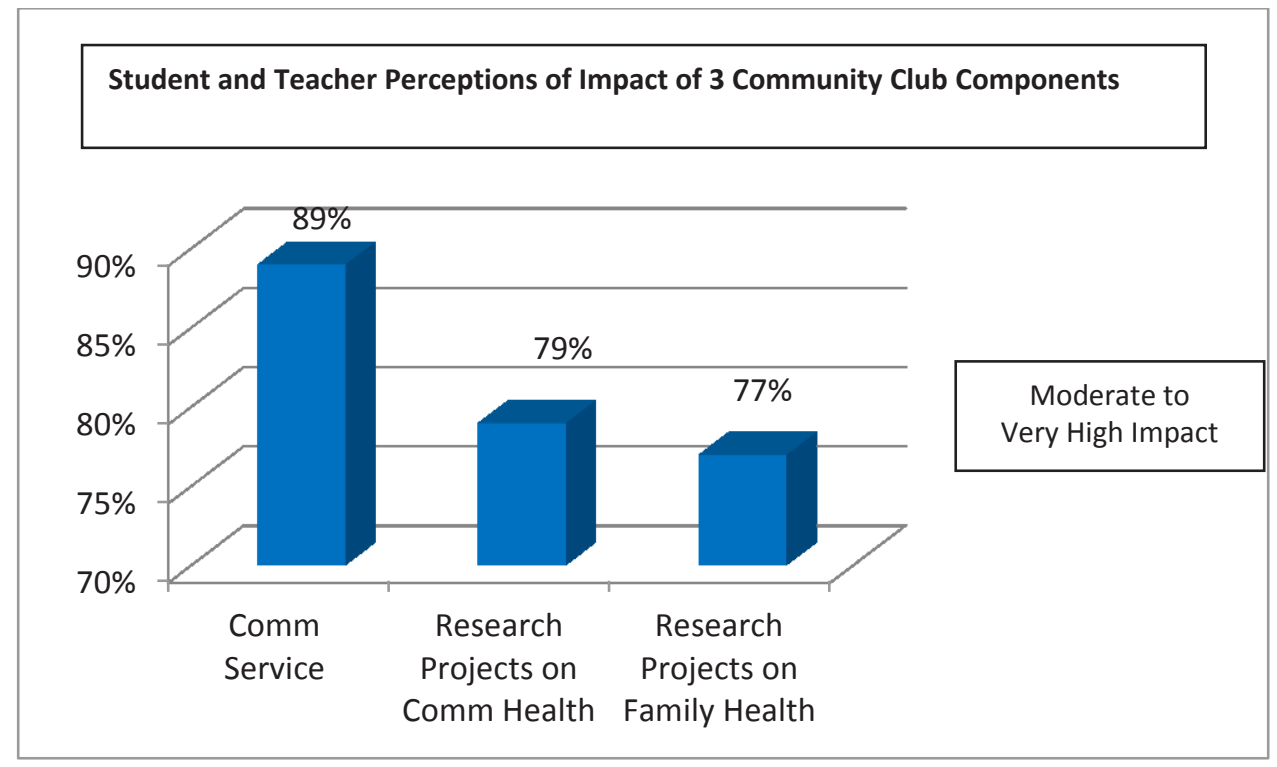

The presentation of findings in respect to RQ 2 is an examination of the four major categories and subtopics that emerged. The frequency of categories differs depending upon the source of extant data and when compared to RQ 1. This is addressed as well as one other category that did not meet the frequency standard to be included, but was close. 
HSTA: A Case Study

\section{Category 1: Community Service}

Health events/institutions. As previously stated, HSTA students are encouraged to volunteer in health related fields and events, but this isn't always practical or feasible considering the rural and sparsely populated areas of our state.

A senior explained in her essay how she became involved in community service:

For my part, I went to two different nursing homes and really enjoyed meeting and working with the elderly. I did everything from hanging calendars to helping them with their physical therapy. I even painted some of the ladies' fingernails. I still go there even though I don't need the hours.

A Field Site report stated: "The HSTA club assisted with the Blood drive last week. This is the third year we have helped the local health department with their annual blood drive." A senior wrote in his essay about working at the animal shelter:

I volunteer at the local animal shelter two Saturdays a month. It is hard work and sometimes sad but I think I make a real difference. I would like to become a Vet someday and that is because of my volunteer experiences.

These shared examples shed more light on the impact on students but the community saw the other side of it which was the good it did for others. It was the broader impact that was noted by the community.

Fund raising for causes. HSTA students assist many organizations in raising money for local, state and national causes. The examples give an insight into the scope of their work. A senior in his essay described his activities with the local fire department:

I have worked with the Volunteer Fire Department since I was a sophomore. We hold car washes and dinners and sponsor a big Firemen's Rodeo each year 
HSTA: A Case Study

to raise money. I have learned so much about sacrifice and giving back from being a part of this group.

A picture of a former field site coordinator, and a few of her students who participated in a Diabetes awareness event in Kanawha County (Appendix R), is a typical example of the community service events in which students are able to participate. The field site reported: "This was a first for them and although the students were reluctant at first to participate, they quickly were caught up in the spirit and fun of the event”.

Another field site reported: "The HSTA club held a "Hoops for Heart" fund raising event for the American Heart Association at 3 home basketball games. The students raised over $\$ 1200.00$ for the AHA."

Other examples from reports discuss winter coat drives for the needy, organizing and collecting food for the food pantry, and getting pledges for a walk for the cancer society.

Festivals and local events. One teacher interviewed and quoted earlier said, "I contract to run all the school fairs and events and the HSTA students are the ones I can count on time and again".

The field site reports from 2008 to 2010 for the above mentioned teacher's region corroborate the events he mentioned as well as others. For the three years he was a HSTA teacher, his students also helped with the county literature fairs and the county basketball, wrestling and softball tournaments.

Several field site reports spanning the years examined 2006-2012 cite examples of HSTA students working home football and basketball games by working the concession stands, cleaning the fields or selling raffle tickets. One field site reported that her students gave healthy 
HSTA: A Case Study

treats and pencils out for Halloween at a home football game. They had approximately 200 students visit their booth.

This is from a field site report: "Our club was asked to have a HSTA booth at the local yearly festival and now we are a fixture there each year."

Environmental issues. A field site report stated "Our students volunteer to plant trees each year with the Department of Natural Resources. It is a huge success and they seem to enjoy working to make our area healthier and more attractive." A more recent field site report shared this:

Three boys in our HSTA club joined the county commission members and the Department of Natural Resources on the local stream stocking day. These boys braved the cold and snowy weather to help stock trout in all the county streams.

Another field site reported that the students had adopted a highway that runs in front of the school, which corroborated the teacher's interview. They were both referring to the HSTA club community project.

Examining six years of Field Site reports indicated students had worked at nursing homes, hospitals, supported blood drives, food collection for pantries, raised money for cancer research, worked local fairs, and volunteered at ballgames, which just begins to cover the breadth of their involvement. Some communities have come to rely on HSTA students to serve and volunteer at local events. Community service activities run the gamut of raising money for national causes such as the American Heart Association to activities as simple as providing concession stand workers for little league ballgames. 
HSTA: A Case Study

\section{Category 2: Community and State}

Educated workforce. HSTA extant data for 2012 shows that $90 \%$ of HSTA college graduates remain in the state. The majority of these graduates, $73 \%$, are the first in their families to graduate from college, (HSTA graduate database, 2012).

A field site coordinator reported:

Our school health clinic is staffed by HSTA graduates. They served as our guest speakers at our club meeting in October and also are going to oversee the student's HSTA project on exercise and heart rate. These ladies are a wonderful resource and example of how HSTA can change lives.

Another field site reported:

The guest speaker at the club meeting this semester was none other than our own HSTA grad. and M.D., Chrissy. She talked about how HSTA was the reason she was a doctor and how it supported her even today. She told the student about her classmates who were deeply in debt with student loans and she wasn't because of HSTA. She then taught all the students how to suture using a pig's foot.

Participatory citizenship. Participatory citizenship is a subtopic that emerged across all of the data. It deserves attention, especially since many of our students enter HSTA with few experiences or role models of how to become engaged in the community.

Field Site Report revealed:

One of own success stories, Jonathan, spent time in our HSTA meeting today. He spoke of how when he was in high school, he really was afraid he couldn't succeed and how HSTA was always there to give him support and a boost. He 
HSTA: A Case Study

spoke so strongly and passionately about how he gives back to our community because they supported him.

A senior in her essay had this to say:

I volunteered at a local long term care facility, which I found to be very rewarding. Helping with crafts, and parties, playing bingo, and pushing residents in their wheelchairs were some of my favorite activities. I have created lifelong relationships with the wonderful residents at the facility and continue to visit on a regular basis.

Another field site report stated:

Joshua graduated this year and was honored at our senior dinner for faithfully serving as our student representative the last two years on our local governing board." Serving on the local board as a student representative is a sacrifice for a high school student but is vital to those he represents.

Rural health care workers. A recent article featured in WVU Healthcare Magazine published in 2012, highlights the tremendous impact HSTA graduates have on a small rural community and the local clinic/ hospital, (see Appendix S). Eight employees are HSTA graduates and are employed as nurses, physical therapy assistants, $\mathrm{x}$-ray technicians and a physician.

A field site report revealed: "Cate finished her certification as a physical therapy assistant, and was recently employed by our hospital."

A field site report had this success story:

Janna recently was hired as the MD at our local clinic. It had always been her desire to return home to work and be close to her family. When I visited her 
HSTA: A Case Study

recently to see if she would be a guest speaker at our opening HSTA meeting, she proudly showed off the clinic now run by her. She scheduled a visit to the club and wants to bring the club to tour the clinic. Janna is the newest shining example of how HSTA is improving healthcare.

Increase tax base \& remain in the state. Extant data shows that HSTA students make an average of $\$ 27,000.00$ more per year than their highest earning parent (Chester \&Dooley, 2011, p. 95). This is a statistic that bears much attention.

The most recent HSTA brochure, (Appendix T) lists the program as having 882 HSTA college graduates and $90 \%$ of those graduates are living in the state of West Virginia. This data segues and overlies the second part of the subtopic which is the impact of graduates remaining in the state.

A Field Site wrote this story as part of a success story about her region:

Cindy was the only person to graduate from college in her family. She was raised on welfare by her grandmother. When her grandmother died suddenly, Cindy was for all intents and purposes, homeless. With community help and HSTA on her side, she is now applying to medical school and wants to be a general practitioner. Her dream is to one day open her practice back home.

Eric, a HSTA grad, wrote in his senior essay:

I am proud to represent my state as a HSTA member and will do my best to give West Virginia a good name. Thank you HSTA for not only the chance of higher education, but for helping me become a more compassionate and more helpful member of my community. 
HSTA: A Case Study

\section{Category 3: Family}

Raise expectations. A senior, in her essay states how important HSTA is to her and her ability to better her life in frank and concise terms.

For too long, I have sat back and watched some of the women in this county struggle; single mothers attempting to raise multiple children, alone, having only government help for income. I absolutely refuse to be a statistic. My every intention and goal is to get myself an education to provide for myself, and if needed my family, one day. I want to able to live independently and not depend on anyone to pay my bills or get me the things I need. I feel that the HSTA waiver grants so many students the ability to do just this. It grants us the chance to make our lives exactly what we want it to be and to change some of these statistics, views, and degrading stereotypes.

Another senior essay explained how he would be the first in his family to attend college:

HSTA has opened many doors and created opportunities that would not have been possible otherwise. I will be the first person in my family to attend college. My mother and father, as well as HSTA teachers and mentors, have always taught me that hard work leads to success and education is the key.

This HSTA grad like so many before him has broken through a barrier to obtain an education which was unattainable for previous generations of his family.

Pride and accomplishments. A senior spoke in his essay of the pride the family had for him because he was the first to go to college.

My grandma raised me and although we didn't have much we had love and determination. From the time I was little, her dream for me was to go to college 
HSTA: A Case Study

and HSTA will make that dream come true. The pride I see in her eyes and hear in her voice makes all the hard work worth it.

Another senior essay speaks of the pride his family has for his accomplishments:

I always knew that I wanted to be the first person in my family to go to college and HSTA is making that possible. My family can't afford to send me to college. Now they are proud that I will be able to fulfill my dream."

Educate \& break cycles. Sonja, a HSTA graduate whom I knew from working with her on her research project several years ago, shared a poignant story that illustrates how family members support one another and value education.

My junior year in high school, my dad was killed. This changed us all, but it especially hit us financially. My older sister was in college and had to drop out because we didn't have the money. I had HSTA to help me and I had a future. My dad always told me and my sister it was important to go to college. He always told us that he was overlooked for promotion because he didn't have a degree. I will finish college soon and I plan to help my older sister be the second member of our family to finish.

One senior in her essay explains how HSTA is relieving a financial burden on the family that had determined that education was the key to success but until HSTA had no hope of sending her to college.

\section{Category 4: Education}

College graduation. The most recent extant data reveals that $96 \%$ of HSTA students attend college and 90\% graduate with a four year degree or better, HSTA brochure, 2012 (see Appendix T). This ranks as one of the most important of HSTA accomplishments. Coupled 
HSTA: A Case Study

with the percentage, $(90 \%)$ of those graduates that remain in the state, it is definitely a main consideration when legislators included HSTA as a line item in the budget, (see Appendix D). HSTA numbers for college attendance and graduation far exceed those of Upward Bound, (56\%), and are better than those receiving the state merit waiver, the PROMISE scholarship (Ed.Gov).

When examining the FSC reports, there was no specific mention of the number of college graduates and that was due to the nature of the reports which reflect the current undergraduate student and club events. There were instances noted where college graduates attended meetings as guest speakers. Education was only mentioned in $11 \%$ of the 473 Field Site reports that were coded. Field Sites however are vital to keeping the database of our alumni current and each fall call families for updates, which are then stored in our database. HSTA has been able to track approximately $98 \%$ of the alumni to date. The master database is used to generate the brochure (see Appendix T) the most recent of which states that $90 \%$ of our HSTA high school graduates get college degrees in 4 years.

Senior students writing the essays, who were soon to be high school graduates, mention college graduation was their goal and dream but there were none that discussed college graduation rate as an impact. Only $19 \%$ of the 43 essays discussed graduation.

Impact local school systems. Essays were a good source for examples that support impact on the local school systems. Many students spoke of their personal growth that led to change in themselves that affected their school experience in a positive way.

A senior, in her essay explained the school community impact this way:

HSTA is a great program and it has helped me develop into the excellent leader, student and person that I am today. When I started HSTA I was a quiet, shy and 
HSTA: A Case Study

not a very out-going person. It was as if I was like a simple flower bud not quite ready to bloom. Just as in spring the warm rains and sunshine starts the process of a simple rose to bloom, so did HSTA provide the same effect to my development as a high school student. I feel a great sense of self-satisfaction after being able to be an active leader and role model in my club, my school and my community.

Another senior essay stated it like this:

The HSTA scholarship gives us the opportunity to give our wonderful state back its dignity and the recognition it deserves. It grants us the chance to make our lives exactly what we want it to be and to change some of these statistics, views and degrading stereotypes that people have of West Virginia and its natives.

HSTA students scored higher on the annual state achievement test, the WESTEST, than a comparative group of students, (Smith, 2012). That is a remarkable statement with broad implications. For example, consider 10 schools each with a HSTA club of 10 students. Because these schools each have a HSTA club, we can expect, collectively, these 100 HSTA students to have higher scores than a comparative group of students and thus increase the performance of all 10 schools. Additionally, these same 100 students will all graduate from high school and $96 \%$ (i.e., 96 students) of them will go to college. Ninety percent of them will graduate from college in four years and of those, $94 \%$ of will live in the state. Comparatively the state average college graduation rate is only $53 \%$ of those that started, and of those only $43 \%$ remain in the state (Luzer, 2010).

Impact teachers. Twenty six teachers have completed their Masters in Secondary Education through the HSTA program at West Virginia University (HSTA Teacher Database, 
HSTA: A Case Study

2012). Teachers were provided tuition waivers to complete course work until 2009. Several cohorts of teachers matriculated through the program that was at its strongest when Dr. Jim Rye was the advisor. Unfortunately though, four years ago the university stopped offering tuition waivers for the HSTA courses. The HSTA masters program is no longer offered.

HSTA has partnered with the National Institutes of Health- WV INBRE program for the last four years. This summer program requires six weeks on campus but provides teachers a well paid opportunity to work in a research lab alongside a scientist. The last three years we have had two teachers schedule to work in INBRE labs in Morgantown and Marshall and this year there will be three attending different labs at Marshall, West Virginia University, and Shepherd University.

If experience alone was a measure of impact, HSTA certainly would score well. Teachers that sign on to HSTA are provided the opportunities to explore and develop skills and interests they otherwise would not get. The opportunities run the gamut from travel to training. National presentations and conferences provide a unique appreciation and way to showcase the novel projects and activities the teachers and students complete (see Appendix U). Working alongside scientists and medical professionals each summer increases skills and depth of subject knowledge their non HSTA peers don't experience. Having the opportunity to publish is something that several teachers have shown interest in and to date, we have 11 teachers who have co-authored peer reviewed publications (see Appendix V).

Community education. An examination of the summary of student research project lists (see Appendix W) shows a sharp increase in research that was on health issues in 2012 when compared to 2011. Students must present their research findings at a local symposium that the public can attend. Since many of the health related projects are driven by interests and issues 
HSTA: A Case Study

that affect the students, the sharing of their findings with the community is a component of community education. Likewise, of the 224 health projects conducted across the state in 2012 , several distributed brochures or displayed posters in public venues of their findings. That was $56 \%$ of all student projects. The percent of projects increased to $72 \%$ in 2013 , (HSTA project database, 2013).

HSTA held 3 district symposia last year where students presented their research findings. These were well attended and offered all teachers, students and staff as well as parents and community members the opportunity to hear and see what others were doing. Even more importantly the students had presented their findings in their home towns to family and friends at an earlier date. This is one form of dissemination of results to the public. Two HSTA regions sponsored health fairs and presented their student project findings in addition to the usually offered health tests that the local clinics and hospitals provided.

\section{Additional Topics: Summer Institute}

One topic emerged from the extant data that was not strong enough to warrant inclusion as a category but none-the-less was important was "summer institute." The summer experience was discussed in extant data. It did not appear with any regular frequency for inclusion but it bears discussion and attention. HSTA requires completion of two summer institutes but students may choose to attend all four of the summer institute experiences that are offered. Each institute is designated by grade level. Rising freshmen just entering the program can choose to attend a week long summer experience traditionally held at Marshall University. Rising sophomores are offered a Forensics camp usually held at West Virginia State University and or Glenville State College. Rising juniors can attend a biomedical camp held at West Virginia University and 
HSTA: A Case Study

finally rising seniors may opt to attend a three week college credit course at West Virginia University.

Field Site reports discussed summer institutes. Most items concerned student attendance and or letters requesting exemption or approval of a substitute camp such as the Governor's Honor Academy, instead of the HSTA summer institutes. Reports also included pictures and even a link to a video made at one camp. http://www.youtube.com/watch?v=xkSXNeth9Zw This video was completed at the HSTA Forensics Camp for rising sophomores held at Glenville State College.

Some student essays mentioned their summer camp experiences and when they did, they spoke of friendships and the college campus experience. The difference between the two sets of data can be attributed to the purpose of the documents. Field Site reports must keep the Local Governing Boards and the central administration abreast of students' attendance at camps whereas the essays are written by a student trying to convince a panel of judges as to the merit of the student seeking the scholarship. It is important to remember that summer institute was also mentioned but not frequently enough to be included under RQ1.

Friendships. This topic that emerged from extant data is important. Student essays were the main source of this topic. There was discussion and mention of the opportunity to meet and associate with students from different backgrounds and ethnicities while attending summer institutes. Students spoke of making life-long contacts and friends from all over the state because of their summer camp experiences. It is an important part of their growth, development, and preparation for college to be able to acknowledge, accept, and appreciate, different cultures, and values other than their own. 
HSTA: A Case Study

\section{RQ3: Experiencing}

The findings presented in respect to RQ 3 are solely about the degree to which my experiences as a participant-observer and HSTA teacher and Education Coordinator support the emergent categories. I was frequently reminded of specific instances, projects and people during the interviews and examination of the extant data and I noted these in my research journal.

\section{Category 1: Education}

College graduation. I previously stated that thirty-six of the forty-two people interviewed discussed the educational opportunity provided by HSTA. In my ten years as a HSTA teacher I have seen freshmen enter the program with the hope of attending college tempered with a hesitancy and insecurity that belied a "too good to be true" skepticism that over the course of the four years in the program, blossomed into skills, confidence and success. Personal correspondence and three graduation announcements from my HSTA students give evidence of this as does Appendix T.

School systems. A notation in my personal calendar dated February 2009, scheduled Saturday the 21 st as a date that a rural HSTA club was hosting what they termed a Prep and Practice Party in the school library for ACT practice tests. The invitation was posted in the school for all interested students to attend. The teacher reported that four HSTA juniors and seven students from the student body attended. This was not a practice of which I was aware that occurred in any of the schools HSTA served and it demonstrated the innovation of the teacher to meet the needs of her HSTA students while providing a service for the school body at large. HSTA policy reimburses students up to two times for the costs incurred when taking the ACT. Knowing what to expect, learning test taking strategies, and actually taking a practice test in test conditions, was a great way to ensure students were prepared for the test. 
HSTA: A Case Study

HSTA students have served as tutors to elementary students in the afterschool setting in two HSTA counties. (Personal Daytimer, 2008) These schools are grades six through twelve or are high schools that are adjacent to the elementary schools. For community service hours, HSTA students have offered study sessions and tutoring while the elementary students wait on their bus. It has not been formally measured or studied since it was community service but this could very well be developed into a research project for the HSTA students.

HSTA teachers. I can speak to the phenomenal impact HSTA had on expanding my subject and background knowledge, my teaching techniques, and my willingness to try novel strategies in the classroom. I wrote an essay in 2005 that explained the effect that HSTA had on me as a teacher. The following is an excerpt.

I was a good junior high science teacher. The high school teachers would often tell me that they could identify my students right away because of their knowledge and skills. However, when I walked into the HSTA summer training for teachers, I very quickly became aware that I could be so much more. The next five intense days had me thinking and planning curriculum and instruction in a fun-filled, exciting way that made me wish every teacher had the chance to learn these skills. I felt as if I were freed from the bonds of the textbook and leaning outcomes that tied us to cookie cutter labs and worksheets. I became more selfconfident and trusting of my judgment and ideas about how to get and keep kids excited and engaged in what they were learning. I have often said HSTA picked me up and turned me on my ear and completely changed the way I taught. That is no exaggeration. I literally loved the fun HSTA put into science and learning and found over the years that transferring these skills to the classroom made my job 
HSTA: A Case Study

fun, the student achievement rise dramatically, and the students enthusiastic about learning. More importantly though, the change in me translated into better prepared students and instilled in them a love of science too.

As an education coordinator I have witnessed a similar phenomenon again and again with the teachers. This is probably most evident when teachers are brought to college campuses to acquire the skill sets necessary to deliver curriculum to the students attending camp the following week. Teachers work alongside professors and scientists and develop activities and schedules that are engaging, innovative and challenging yet fun. I see these same skills and activities taken back to their regular classrooms and used. Not only are the teachers sharing their newly acquired skills and pedagogy with their HSTA community clubs they are incorporating them into the classroom.

Teachers also gain a new sense of professionalism through contact with fellow teachers and by participating in the development and implementation of curriculum components. The Summer Institutes provide an opportunity to practice new teaching strategies in a less pressured environment. Teachers can hone their skills before taking them to the classroom.

As a HSTA teacher I can attest to the ability HSTA experiences gave us to be leaders in our own schools. We were the teachers who had learned the newest and best methods and had the latest technology and educational experiences. Often other teachers in our school looked to us to get them up to speed and to put our school ahead of the others in the county.

Community education. Community education is a key component of the research projects completed by HSTA students as part of the program requirements. Each yearly research project must have a community focus and student findings are presented to the community in 
HSTA: A Case Study

different venues but all students must present at a local HSTA symposium (in addition to the state symposium) so community and family members can attend.

I have had students design and develop a simple pre-post test to use at their HSTA symposium. (Webster County Practice Symposium, 2004). The students gave every audience member a 20 question pre-test that asked questions about the main points of their research projects they were about to present. After the presentations the students administered a post test and measured the difference. The students wanted to see if they translated their findings via their presentations to the audience. As was expected, the post scores were much higher than the pretest scores. What the students didn't realize was they were also informally modeling an educational intervention and measuring how well they educated the public. Although rife with research design flaws, the activity led to students designing a similar component and adding it to their projects the following year to measure their effectiveness as community educators. They enjoyed analyzing this feedback and it in turn helped them polish their presentations before having to present at the state level.

As education coordinator I assisted the students with a project that required the participants to complete a series of tasks and $\log$ them in a particular order. When the students gathered the logs they found that some of the participants didn't follow procedures. If the HSTA students who were some of the participants didn't fully understand the importance of following directions, then it wasn't a stretch to also assume that many of the community participants had little or no idea that to be a part of a research study they have to follow the rules or parameters of the study. Going rogue means that the data is invalid and can't be used. This was a teaching moment even though the HSTA students weren't happy. The following year the students repeated the project and had valid results. The take away from all of this is that educating the 
HSTA: A Case Study

subjects thoroughly as to the expectations and rules of a research protocol should have occurred first and serves as an example of the critical nature of community education.

Today, community engagement is the hottest avenue to funding in the science and health fields. HSTA has been doing this for 19 years. As Education Coordinator I contributed the plan and vision of community engagement in research and am responsible for the implementation. HSTA trains teachers, students and communities to work with scientists and health professionals to address community needs as one of many parts of the HSTA curriculum. Since 2007, we have increased our focus and now strongly encourage all 800 students to work on research projects that are meaningful for their communities. They are encouraged to meet with community groups and discuss concerns, issues and resources. HSTA community research associates pair students with scientists interested in the same topics. In 2011, HSTA revised the mission statement and strategic plan (see Appendix X), to reflect our goals of "Improving Healthcare through Education," while preparing our students to be successful $21^{\text {st }}$ century citizens and life-long learners.

If organizations are conducting community participatory research they can find a myriad of opportunities for grant funding. Community research is important, but community education to gain support for and participation in research is vital.

The Education category has many facets and levels but the overlying messages from the community perceptions are distinct. The community recognizes the change in student ability, the peer influence of the HSTA students, the leadership and confidence gained from participation in HSTA, the diverse, global and cutting edge opportunities for HSTA teachers, and dissemination of findings to the community. 
HSTA: A Case Study

\section{Category 2: Community Service}

As a HSTA teacher and curriculum coordinator I have witnessed and participated in community service events. Many are formal such as HSTA clubs organizing their own community health events but the majority of community service has been assisting other entities no matter how large or small. Community service serves both obvious and subtle functions. The intrinsic personal growth allows students to see themselves as true contributing members to communities and fosters empathy, generosity, and leadership.

Our HSTA club was frequently asked to help out and volunteer. One year in particular, our club was asked to help with the county wide pre-school health screening day for parents and students. This event offered immunizations, eye and dental exams. One student dressed up as Barney the Dinosaur and another student was dressed as the Cat in the Hat. Others were preparing and serving food, manning learning stations, and reading to or working puzzles with children.

Fund raising for causes. When I was still a HSTA teacher in 2001, our club organized a county-wide diabetes screening for all school age students. The students recruited the local hospital to supply the test strips, and the health clinic to supply the nurses on the days of testing. Although not fund raising per se, the students did get all supplies donated and the staff to donate their time (which is a form of funding). The HSTA students worked diligently before the event and distributed the permission forms to all schools and wrote the advertisement for the newspaper article. On the days of the testing, the HSTA students worked at their local schools by helping register kids, collecting permission slips, and escorting students to and from the testing areas when their class was called. The results found one student that was referred for 
HSTA: A Case Study

further testing and, indeed, had type 1 diabetes. The testing identified several adults that were later diagnosed with type 2 diabetes.

A southern HSTA region played a big role in their county's Cancer Society Relay for Life. The club divided up tasks and worked as a team not to just raise money but to help set up. I was invited to attend so one rainy spring Saturday (Personal Calendar, 2009), I drove two hours to the location. It was a moment that made me proud to see the kids practically running the event. It bears noting that a few HSTA graduates from the region returned to help the club during the walk. This yearly event that was spearheaded by the field site coordinator was important to the graduates, and they returned to help and participate.

Festivals and local events. Early in my teaching career, I had my students keep notebooks and journal their experiences in HSTA. Joe had forgotten his notebook and handed me his entry to keep after our meeting. The following contains an excerpt from his journal that he allowed me to use in a paper I had to write for a graduate class when I was working on my master's degree in 1997 (Unpublished personal work, 1997).

Joe's HSTA club traditionally helped the local charity organization, box meals, and wrap and prepare for delivery, presents for needy families at Christmas.

Joe: I was the Grinch. I didn't want anything to do with this. My aunt was always one of the first people in line for any handout and in this small town, everyone knew it. My mom had used the local food pantry more than I wanted to admit. I let you (sic my teacher), talk me into helping and I reluctantly went because they needed guys who could lift and unload the truck that brought the turkeys and food. There were 350 frozen turkeys and a semi full of pallets of canned food to unload. It was hard, hard, work. We spent hours unloading and 
HSTA: A Case Study

repackaging meals for others. What I noticed the most was how so many important people pitched in. The mayor was there and the principal of the elementary school, too. It let me see a whole other side of how it feels to help others. I always figured that people who gave handouts looked down on those needing them. It wasn't like that at all.

When Joe let me use his entry for my paper I saw it as confirmation that he had grown beyond the boy who was uncomfortable about receiving help to one who saw the spirit in which the help was given.

A large cultural festival is held yearly at which HSTA has a booth. Students from the local clubs and two to three Field Sites as well as members of the central administration help staff the booth. The most recent year I attended we had stations teaching visitors how to make polymers (see Appendix Y)

Environmental issues. As a teacher my HSTA club adopted the river through town and worked to clean the trash and debris from the banks and riverbed. They elicited the help of the local town council for garbage bags, work gloves, and got the local trash service to volunteer to haul away the trash.

On club visits as the education coordinator, I have seen the sign that designates the part of the highway that is adopted by a HSTA club, and I have been invited to help the students pick up trash.

I have noted in my calendar in April that a tree planting and conservation event was sponsored by a local HSTA club and teacher in the spring of 2007. This same group cut the brush at a scenic overlook (Personal Calendar, 2007). 
HSTA: A Case Study

Twenty-four of the interviewees discussed and cited examples of community service and its benefits. The Field Site Reports were a corroborating source for the types of community service, however, I found that the Field Site reports indicated that the regions are not consistent in group community service events or the reporting thereof. I attribute this to the distinctness of each region. This is in no way a criticism but an observation. Regions with rich histories of large and yearly community service activities continue to do so and report the same.

Participation in these events had a watershed effect and were mentioned in interviews, and showed up in the local newspapers (Appendix R). They sometimes became the foundation of student research projects and provided a service that otherwise might not occur. Four regions did not list any large community service activities or regional community service activities for the eight years I examined the data. This does not necessarily mean there weren't any that occurred but indicate that it is not a focus. The students in these regions must complete 75 hours of community service so it stands to reason that they find their own opportunities to serve.

Our graduates stay in the state compared to $48 \%$ of the general population (USA Today, 2012).

\section{Category 3: Family}

Raise expectations. A more subtle incident to share was one of the grandpa and dad who attended a parent night. HSTA held a parent night to give simple lessons on DNA and offer parents an opportunity to be a part of a genetic study their HSTA students were conducting. To teach a little bit about DNA one station had participants learn about the base pairs AT and CG and then use beads to build DNA bracelets. The students led this and when their parents arrived they gave the lesson and helped build the bracelets. It was toward the end of the meeting and Amy was anxiously awaiting the arrival of her dad. These kinds of events were way out of her dad's comfort zone, according to Amy's teacher, but since her mom worked at the rest home on 
HSTA: A Case Study

evening shift she was making her dad come. He walks in with an older man who was her grandpa. Amy's face lit up. Her dad and grandpa would best be described as rough, and I really wondered how successful she would be getting them to make bracelets. To their credit these gruff men with large, calloused, and stained hands, listened and in a short time were weaving beads onto strings and measuring lengths to make their bracelets. They were coaching each other. When I noticed them at the next station, they both were wearing their bracelets. During refreshments Amy's grandpa told me he went to the $8^{\text {th }}$ grade and her dad didn't finish high school. Amy's teacher told me that her mom and dad, whom she knew personally, were going to make sure Amy made something of herself. Those words, but perhaps even more so seeing the bracelets on her daddy's and grandpa's wrist, spoke volumes about pride and change and a willingness to step out of a comfort zone and expect more from yourself especially if you are asking it of your child.

I personally have seen family members, mothers and fathers, become the vocal leader of their extended families and encourage their nieces and nephews to set a goal to attend college. They, having lived through the experiences of their HSTA student, know about college applications, ACTs, and FAFSA. They are the gatekeepers that assist their loved ones, extended family and neighbors on to a better life.

As a teacher I have witnessed the ripple effect of raised expectations for many family members of HSTA students. I have seen parents gain confidence and participate more because they have gained skills from their students. I know of many families who have a second or third child that is matriculating through HSTA. I believe the senior essay written in 2011, I used as an example in research question 2 above perhaps said it best when she said "I absolutely refuse to 
HSTA: A Case Study

be a statistic. My every intention and goal is to get myself an education to provide for myself, and if needed my family, one day.

Pride. My research journal notes are especially rich with descriptions of the pride and joy expressed verbally and non-verbally during interviews. Parents would tear up when talking about how much it means to have a student graduate and fulfill a dream. Field Sites would smile and relate story after story of students' successes and the effect it had on the families and relatives of their HSTA students. Teachers described changes that their students initiated within their families to make them healthier. They spoke of how gratifying it is to have a graduate return and thank them or to see a graduate live in the community at a standard that just wasn't possible without the opportunity HSTA provided. More powerful, however, is the fact that community members at large spoke of how they were proud of the HSTA students and the change it was making in their communities.

I end this section with a vignette that I wrote after attending a science symposium that captures the essence of the change in family members.

2010 I saw it again tonight. Parents knowing what the kids needed to do to improve their projects. But most importantly the family members speaking up, asking questions, and,-this is the kicker-making wonderful suggestions and giving constructive comments to the students. I witnessed it again and again tonight. I remembered and recognized families, teachers, and many of the students from last year and saw a marked difference in interaction.

After presentations, when students ask if there are any questions, parents commented on the work of the students so much more so than last year. I saw other parents' heads nodding in agreement. I witnessed rooms full of family 
HSTA: A Case Study

members critically looking at and most importantly understanding the needed changes that were suggested when students presented their work.

I recalled seeing a pair of timid parents who last year, were shy, quiet, and withdrawn. It appeared as if they couldn't understand or grasp what was going on. There was no way they were going to ask a question. They appeared to feel out of place and their facial expressions and body language signaled the same.

This year those same timid parents are much more at ease. They have with them extended family, including both grandparents, to watch their daughter present her project. The father spoke up and suggested a group make a slide and graph their results to better illustrate the findings. He was participating and engaged with confidence when last year he remained silent.

The extant and interview data for this category and subtopics are intertwined in such a way that it was often the case that one excerpt could be used under several sub topic headings. Although this was the case in the other three categories, it was more pronounced in the family category.

HSTA has always called itself a family and that was reflected in several interviews, extant data and publications. Graduates, teachers, Field Sites, family members and authors, make reference to the HSTA family throughout. A sense of family truly describes the nurturing and supportive style, approach, and environment that exists at all levels of the HSTA program.

\section{Category 4: Community/State}

Educated work force. My first group of HSTA students resulted in two medical doctors, one Veterinarian, two teachers, a chemist, a computer programmer and one ecologist. Only one of this group lives out of state. 
HSTA: A Case Study

As I write this I can report that the high school principal in our county is a HSTA graduate, the local hospital/clinic is staffed with eight HSTA graduates, the physician who runs the rural health clinic on the other end of the county is a HSTA graduate. In a small county with a population of less than 10,000, HSTA has increased the educated workforce, helped to meet the health care needs of our citizens, and has provided an opportunity for students who wanted to remain in their hometown communities the ability to do so and make a good living.

The benefits of an educated work force need not be argued. Every business needs prepared, talented, and educated employees to meet the demands of remaining competitive. Rural communities need educated young people to return and work to keep the communities vital. West Virginia is no different.

Participatory citizenship. Examples of participatory citizenship are widespread. Noted especially are the examples of the involvement of HSTA grads in our communities of which I have first-hand knowledge. Some graduates champion Relay for Life teams, serve as officers in the local elementary PTO organization, or serve on the local little league board. We have regions that have graduates volunteer to serve on the local HSTA boards (HSTA Local Governing Board database). One HSTA graduate donates scholarship money to be awarded to a HSTA high school graduate from her region each year. Another HSTA graduate, now a nurse, runs the local school satellite clinic and is on the board at the main clinic. In my position with HSTA I see the long term growth of our students and the difference they make in their communities.

Rural healthcare workers. My research notes and my experience indicate that the prevalence of HSTA health care providers is having an impact on providing needed rural health care workers. I have had family members living in surrounding rural counties who are either 
HSTA: A Case Study

treated by or in contact with HSTA graduates as part of their care. The dental assistant for my niece is a HSTA graduate. The local home health nurse is a HSTA graduate. The pharmacists in the neighboring counties to the east and west of me are HSTA grads. The respiratory therapist that treated my brother is a HSTA graduate. These are just a few examples of the many healthcare workers I have come in contact with who are practicing locally, in their rural communities thanks to HSTA.

Tax base \& remain in the state. I am not an economist but common sense and my observations tell me that HSTA graduates have an enormous impact on the tax base of West Virginia. I say this because if I look at the number of college graduates, 882 of which $90 \%$ stay in the state $(n=794)$, and use the HSTA number generated by the WVU College of Business and Economics, (2007), the increased tax base for one year is just shy of 24 million dollars.

A concern I heard often from parents was they had a deep fear that if their children went off to college they would not return. It is not unjustified and it is a common concern of our parents. What I have seen and shared frequently with parents is that HSTA students will obtain skills and an education that will allow them to work in their communities and make a good living. Many of our communities see young students go off to college and leave the state. HSTA is a program that encourages and promotes opportunities to give back to the state. As stated previously.

\section{Peer Review}

I included data from multiple sources and included several of my experiences throughout. I gave a draft of the final report to three of my peers and outside editor who is a retired English teacher. The procedure is to have the draft report reviewed not just by peers but also by the participants and informants in the case, (Yin, 2004, p. 181). Their feedback was useful, and 
HSTA: A Case Study

because of it, I did not include many of my personal experiences because it was described by one peer as "overkill". According to Stake, when writing a good a case study, "We seek to portray

the case comprehensively, using ample but non-technical description and narrative" (1995, p. 34) Another suggestion from a peer reviewer was to explain to the reader that I recognized the category of family and its subtopics as more difficult to separate out as distinctly as the other three categories because the nature of the topic and the flow of the comments in the interviews, essays, and field site reports made them fall under more than one subtopic. When I struggled with grouping or naming the subtopics in the categories, their suggestions guided me. My peers, who are also researchers, were extremely helpful in identifying that I used data source triangulation as well as investigator triangulation as defined by Denzin (Denzin, 1984).

\section{Summary of Findings}

RQ 1. The first research question, "How do various stake holder and community members perceive the impact of HSTA on the community?" resulted in the following four categories as they emerged from the interviews, Education, Community service, City/State and Family.

These are the aspects and themes of perceived community impact as taken from the interviews. The subtopics that emerged from the interview categories were identified before coding of RQ 2extant and RQ3 participant-observer data. I employed data source triangulation to ascertain if my personal experiences added to or supported those subtopics emergent from RQ 1.

\section{Comparisons: urban vs. rural; stakeholder vs. community members at large.}

The case study plan included an examination of interview data to determine if significant differences would emerge when comparing urban and rural participant responses and also the responses comparing stakeholders and community members at large. 
HSTA: A Case Study

There was no distinction between rural and urban participants in their responses for all subtopics but one. Urban community member participants $(n=6)$, did not discuss specific community service events in which the students participated, but all six did state that community service was a HSTA impact.

There was a noted distinction between the stakeholder responses and the community members at large on school impact. Stakeholders discussed the impact on schools, peers and teachers. The community members at large did not have this as a focus. This can likely be attributed to the close tie HSTA has as an afterschool program, and the various relationships stakeholders have with the local schools whether parents, graduates, teachers, or Field Sites.

It is important to note here that the rural community members at large, were more knowledgeable and could tell first hand stories and name specific students much more frequently, three to one, than community members at large in urban areas as defined by this study. This was expected and is attributed to the nature of a small community or region where non-stakeholders or community members at large, would be more likely to have first-hand knowledge due to the close knit familiarity that is common in rural communities.

RQ2. Answering the second research question "What do extant data sources used for program evaluation say about the impact of HSTA on the community?" There were numerous examples in support of the subtopics identified from the interviews. Examination of the coded interviews and extant data permitted the subtopics to be more clearly labeled and defined. When examining the extant data, it often could be matched to the interview data when interview participants, who named specific examples of impact, were identified in field site reports.

RQ 3. In answering the third research question, "As a participant observer what are the investigator's perceptions of the impact?" I agreed with the stakeholders and community 
HSTA: A Case Study

members, but, I must honestly answer that I experienced and observed two impacts not directly named in their observations and that I had not previously recognized or named as an insider looking out. My main focus and gauge for determining the success of the program these last 18 years was the number of students completing the program, graduating from college, and remaining in the state. In other words, I was using the success which was measured quantitatively and assumed the impact as viewed by the community was the same. This view looked at what the program was doing for them, the students. What was there for me to see all along was revealed from the interviews and supported by the extant data and to a lesser extent, my personal notes and calendars. The participants recognized the story of impact the numbers told but they saw much deeper and personal effects as well. They saw the benefits and give back the students demonstrated that comes from the involvement and empowerment that allows the students to become vectors of change among their peers, in their families, communities and even state, while they are in high school and matriculating through the program.

The second impact that I had not named or identified was the impact on the parents and family members of the HSTA students. I have attended enough symposiums to remember parents from one year to the next, and I have seen the parents and family members gain an understanding and knowledge of the research methods and expectations to be able to ask questions and examine results with an understanding that wasn't there the year before. Stakeholder parents discussed the knowledge and changes they experienced as their child completed the HSTA requirements and prepared for college. That is a powerful impact. Many of the parents who are not comfortable in academic settings regardless of the reason were demonstrating enough self confidence to participate and engage in the events. I included the vignette on page 109 that I wrote several years ago after attending a local HSTA symposium. 
HSTA: A Case Study

Below is the ending interpretation of my vignette. I think it still illustrates the epiphany I had when I reflected upon my experience.

HSTA is changing and empowering families and communities. We are nurturing and growing our cultures, celebrating our talents and successes, understanding and appreciating our diversity, raising expectations and impacting families in such a far reaching way (Personal Vignette, 2010).

The community has defined this more clearly. It is valuable information and speaks to the heart of the success of the program as seen by the community. 
HSTA: A Case Study

\section{CHAPTER FIVE}

\section{SUMMARY, CONCLUSIONS, IMPLICATIONS AND RECOMMENDATIONS}

\section{Summary}

This case study has investigated the impact of an informal after-school pipeline program designed to increase the college going rate of under-represented students majoring in STEM and the health sciences. Interviews, extant data, and participant-observer documents were coded, examined and analyzed.

Interviews in this study occurred over a nine month period. The 42 interviews were coded and sorted using inductive analysis which resulted in both categories and subtopics. One form of triangulation was used to validate the categories and subtopics. To insure understanding and maintain consistency, the participants were all asked the same question which was, "When you think about your community, what do you perceive as the impact of HSTA on the community?" The atmosphere and tone of the interviews was informal and casual. Interviews were transcribed in-vivo and were coded which resulted in four categories. The extant data, specifically the 473 Field Site reports and 43 senior essays, were coded, sorted, and analyzed. The remainder of the extant data which was the three questions from the 2012 community club evaluations, the HSTA database, and the five years of student project topics, was not coded due to the nature of the sources. Participant-observer documents that consisted of five years of daily calendars, essays and vignettes as well as the research journal kept while working the case study, were also examined. Data source triangulation (Stake, 2004) occurred when the interview, extant, and participant-observer data was used to support or refute the categories and subtopics. There were three research questions (RQ) investigated in this study. 
HSTA: A Case Study

\section{RQ 1: What do various stakeholders or community members perceive as the impact of}

\section{HSTA on the community?}

This question identified four categories participants believed were community impact. From the 42 interviews and in order of significance-education, community service, family and community, and state were identified. Subtopics emerged under each category as participants shared examples during interviews which served as evidence to support their statements. Subtopics were listed and discussed in order of frequency under each category. The following lists the categories and respective subtopics. Education: college graduation, local school system, teacher training, community education; Community Service: health events, fundraising for causes, festivals and local events, environmental; Family: raise expectations, pride, family education; Community \& State: educated work force, participatory citizenship, rural health care providers, remain in the state/economic.

An examination of the 42 participants' interview transcripts reveals that 36 of the 42 people interviewed believed education was an impact which is 86 percent of the participants. Twenty-four of the 42 participants (57 percent) discussed the importance of community service as an impact. The third category, the impact on family, was discussed by 20 of the 42 participants or 48 percent. Lastly, the category of the impact on community and state was identified and of those participants' interviews, 14 of the 42 discussed the benefits to the community or state, which was 33 percent.

\section{RQ 2: What do extant data sources reveal about the impact of HSTA on the community?}

Extant data varied in frequency of importance but supported the findings from the interviews. Coding of the Field Site reports identified community service as the first category at 63 percent, followed by community and state at 18 percent; education at 11 percent; and family 
HSTA: A Case Study

at 9 percent. Examples corroborated the impact as identified by participant interviews but not in frequency. This inconsistency, a limitation in the data, can be attributed to the purpose of the Field Site reports which are to provide the central administration documentation of events, attendance, and activities of the community club experiences in their regions. Coding of the senior essays resulted in an inverse of the categories as identified from interviews when comparing frequencies. Community and state were identified $33 \%$ of the time by seniors who composed the essays with most believing they could change their communities and the state for the better. Twenty-six percent discussed their family as being affected by HSTA. In $22 \%$ of the essays, students discussed their community service, and 19\% discussed the educational opportunities provided by the program. The inverse of categories, a limitation of the data, quite possibly is due to the reason the essays are written in the first place. Seniors submit the essays in the hopes of receiving a one-time scholarship of $\$ 500.00$ dollars. It makes sense that the most powerful essays would address the future plans and changes the students would like to bring about when completing their college degrees. The three questions from the community club evaluations supported community service as an impact as did the two remaining questions which addressed student research projects as they supported impact on family and community. Five years of student research project titles served to support community research and more specifically the subcategory of health under community research. Numerous titles were given to projects that did not lend themselves to determining what they addressed.

\section{RQ 3: As a participant-observer, what are the investigator's perceptions of impact of}

\section{HSTA on the community?}

Participant-observer data identified education, family, community and state, and community service as impacts. I have an 18 year history with HSTA, first as a teacher, a 
HSTA: A Case Study

graduate student in the HSTA master's program, and then as education coordinator. This has allowed me to experience HSTA in a unique way from three different angles and across the entire program. My teaching experience provided numerous examples from working with students that covered all four of the categories. As a graduate student, I experienced the impact of furthering my education and obtaining a degree for a minimal financial investment. It was because of my experience in the field with clubs and student projects as education coordinator that I was able to match some student project titles with their community service as reported by Field Sites. I could match the year and month of the Field Site's reported club community service event to the yearly project. Personal calendars triangulated the dates of state events and of those community events of which I was a part under the community and state category. The research journal captured issues as I examined and analyzed data. My personal impressions of participants and their voice and expressions during interviews provided first-hand evidence of the conviction of the beliefs and attitudes of participants as recorded in my journal.

\section{Conclusions}

There is little literature regarding after-school high school programs and the reasons are varied. Most after-school programs are targeted for younger students who do not have safe places for care and have become known as latchkey kids (Ross, et al.,1992). High school students have more opportunities available to them such as sports or even part-time work, besides the fact that they are more able to care for themselves. The secondary school programs that do exist are mainly those like TRIO of which Upward Bound is one. In many ways Upward Bound mirrors HSTA as it prepares underrepresented students with skills needed for college success. We recruit the same demographics. Studies of Upward Bound measure impact and success from within or inside out (Falk \& Needham, 2011). A survey of students and their 
HSTA: A Case Study

parents of Upward Bound indicated they recognized the worth of the program and its intended outcomes for the students but did not examine the community at large, to measure impact as they perceived it (Jarosewich \& Stocking, 2003).

Examination of elementary after-school programs reveals similar results. Although there are numerous programs, most if not all examine success and measure impact from within. KEMET in Alabama is one program that targets younger students but with similar demographics to those of HSTA. KEMET's goals are to improve the likelihood of students attending college and upon graduation, return home to their communities and contribute to their sustainable growth. This has yet to be measured but does have the potential to examine the community perception of impact as it applies to the community.

In summation, the literature that measures community impact from outside-in (Falk \& Needham, 2011), is non-existent. It is not a consideration regardless of the program or age group the program addresses. It could be considered vitally important to the program itself and would serve several purposes, the strongest of which are a more complete evaluative look at outcomes, increased community support, justification for funding and program sustainability.

The findings of this case study show that the community defines the impact of HSTA as four fold. The first is providing an educational opportunity for students who might otherwise not have the means or the know how to attend college. The findings demonstrate the recognition of the program's ability to nurture and educate students bringing them up to a competitive standard that levels the playing field by giving them the skills, experiences, and confidence that would not occur otherwise. Triangulation provided truth value of the aforementioned findings. This is extremely significant as participants understand the needed skills are correlated to the college graduation rate of HSTA students which is the first subtopic they related to education. Likewise, 
HSTA: A Case Study

this study validates that the schools and school climates are positively affected by HSTA clubs. Evidence of student grade averages, Westest scores (Smith, 2012), high school graduation rates, and college attendance are validation of this impact. Teacher training and experiences were carried back to the schools and were shown to have a positive effect on peers and students alike. Community education was cited as an occurrence as students presented problematic and complex issues they had studied and then were able to share them in terms and meanings that were easily understood by the general population. Member checks provided trustworthiness to the findings and triangulation supported these impacts.

Community service was cited as the second most important impact which extant data overwhelming supported in scope and frequency. Instilling a spirit of giving allows a selfrationalization of students' intrinsic worth when they help others. Giving was seen as significant and served as a measure of impact as instances of community service were recognized as having a global, positive influence. There were four subtopics identified with community service from interviews and supported by extant data. The first was health events, where participants named and identified specific occurrences. The second subtopic cited was fund raising for causes. Students were viewed as strong advocates as they worked for the causes. Festivals and local events were named as the third subtopic. Reported knowledge of and witness to regular attendance at named events were frequent and specific. The fourth subtopic, environmental, identified numerous community projects clubs adopted that were improvements to the environment. Field Site report frequency of community service was the highest when coded. However, senior essay frequency ranked it third. Triangulation verified the scope of impact. Member checks and participant-observer documentation provided truthfulness to these findings. 
HSTA: A Case Study

The third category identified was family. There were three subtopics that emerged. The first subtopic, raise expectations, covered the growth of the student, family, and peers as students broke barriers and escaped from poverty when completing degrees. Community members witnessed notable differences in families having students in HSTA. One parent stated she had never attended any of her other children's school events until her child was in HSTA. The second subtopic identified pride as intrinsic and extrinsic spread across self, family and community. Participant-observer notes and senior essays provided trustworthiness to the finding. The final subtopic, family education, was identified to mean the secondary experience caused by the necessary activities, experiences, and growth of the student. Growth, opportunity, knowledge, and change were evidenced as family knowledge from participation in student research projects proved a recognizable reported positive result. Member checks and participantobserver notes served as measures of truthfulness. Triangulation verified the scale of this impact. Note that family was the category second in frequency in senior essays but ranked fourth in Field Site in reports.

The fourth category of community and state impact identified four subtopics from interviews and was corroborated by Field Site reports and senior essays when triangulated. Providing an educated workforce was cited as most significant. Magazine articles written about the phenomena, participant-observer observations and experiences, were a measure of trustworthiness to the findings as were member checks. The second subtopic was participatory citizenship. Field Site reports and participant-observer notes provided truthfulness. Member checks were a source of triangulation. The third subtopic, increasing rural health care workers, was corroborated using the database and Field Site reports for trustworthiness. Graduates remaining in the state and the economic impact they have was the fourth subtopic. The HSTA 
HSTA: A Case Study

database and senior essays, as well as participant-observer documents, lent truthfulness to the impact and triangulation verified it. Community and state was the category with the highest percentage of frequency in student essays and the second highest frequency in Field Site reports. Student essays and Field Site reports confirmed the impact.

\section{Implications}

The findings of this study have implications for policy and practice; some are more likely than others to be realized. One implication for practice that HSTA program administration has agree to implement beginning in Spring, 2014, is to develop and implement a yearly community evaluation that measures the community perception of impact of the program. HSTA has a measured impact that serves to begin to complete a missing component of the programmatic evaluation. Nineteen years of extensive evaluations measuring major events, initiated, and ongoing programs have been done as part of formative and summative tools to guide and measure the usefulness of the same. All stakeholders in HSTA have been integrated into the process, where appropriate, to measure their experiences. Any faculty and providers outside of HSTA, but providing the services attended by HSTA, have also been included in the evaluations. The evaluations measure the effectiveness of the events, people, and programs as they pertain to meeting the goals of that component of HSTA. Additionally, the evaluations measure the influence the event or program had on the students' attitudes, beliefs, and future plans. This study is the first to examine the impact of the program on a formal and larger scale from the community perspective by giving voice to the community. This view from the "outside in" provides the mirror that allows HSTA to examine itself from a perspective not available until now. 
HSTA: A Case Study

The database maintained by HSTA contains the information of all past and present students and is annually updated allowing the program to track the various fields in which graduates obtained degrees, employment, and location of residence. Data is gathered confirming the school of attendance and field of study of current college students. Former and current board members, Field Sites, and teachers are listed in the database. Articles written to date about HSTA use this data to describe the program, but only one discussed community impact (Rye, et al., 2008) had community feedback from community members at large. All previous research findings strongly give evidence of community impact to a scale that is highly significant but have been measured from within.

Developing and implementing a yearly community evaluation of impact would serve to give voice to the community members via a formal measure, and add a balance to what is otherwise an inside-out measure of impact (Falk and Needham, 2011). The information could be published as it would add to, strengthen, and enhance the existing body of longitudinal program evaluations and literature. Community impact is a relatively empty literature field and one that deserves attention.

This leads to another implication for practice which is garnering support and funding from state legislators for program expansion. The likelihood of this implementation being realized is dependent upon the state budget as well as the degree to which HSTA program administration can convince legislators. The HSTA program provides results that are one way to address the many issues of our state. Interviews found that citizens recognized the high school and college success of the HSTA students. They discussed how HSTA was providing a health care work force, and retaining educated citizens who are community-service minded. Participants also recognized that HSTA graduates had a higher the standard of living, when they 
HSTA: A Case Study

broke the cycle of poverty. It was noted that HSTA had access to and involvement with a traditionally untapped strata of population. These are streams in the watershed effect of matriculating through the program. In a state that averages only a $72 \%$ high school graduation rate, perhaps HSTA like clubs could be a way to mentor and assist students who otherwise wouldn't finish high school or attend college. In addition, and more importantly it could be argued that the program graduates remain in the state at a rate that is double to that of student graduates of the Promise scholarship. Evidence of community support and cognizance of the results lets politicians know voting constituents give worth and value to the program. HSTA has a strong and large block of voters (see Appendix C).

Serving as a model for other programs, standing as an example of how to engage and change from within, leading by allowing growth and change, supporting and preparing the future of the state, changing program policy to improve life, and giving voice to those who personally benefit from the program, are topics that have been researched and are all examples of measurement of impact from within. Arguably, the more community members, academia, and program leaders can demonstrate how individuals, families, communities, and the state benefit from the HSTA program, the more support the program is likely to receive from local, state, and national funding sources.

Rather than simply stating that HSTA is beneficial for local communities and assuming participants' expectations and knowledge of the program are positive but vague, this study revealed participants were very aware of the positive impacts associated with HSTA, which suggests a consistency within and across these communities in the state. A strong sense of ownership shared through experiences and stories from the various groups of participants suggests a common identity or community and suggests why this is a united force that can 
HSTA: A Case Study

change public policy. The implication for practice is to use this power of the people to garner funding for increasing the scope of the program into other regions of need in West Virginia.

Another recommendation for practice, which will be introduced to HSTA teachers at the Spring, 2014 workshop, is for implementation (beginning in Fall, 2014) of a reflective journal as a part of the HSTA club requirements for students. The journaling would include a few standard probes to which students can be mindful and that seek to elicit ways that HSTA is impacting their lives and the lives of other in their communities. Example probes could be: What did you learn today that is new or novel and how do you see yourself using this outside of the HSTA club? How can you use what you have learned from HSTA today to better yourself, your family, and your community? This journaling might serve to increase student retention in HSTA clubs as students actively reflect upon and journal their perceptions.

Examination of the educational impact and specifically teacher education leads to another implication: a master's program for HSTA teachers. The ability to provide a graduate program tailored to HSTA teachers was an extremely effective recruiting tool for regions seeking teachers, but the primary result was teachers were trained in and used inquiry based pedagogy. When the grant funds supporting the program evaporated and tuition waivers were no longer offered, teachers in the program were left with the choice of finishing their degrees at their own expense or dropping out of the degree track. . Strong, competent, well-trained teachers result in enriched and rigorous experiences for students who have been identified as at risk. A stronger HSTA experience better prepares students for college. Teachers modeling best practices who learned because of the opportunity for advanced degrees had the watershed effect at the various school sites on fellow-educators and classroom students. 
HSTA: A Case Study

It is my assertion then, that HSTA policy should be revised and changed to include and incorporate a teacher advanced degree program. This, in turn, requires a funding source that is reliable. It would mean funding or partially funding a position to run the program as well as finding a way to finance the tuition costs of teachers in the program. The program should be rich in substance and emphasize STEM subjects, community participatory research, and $21^{\text {st }}$ Century teaching skills. Policy change that has financial implications is difficult at best to execute, but would strengthen the program by providing well-trained teachers who, in turn, strengthen the student experience as well as model best practices for non-HSTA teachers.

\section{Recommendations for Research}

The findings of this study warrant further research in several areas. First, further research should be conducted on only the "community members" subset of all those interviewed. The sample interviewed by this study was comprised $72 \%$ of stakeholders and only $28 \%$ of community members at large. The findings of this study showed that community members spoke more to the HSTA impact on college graduation rate as opposed to impacts on local school systems. The finding of this proposed research would be useful in determining if it supports or refutes the findings of this study and add to impact literature.

A second recommendation for research, which would complement the assertion for a teacher graduate program, is a study designed to assess the impact of the HSTA teacher graduate program. It would be interesting and powerful to obtain the perceptions of school officials and the teachers themselves as to the impact. Data sources would include reflective journals, focus groups, and interviews. Teacher classroom evaluations conducted by school principals before and after entering the degree program could provide another data source (qualitative and quantitative. 
HSTA: A Case Study

A third recommendation for research would be to design a study that would seek to examine how, if at all, lives are changed in counties where HSTA exists. This could have retrospective and prospective components. For example, and retrospective study would be to interview a cohort of HSTA Alums (already have college degrees and are in the workforce) to compare their life before HSTA and now: What do you see different about live now compared to when you were growing up? If you have children, how are their lives different than yours? A prospective study would be longitudinal and start with high school freshman as they matriculate into HSTA. The random sample could be stratified by rural vs urban and gender. Several data points (e.g., enter HSTA, high school graduation, college graduation, workforce member) in the form of interviews would be collected and contrasted. Focus groups as well as surveys could be additional data collection methodologies, which may lead to a broader scope in measurement of impact.

A third suggestion is to examine the community perception of impact of programs similar to HSTA. Upward Bound is similar to HSTA in that its mission is to increase the college-going rate. It has an after-school community component in addition to a summer campus experience where students are prepared for college success with curriculum that builds a strong foundation. Included in this study should be an examination of cost effectiveness as compared to HSTA. This study could serve to justify expansion of the HSTA program if results show the cost effectiveness and success rate warrants it. 


\section{References}

Adams, C., Brown, P., Morello-Frosch, R., Brody, J., Rudel, R., Zota, A., Dunagan, S., Tovar, J., Patton, S. (2011). Disentangling the exposure experience: The role of community context and report back of environmental exposure data. Journal of Health and Social Behavior 52(2), 180-196.

Badenhausen, K., (2009). Will you want a job in that state after college, Forbes.com, Retrieved from http://www.fores.com/2009/03/04/jobs-states-college-leadership-care...

Bardwell, G., Hyde, J., Lewis,J., Morton-Mcswain, C., Rye, J., Simoyi, P., (2001) Teens take a healthy interest in theircommunities.ENC Focus.8(1). 40-42.

Bardwell, G., Branch,R., Buch, S., Cecchetti, A., Chester,A., Groark, S., Morton, C., Pancoska, P., Paulsen, S., Vecchio, M. (2009). Feasability of adolescents to conduct community based participatory research on obesity and diabetes in rural Appalachia. Clinical Translation Science 2(5), 350-354.

Bardwell, G., \& Kincaid, E. (2005), A rationale for culture awareness in the science classroom. Science Teacher .72(3), 32-35.

Bock, S. (1996). Program fosters young students' pursuit of health science careers. Rural Health. $18(5), 16-17$.

Bowen, E. (2013). From higher education to work in West Virginia 2011. Retrieved from http://wvutoday.assets.slate.wvu.edu/resources/1/1362756561.pdf.

Branch, R., Chester, A., Morton-McSwain, C., Udin Al Ayubi, S., Bhat Shelbert, K., Brimson, P., Buch, S., Nuke, T., Panakoska, Pl, BanBang, P., Paulsen, S.,Wahl, E.,(2011). A novel approach to adolescent obesity in rural Appalachia, West Virginia: Educating adolescents as family health coaches and research investigators. Topics in the Prevention, Treatment 
HSTA: A Case Study

and Complications of Type 2 Diabetes. Mark B. Zimering ED. ISBN: 9780953-307-5097, In Tech.

Brody, L., \& Mills, C. (2005). Talent search: What have we learned? High Abilities Studies 16(1) $97-111$.

Chester, A., \& Branch, R., (2009).Community based participatory clinical research in obesity by adolescents; pipeline for researchers of the future. Clinical Translation Science, 2(5), 340-349.

Chester, A., \& Dooley, E. (2011). West Virginia University's health sciences and technology academy. Journal of Higher Education Outreach and Engagement, 15(87), 87-97

Cooper, H., \& Valentine, J. (2001).Using research to answer practical questions about homework. Educational Psychologist, 36(3) 143-153.

Corbin, J., \& Strauss, A. (2007). Basics of qualitative research: Techniques and procedures for developing grounded theory ( $3^{\text {rd }}$ ed.). Thousand Oaks, CA: Sage.

Coyne, C., Demain-Popescue, C., Friend, D. (2006).Helping older youth succeed through expanded learning opportunities. Harvard Family Research Project Brieffor National Conference of Legislators: The Forum for American Ideas Retrieved from http://www.hfrp.org/RU7-OlderYouth.

Davis, D., Davis-Maye, D., Thomas, C., Alfred, C., Tripp, L., King-Jupiter, K., Seals, C., \& Lovett,G. (2011). KEMET Academy: A university nodel for addressing the wholeness of learning in a rural context. International Journal of Progressive Education 7(1), 6-27.

Denzin, N. (1984). The research act. Englewood Cliff, NJ: Prentiss Hall.

Diem, K. (2002).Measuring impact of educational programs .Abstract retrieved from http://www.joe.org/joe/2003/February/a6.php. 
HSTA: A Case Study

Dooley, E., \& Bardwell, G. (2000). Mentors in medicine. Science Teacher, 67(3), 36-40.

Falk, J., \& Needham, M. (2011). Measuring the impact of a science center on its community. Journal of Research in Science Teaching,48 1-12.

Fashola, O. (1998). Review of extended-day and after-school programs and their effectiveness (CRESPAR Report No. 24). Retrieved from Johns Hopkins University School of Education, Center for Social Organization of Schools website: http://www.csos.jhu.edu/crespar/techReports/Report24.pdf

Gentry, VanLaanen, P., \& Nies, J. (1995). Evaluating extension program effectiveness: Food Safety Education in Texas, Retrieved from http://www.joe.org/joe/1995october/a4.php.

Haggis, C., Sims-Gould, J., Winters, M., Gutteridge, K., \& McKay, H. (2013). Sustained impact of community-based physical activity interventions: key elements for success. $B M C$ Public Health, 13(1), 1-8. Doi: 10.1186/1471-2458-13-892

Harris, Deschenes, \& Wallace, (2011). Helping older youth succeed through expanded learning opportunities. Conference of Legislators: The forum for American ideas. Harvard Family Research Project. Brief\#1, August 2011

Hatch, D. (2012). Unpacking the black box of student engagement: the need for programmatic investigation of high impact practices. Community College Journal of Research \& Practice, 36(11), 903-915. Doi: 10.1080/10668926.2012.690319.

Health Sciences Technology Academy Database. (2012) Graduates, Joint Governing Board, Local Governing Boards, Projects, Students, Teachers. [Microsoft access \& excel] Retrieved from https://www.hs.wvu-ad.wvu.edu/-ur/public(I):/HSTA/public/database.0329-12HSTAdb. 
HSTA: A Case Study

Higher Education Policy Commission, West Virginia Report Card (2012). Report from the West Virginia HEPC. Retrieved from https://www.wvhepc.org/resources/Report_Card_2012. PDF.

Jamelske, E. (2009). Measuring the impact of a university first-year experience program on student gpa and retention. Higher Education, 57(3) 373-391 doi: 10.1007/s10734-0089161-1.

Jarosewich,T., \& Stocking, V. (2003). Talent search: Student and parent perceptions of out-oflevel testing. Journal of Secondary Gifted Education 14.137-150.

Johnson, B., Christensen, L., (2008). Educational Research: Quantitative, Qualitative \& Mixed Approaches. Thousand Oaks, CA. Sage Publications

Law, J. (1999). The influence of upward bound on freshmen grade point average, dropout rates, mathematics performance, and English performance. Western Journal of Black Studies, 23(3) Retrieved from htpp://public.wsu.edu/wjbs/vol23.3.html.

Lester, J., Kronick, B., Benson, M. (2012). A university joins the community. Phi Delta Kappan, 93(6). 42-44.

Lincoln, Y., \& Guba, E. (1985). But is it rigorous? Trustworthiness and authenticity in naturalistic evaluation. In D. D. Williams (Ed.). Naturalistic Evaluation, 73-84. San Francisco:Josey-Bass.

Luzer, D. (2010, May 6). How education pays in West Virginia [Web blog post] Retrieved from http://www.washingtonmonthly.com/college_guide/blog/how_education_pays_in_west_v ir.php

McMillan, J., \& Schumacher, S. (2006). Research in education. Open Journal of Education. Doi. 10.12966/oje.05.07.2013. 
HSTA: A Case Study

Merriam-Webster's Dictionary, (10 ${ }^{\text {th }}$ ed.). (1993). Springfield, MA: Merriam-Webster

Novick, P. (1993). That noble dream: The objectivity question and the American historical profession. Cambridge England: Cambridge University Press.

Pancoska, P., Buch, S., Cecchetti, A., Parmanto, P., Vecchio, M., Groark, S., Paulsen, S., Bardwell, G., Morton, C., Chester, A., \& Branch, R. (2009). Family networks of obesity and type 2 diabetes in rural Appalachia. Clinical and Translational Science 2(6), 413421.

Patel, N., Franco, S., Lindsey, J. (2011). Examining student engagement in open enrollment STEM-focused schools. Open Journal of Education 1(2), 52-60

Patton, M. (1990). Qualitative Evaluation and Research Methods (2 ${ }^{\text {nd }}$ ed.) Newbury Park, CA Sage.

Patton, M. (2002). Qualitative Research and Evaluation Methods 3e. Retrieved from: https://www.scribd.com/doc/44478053/Patton-2002-Qualitative-Research-andEvaluation-Methods-3e

Ross, J, Saavedra, P., Shur, G., Winters, F., \& Feldner, R., (1992) The effectiveness of an afterschool program for primary grade latchkey students on precursors of substance abuse. Journal of Community Psychology (OSAP Special Issue), 22-38.

Rye, J. (1997). Grape expectations, Science Teacher, 65(Sept), 41-46.

Rye, J. (1998). Teacher professional development through an academic enrichment program for under-represented secondary students in West Virginia. Rural Educator, 19(3), 713-719. Rye, J. (2001), Enhancing teachers' use of technology through professional development on electronic concept mapping. Journal of Science Education and Technology.10(3), 223235. 
HSTA: A Case Study

Rye, J., Bardwell, G., Hu, J. (1999). Connecting science, health and technology through authentic investigation. Science Educator, 8, 19-24.

Rye, J., \& O’Hara-Thompkins, N., McClure, D., Aleshire,J. (2008) Increasing physical activity opportunities in a rural community through a participatory school based project that engaged youth, The Rural Educator, 30(1), 39-48.

Rye, J., Richard, A., Mauk, D., Waterworth, B., Poling, J., Cool, T. (2007). Science as a moving experience for all learners. Science Teachers, 74(9), 53-57.

Rye, J., \& Smolski, S. (2007). Pedometer and human energy balance applications for science instruction. Science Activities, 44(3) 95-104.

Rye, J., Zizzi, S., Vitullo, E., \& O’Hara-Tompkins, N. (2005). The pedometer as a tool to enrich science learning in the context of public health. Journal of Science Education and Technology.14(5). 521-531.

Sanger, C., \& Heckman, P. (2011). Expanded learning the LA's BEST way, New Directions for Youth Development, $2011(131)$ 69-79.

Smith, F. (2011). Bridging the gap through academic intervention programs: A quantitative study of efficacy of the health sciences and technology academy, (HSTA) on underrepresented students' state standardized test scores. (Doctoral dissertation). Retrieved from http://search.proquest.com.www.libproxy.wvu.edu/docview/1008915946.

Stake, R. (1995). The art of case study research. Newbury Park, CA: Sage Publications.

Stake, R. (2004). Standards-based \& responsive evaluation. Thousand Oaks, CA: Sage Publications.

Strauss, A., \& Corbin, J. (2008). Basics of qualitative research: Techniques and procedures for developing grounded theory. Thousand Oaks, CA Sage Publications. 
HSTA: A Case Study

Tellis, W (1997). Application of a case study methodology. The Qualitative Report,3(3). Retrieved from http://www.nova.edu/ssss/QR/QR3-3/tellis2.html.

Torpy, J., Burke, M., Golub, R. (2011) Health literacy, The Journal of the American Medical Association, 306(10): 1158. Doi:10.1001/jama.306.10.1158.

Wolcott, H., (2009). Writing Up Qualitative Research. Thousand Oaks, CA Sage Publications Workman, (2010). Exploring the Level of Evidence of Impact Collected through Program Evaluation by Cooperative Extension as Published in the Journal of Extension. (Electronic Thesis or Dissertation). Retrieved from https://etd.ohiolink.edu/ Yin, R.(1994). Case study research: Design and methods (2 ${ }^{\text {nd }}$ ed.) Newbury Park, CA: Sage Publications.

Yin, R.(2009). Case study research: Design and methods, $\left(4^{\text {th }}\right.$ ed.) Thousand Oaks, CA: Sage Publications.

Zizzi, S., Rye, J., Vitullo, E., \& O’Hara-Tompkins, N. (2009). Empowering youth through research: Adolescents' perceptions of physical activity interventions in Appalachian communities. Journal of Rural Community Development 4(1)1-14.

Zulli, R., \& Frierson, H., Clayton, J(1998). Parents' perceptions of the value and nature of their involvement in an Upward Bound program. Journal of Negro Education, 67(4) 346-364. 
HSTA: A Case Study

Appendix A

- 144 - 
HSTA: A Case Study

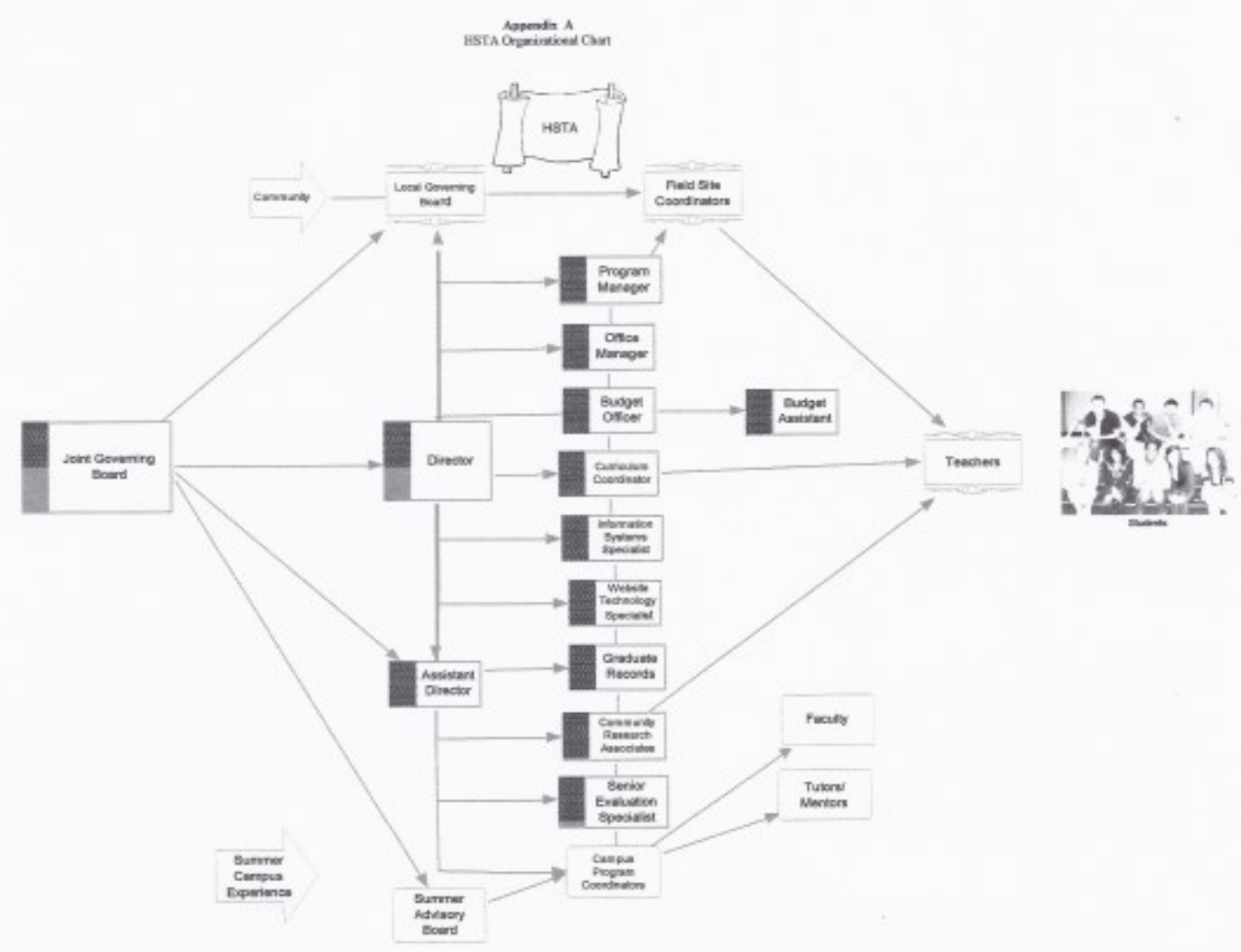

Appendix B

hSTA PUblications 
Bardwell, G, J. Hyde, J. Lewis, C. Morton-McSwain, J. Rye, and P. Simoyi "Teens Take a Healthy Interest in their Communities." ENC Focus. 8.1 (2001): 40-42. Print.

Bardwell, G., Branch, R.A., Buch, S., Cecchetti, A., Chester, A., Groark, S., Morton, C., Pancoska, P., Paulsen, S., Vecchio, M."Feasability of Adolescents to CONDUCT COMMUNity BASEd PARTICIPATORY RESEARCH ON OBESITY AND DiabeTES IN Rural Appalachia." Clinical Translation Science. (2009).

Bardwell, G., Branch, R.A., Buch, S., Cecchetti, A., Chester, A., Groark, S., Morton, C., Pancoska, P., Parmanto, B., Paulson, S., Vecchio, M."Family and Social Networks with Obesity and Diabetes Type II in Rural Appalachia." Clinical Translation Science. (2009).

Bardwell, J., A. Chester, C. Fitch, P. Mujuru, G. Seidel, K.Sogodogo and W.Hu, "ENGAGING YOUTH TO EXAMINE LIFESTYLE BEHAVIORS THROUGH INTERNATIONAL RESEARCH WITH UNIVERSITY PARTNERSHIP." INTERNATIONAL ELECTRONIC JOURNAL OF HEALTH EdUCATION. 10. (2007): 95-103.

Bardwell, J., and E. Kincaid. "A Rationale for Culture Awareness in the Science Classroom." Science Teacher. 72.3 (2005): 32-35.

Bardwell, J., R. Herold, ANd P. MUjuRU. "Walk fOR Life." Third International Conference on Technology, Knowledge and Society, Cambridge University, CAMBRIDGe, UK.. (2007).

Bock, S. "Program Fosters Young Students' Pursuit of Health Sciences Careers." Rural Health. 18.5 (1996): 16-17.

Branch, R., Chester, A., Morton-McSwain, C., Udin Al Ayubi, S., Bhat Shelbert, K., Brimson, P., Buch, S., Nukue, T., Panakosk, P., Banbang, P., Purlsen, S., Wahl, E. (2011) A NOVEL APPROACH TO ADOLESCENT OBESITY IN RURAL APPALACHIA, WEST VIRGINIA: EDUCATING ADOLESCENTS AS FAMILY HEALTH COACHES AND RESEARCH INVESTIGATORS. TOPICS IN THE PREVENTION, TREATMENT AND COMPLICATIONS OF TYPE 2 DIABETES MARK B. ZIMERING ED. ISBN:9780953-307-590-7, IN TECH

Chester, A, and R.A. Branch."Community Based Participatory Clinical Research in Obesity by Adolescents; Pipeline for Researchers of the Future." Clinical TRANSLATION SCIENCE. (2009).

Chester, A, M. Bowers, A Bushy, M. Huppert, and S. Jiang. "A National Agenda for

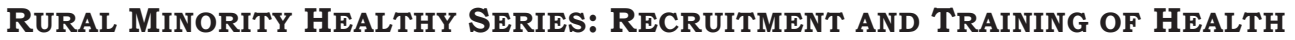
Professionals." National RuRal health Associations. (2001).

Chester, A., W. Brown, S. McKendall, C. Moreno, and C. Phillips. "Evaluations for Novices." National AHEC Bulletin. (2003).

Chester, A., DOOley, E., (2011) West Virginia University's Health Sciences and TEChNOLOGY ACADEMY. JOURNAL OF Higher EduCATION OUTREACH AND ENGAGEMENT 15 (87)

Cool, T., J.RYe, A. Richards, D. Mauk, B. Waterworth, J. Poling. "Science as a Moving EXPERIENCE FOR ALl LEARNERS."SCIENCE TEACHERS. 74.9 (2007): 53-57.

Dooley, E, ANd G Bardwell. "Mentors in Medicine." Science Teacher. 67.3 (2000).

Gomez, L.M. "The Selection of Counties and locations of Field Site CoORdinators." Master Dissertation, West Virginia University. (2004).

McKendall, S, P. Simoyi, A. Chester, ANd J. Rye. "The Health Sciences and Technology ACademy: Utilizing Pre-College Enrichment Programming to Minimize Post-

Appendix B (cont)

Secondary Education Barriers For Underserved Youth." ACAdemic Medicine. 75.10 (2000): S121-S123.

Nisan-Nelson, P. D. "Technology integration: A Case of Professional Development." Journal of Technology and Teacher Education. 10.3 (2001): 223-235.

Osei-Yeboah, C., and P, MuJuRu. "Use of Technology to bRidge the Gap in Science EDUCATION: AN EDUCATION OUTREACH INITIATIVE.." INTERNATIONAL JOURNAL OF TECHNOLOGY KNOWLEDGE AND SOCIETY. 3.3 (2007): 53-58. 
Rye, J, ANd G. Bardwell. "A Model and Strategies for Realizing Secondary level INTERDISCIPLINARY INSTRUCTION." CONFERENCE OF THE ASSOCIATION FOR THE EDUCATION OF TEACHERS OF SCIENCE.(1999) 713-719.

Rye, J, G. Bardwell, and J. Hu. "Connecting Science, Health and Technology through AUTHENTIC INVESTIGATION." SCIENCE EDUCATOR. 8. (1999): 19-24.

Rye, J, G. Bardwell, and N. Priselac. "Connecting Science, Math and health: Applications of the Graphing Calculator in Teacher Professional Development and Student ACAdemic Enrichment." Education of Teachers of Science (AETS). 443.681 (1999).

Rye, J. "Enhancing Teachers' Use of Technology Through Professional Development on Electronic Concept Mapping."Journal of Science Education and Technology. 10.3 (2001): 223-235

Rye, J. "Exploring Dietary Kilocalories: An Activity Exemplifying the Personal Value of Science AND Mathematics." School Science and Mathematics. (1999).

Rye, J. "Grape Expectations." Science Teacher. 65. (1997): 41-46.

Rye, J. "Teacher Professional Development through an ACAdemic Enrichment PROGRAM FOR UNDER-RePRESENTEd SECONDARY STUdents IN West Virginia." RURAL EDUCATOR. 19.3 (7-14):(1998). 713-719.

Rye, J. and A. Chester. "The health Sciences and Technology Academy: Growing Our Own Health Professionals." Academic Medicine. (1998)

Rye, J., AND S.SMOlski. "Pedometer and Human ENERgy Balance ApPlications for SCiEnCe Instruction." SCience ACtivities. 44.3 (2007): 95-104.

Rye, J., N. O'Hara-Tompkins, J. Aleshire, and D. McClure. "InCReasing Physical ACTIVITY OPPORTUNities In A RURAL COMMUNITY THROUGH A PARTICIPATORY SCHOOLBased Project that Engaged Youth." RuRal Educator. 30.1 (2008): 39-48.

Rye, J., S. Zizzi, E. Vitullo, and N. O'HaRa-Tompkins. "The Pedometer as a Tool to Enrich Science Learning in the Context of Public Health." Journal of Science EDUCATION AND TECHNOLOGY..(2005).

Thompkins, N.O., J. Rye, E. Vitullo, and E. Zizzi. "Engaging RuRal Youth in Physical Activity Promotion Research in an After-School Setting." Preventing Chronic DISEASE. (2005).

Thompkins, N.O., J. Rye, E. Vitullo, ANd E. Zizzi. "Impact of FouR-Week Pedometer Intervention on High School Students' Daily Step Counts and Perception of Physical Activity.." American Journal of Health Education. (2005).

Vitullo, E.A., S. Zizzi, J. RYe, AND N. O. "EMPOWeRing YouTh Through Research: Adolescents' Perceptions of Physical ACtivity Intervention in Appalachian Communities." Journal of RuRAl Community Development. 4.1 (2009).

Chester, AL, and Dooley, E. West Virginia University's Health Sciences and TeChNology ACAdemy. JOURNAL OF Higher EdUCATION OUTREACH AND ENGagement, VOLUME 15, NUMBER 3, (2011) P. 87-99.

Branch, RA, Chester, Al, Morton-McSwain, C, Al Ayubi, SA, Bhat Schelbert, $\mathrm{K}$, Brimson, P, Buch, S, Cannon, Y, Groark, S, Hanks, S, Nukui, T, Pancoska, P, Parmanto, B, Paulsen, S, and Wahl, E. A Novel Approach to Adolescent Obesity in RURAl APPalachia OF West Virginia: EdUCATING AdOlescents as FaMily Health Coaches and Research Investigators, Topics in the Prevention, Treatment and

Appendix B (cont)

Complications of Type 2 Diabetes, MaRk B. Zimering (Ed.), ISBN: 978-953-307590-7, INTECH, AVAILABLE FROM:

HTTP: / / WWW.INTECHOPEN.COM / ARTICLES / SHOW / TITLE / A-NOVEL-APPROACH-TOADOLESCENT-OBESITY-IN-RURAL-APPALACHIA-OF-WEST-VIRGINIA-EDUCATINGADOLESCENTS-AS. (2011).

Chester, Al, Bushy, A, Forti, E, Kasten, K, McKendall, S. Recruitment and Training of Racial/ Ethnic Health Professionals in RuRal America. National RuRal Health Association Policy Paper adopted February 2, 2013. 
McKendall, A, Iskander, W, McKendall, S, Chester, Al. An Application of A Generalized Assignment Problem: ASSIGNing ReCRUiters to geOGRAPHical LOCATIONS. INTERNATIONAL JOURNAL OF OPERATIONAL RESEARCH. (ACCEPTED APRIL 2013).

McKendall Sb, Kasten, K, Hanks, S, and Chester, Al. The Health Sciences and TECHNOLOGY ACADEMY: AN EDUCATIONAL PIPELINE TO ADDRESS HEALTHCARE disparities in West Virginia. ACademic Medicine. (ACCepted July 2013).

Hanks S, Chester Al, Morton-McSwain C, Kuhn S, McMillion M, Paulsen S, Para U, Groark S, CanNon Y, BRANCh RA. OBESity MANAGEMENT ORganized BY Adolescents in Rural Appalachia. John Hopkins University Press (In Press) 
HSTA: A Case Study

Appendix C

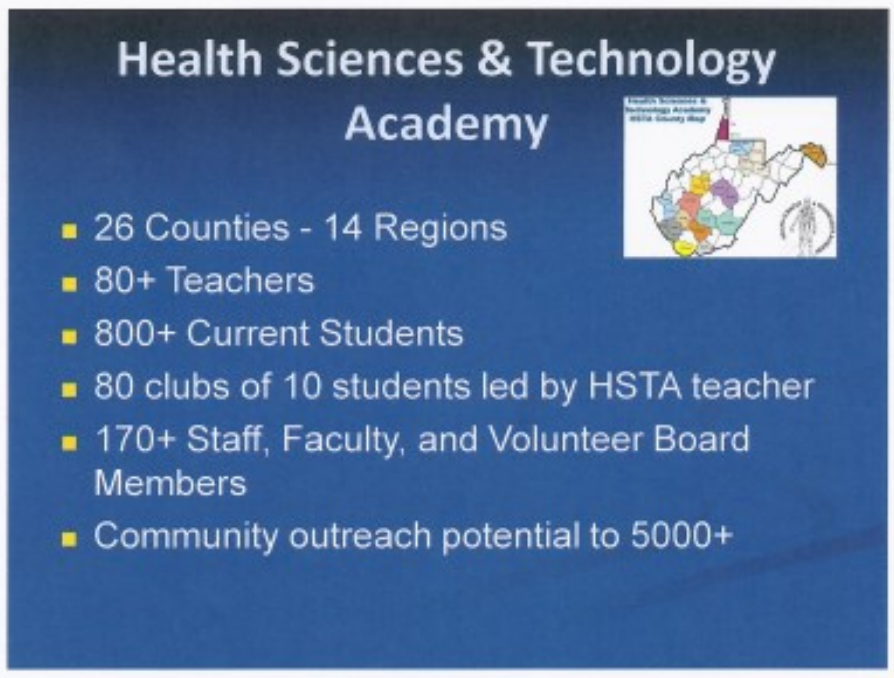


HSTA: A Case Study

\section{Appendix D}

\section{Legislative line item in the budget 2012}

16 Vice Chancellor for Health Sciences -

Rural Health Residency

Program (R) .............. $601 \quad 267,882$

19 MA Public Health Program and

20 Health Science Technology (R) . . . $623 \quad 62,483$

21 Marshall University Graduate

22 College Writing Project (R) ...... $807 \quad 25,000$

23 WV Engineering, Science, and

Technology Scholarship

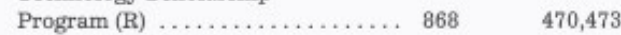

26 Health Sciences Career

27 Opportunities Program (R) . . . . . . $869 \quad 378,192$

28 HSTA Program (R) $\ldots \ldots \ldots \ldots \ldots \ldots . \quad 870 \quad 1,543,868$

29 Center for Excellence in

Disabilities (R) .............. 967

Total ................

$967 \frac{350.000}{\$ 2,888,744}$

31

$\$ 7,888,744$

Any unexpended balances remaining in the appropriations 3 at the close of fiscal year 2012 are hereby reappropriated for 34 expenditure during the fiscal year 2013.

35 The above appropriation for Higher Education Grant 36 Program (activity 164) shall be transferred to the Higher 37 Education Grant Fund (fund 4933, Org 0441) established by 38 W.Va. Code $\$ 18 \mathrm{C}-5-3$.

39 The above appropriation for Underwood-Smith Scholar-

40 ship Program - Student Awards (activity 167) shall be

41 transferred to the Underwood -Smith Teacher Scholarship

42 Fund (fund 4922, org 0441) established by W.Va. Code $\$ 18 \mathrm{C}-$

43 4-1.

44 The above appropriation for WV Engineering, Science, and 45 Technology Scholarship Program (activity 868) shall be

46 transferred to the West Virginia Engineering, Science and

47 Technology Scholarship Fund (fund 4928, org 0441) estab-

48 lished by W.Va. Code $818 \mathrm{C}-6-1$.

49 Total TITLE II, Section 4 -

50 Lottery Revenue ............ \$145.025.203 
HSTA: A Case Study

Appendix E

\section{IRB PROTOCOL}

Version 1

Exempt

\section{PRINCIPAL INVESTIGATOR}

TITLE

Title:

HSTA: A case study of the community impact of a 9th though 12th grade after school pipeline program

Does your research study have a sponsor protocol number?

(Please note the BRAAN2 IRB Tracking Number will be automatically assigned at time of submission.

No

Sponsor Protocol Number:

(no answer)

Page 1 of 32 
HSTA: A Case Study

Appendix F

HSTA districts

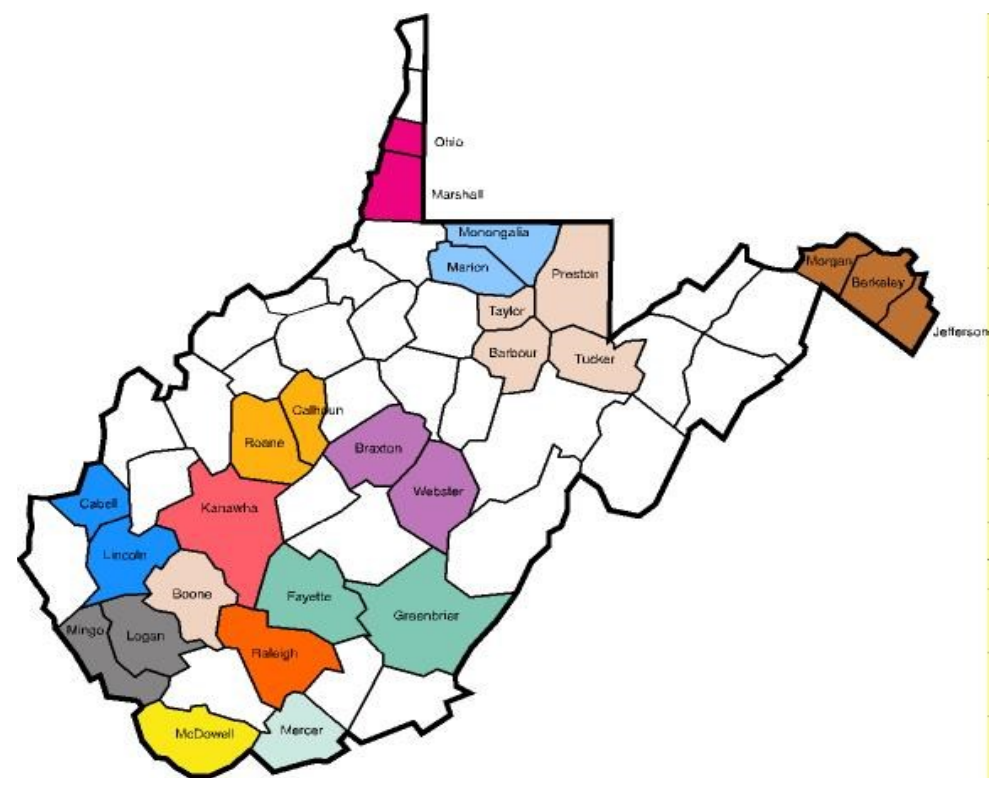

\begin{tabular}{llll}
\hline District & CRA & Region & \# Clubs \\
\hline NORTH EAST & SH & Ohio Marshall & 5 \\
& CM & Mon-Marion & 6 \\
CENTRAL & Eastern Panhandle & 6 \\
& MM & Mountain & 9 \\
& & Braxton /Webster & 4 \\
SOUTHERN & Calhoun/ Roane & 2 \\
& Greenbrier/ Fayette & 5 \\
& Kanawha & 9 \\
& SK & Raleigh & 7 \\
& Boone & 3 \\
& Cabell/Lincoln & $\mathbf{5}$ \\
& Logan/ Mingo & 4 \\
& McDowell & 7 \\
& & Mercer & 4
\end{tabular}


HSTA: A Case Study

\author{
Appendix G
}

Questions for Case study Interview

\title{
Guide for when you get stumped!!
}

Q1. Tell me how HSTA has had an impact on your community?

Q2. What do you see as the community benefits?

Can you give me an example?

What do you believe are impacts?

Do you know anyone that has been in HSTA or worked for HSTA?

Have you been at an event or activity and have heard about HSTA or known of a HSTA person participating? 
HSTA: A Case Study

\section{Appendix $\mathrm{H}$}

HSTA Field Site Coordinator Bimonthly Report

Due electronically to achester@hsc.wvu.edu and to cbragonje@hsc.wvu.edu and to your

LGB Chairman, by the $10^{\text {th }}$ of October, December, February, April and June.

\section{HSTA Region}

FSC and Date

$12 / 9 / 05$

Club Roster Updates

Students added to HSTA NA

\begin{tabular}{|l|l|}
\hline \multicolumn{2}{|c|}{ STUDENTS DROPPED FROM HSTA } \\
\hline Student Name & \\
\hline 3. Melissa & \\
\hline
\end{tabular}

\begin{tabular}{|l|l}
\hline High School & \multicolumn{1}{|c}{ Reason for Drop (grades/attendance dismissal, move, etc.) } \\
\hline & Move \\
\hline
\end{tabular}

Student/Teacher/Club Activities

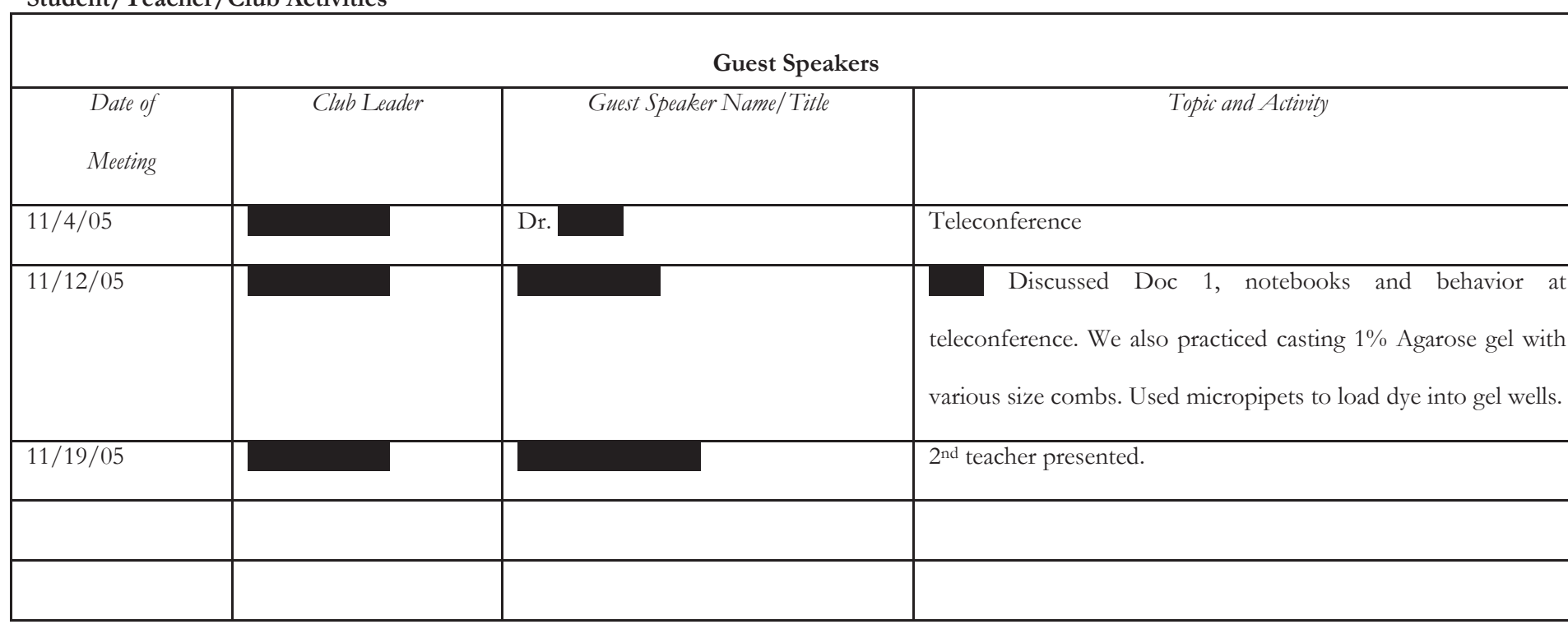

Local Governing Board Information

COUNTY HSTA LOCAL GOVERNING BOARD MEETING MINUTES

MEETING DATE: 10/18/05

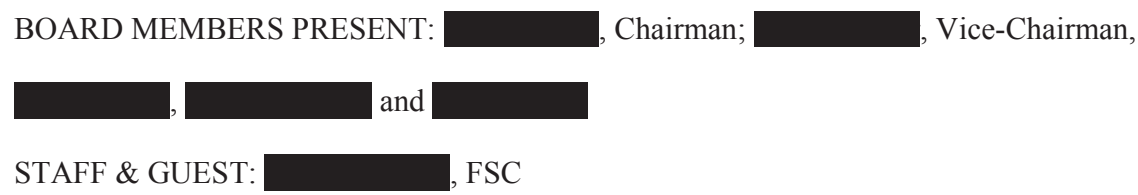


HSTA: A Case Study

\section{Appendix $\mathrm{H}$ (cont)}

The

County HSTA Local Governing Board meeting was held in

Hall room

on the

campus at 5:00pm.

I. Chairman

II. Motion to approve minutes by

Motion carried.

III. Motion to approve budget by Seconded by have a question about something in the budget later or they can bring it up anytime afterwards.

Motion carried.

IV. Correspondences

Board reviewed letters from:

1. Reviewed request and decided due to numerous issues with student completing requirements and also final GPA, the tuition and fee waiver was not awarded. Motioned by as a Tuition and Fee Waiver recipient due to issues and GPA. $2^{\text {nd }}$ by will send letter from board to let Mr. know what the decision has been.

to not accept

Motion carried.

2. sent a letter to be excused from Summer Institute 2005. She had classes. Board reviewed letter. This letter was also request by 
HSTA: A Case Study

\section{Appendix I}

Daytimer entries color-coded

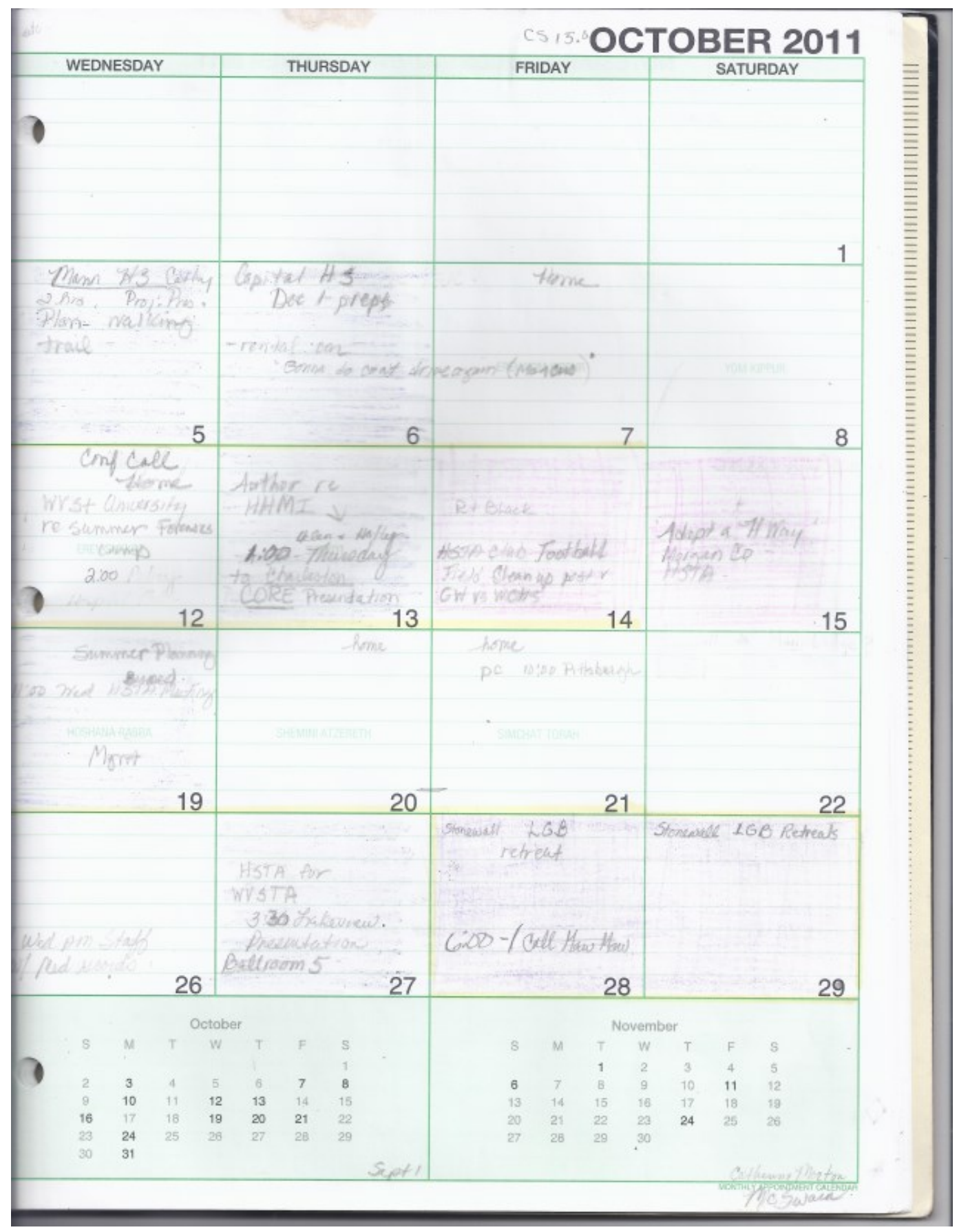


HSTA: A Case Study

\section{Appendix J}

\section{Reflection Guide}

Who was interviewed:

Observations and notes from interviews

1. How do I feel the participant behaviors complimented their responses?

2. What verbal or visual cues stood out?

3. Additional questions or comments noted.

4. What was the mood?

5. Overall impressions 
HSTA: A Case Study

Appendix K

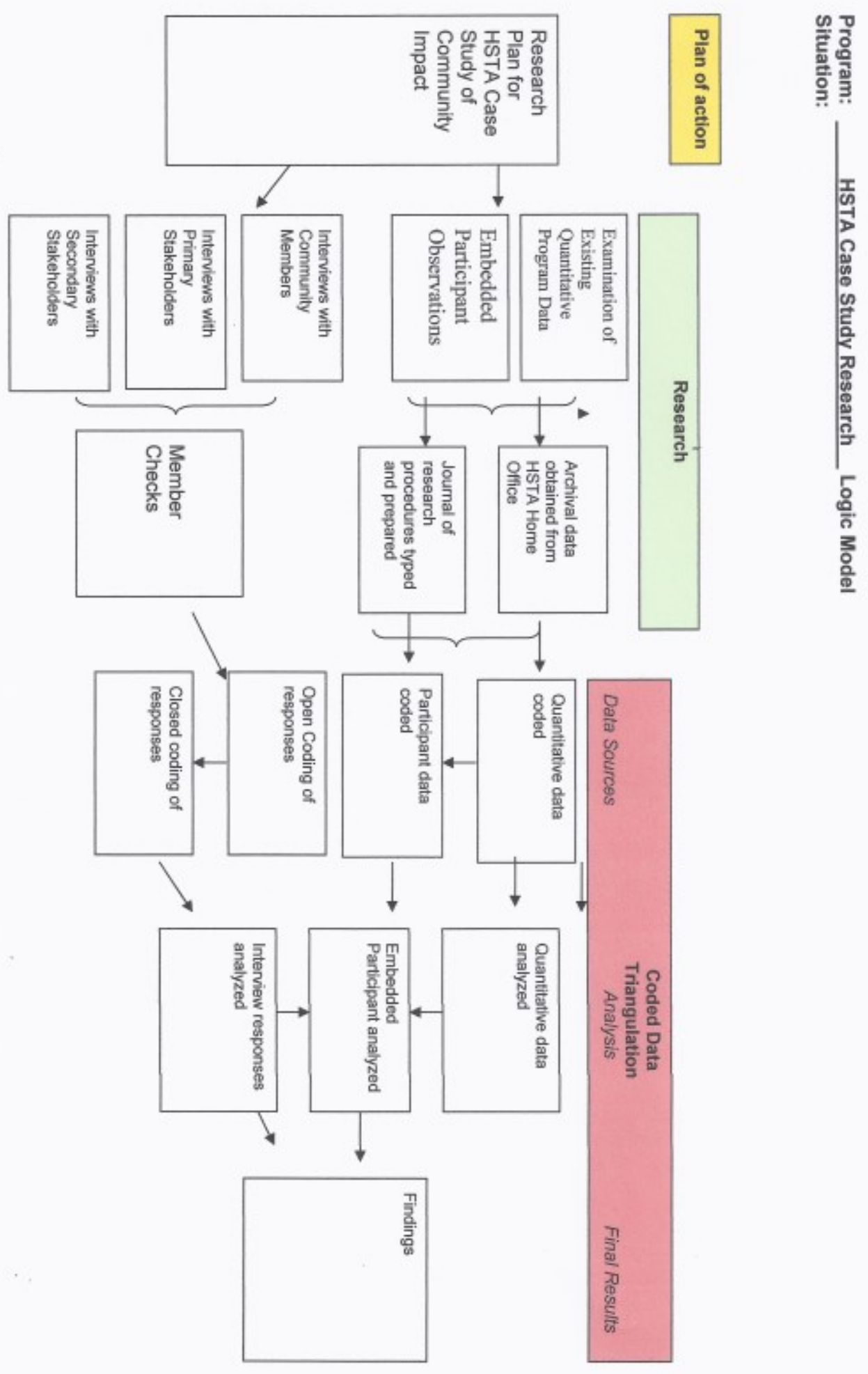


Appendix L

IRB Letter

\title{
Department of Curriculum \& Instruction/Literacy Studies WestVriginiaUniversity. \\ College of Human Resources and Education
}

\section{Dear Participant,}

This letter is a request for you to take part in a research project to assess how the HSTA program has had an impact on your community. This project is being conducted by Cathy MortonMcSwain, MS, in the College of Human Resources and Education, with supervision of Dr. Jim Rye, Professor, in the College of Human Resources and Education, for a Doctoral degree in Curriculum and Instruction. Your participation in this project is greatly appreciated and will take approximately 10- 20 minutes to complete the interview.

Your involvement in this project will be kept as confidential as legally possible. All data will be reported in the aggregate. You must be 18 years of age or older to participate. I will not ask any information that should lead back to your identity as a participant. Your participation is completely voluntary. You may skip any question that you do not wish to answer and you may discontinue at any time. Your class standing or position with HSTA will not be affected if you decide either not to participate or to withdraw. West Virginia University's Institutional Review Board acknowledgement of this project is on file.

I hope that you will participate in this research project, as it could be beneficial in understanding the impact of the HSTA program on your community. Thank you very much for your time.

\author{
Cathy Morton-McSwain \\ Health Sciences Technology Academy \\ 303 S. Union St \\ Webster Springs, WV 26288 \\ Telephone: (304) 644-2553 \\ Email: cmortonmcswain@hsc.wvu.edu
}

This letter has been approved by the West Virginia University Institution Review Board.

602 Allen Hall PO Box 6122 Morgantown, WV 26506-6122

Phone: 304-293-3441 Fax: 304-293-3802

Equal Opportunity / Affirmative Action Institution 


\section{Appendix M}

Consent Dialog for phone or in person.

Hi, I am Cathy Morton-McSwain with HSTA and I was wondering if you would like to take part in a research project to assess how the HSTA program has had an impact on your community?

This project is being conducted by me with supervision of Dr. Jim Rye, Professor, in the College of Human Resources and Education, for a Doctoral degree in Curriculum and Instruction. Your participation in this project is greatly appreciated and will take approximately 10-20 minutes to complete the interview.

Your involvement in this project will be kept as confidential as legally possible. All data will be reported as a whole finding I will not ask any information that should lead back to your identity as a participant I am coding all responses so no one but me can identify responses.(who said what) You must be 18 years of age or older to participate.

Your participation is completely voluntary. You may skip any question that you do not wish to answer and you may stop at any time. (Your class standing or position with HSTA will not be affected if you decide either not to participate or to withdraw)

West Virginia University's Institutional Review Board acknowledgement of this project is on file.

I hope that you will participate in this research project, as it could be beneficial in understanding the impact of the HSTA program on your community.

Thank you very much for your time. 
HSTA: A Case Study

\section{Appendix N}

7

Member Check

Code: S6t

What impact has HSTA had on the community?

This is a difficult question to answer. HSTA students don't wear a badge after they graduate stating that they are graduated, probably successful members of HSTA. Frequently, what happens is that HSTA comes up in conversation and this information is unearthed. The most prominent HSTA graduate that I know is a teacher, here in my school, and she talks eloquently about how HSTA helped her learn she was not headed for Health Sciences. That is as beneficial as anything since she didn't make the mistake of trying to go to medical school and being stuck returning to school for further education to recover from that possible mistake made later on in life. She is working in West Virginia and working with students, so that is a positive result.

As far as my interactions with the Raleigh County community, I see hope in family member's eyes, where they might not have had hope for their students graduating high school and going on to college. I expect next year to have the first student of 15 in one family apply to the program. I talked to a granny last year about her family and the opportunities available to those children. She is excited about the program. I have another grandchild that enrolled this year and is clearly eager to be successful in the program. HSTA has a visible presence at public activities and our student are doing a lot of volunteer work, most above and beyond the requirements. I only truly have trouble identifying graduates and their contributions to our community. What do you define as community? Community has many levels starting with family, where HSTA has had a major impact on our family, up to national and international communities. I know that HSTA is gaining a national reputation, and I know my group is gaining a good reputation for excellence in academics. The HSTA community provides wonderful support for the students and their families. There are students in my program that meet our target demographic and I can tell that they now know more than they did when they started and now have more opportunities open to them than they did before. In this case, community is undefined by physical boundaries, but has intentional boundaries where the group comes together with a shared intention, especially including underserved and often undereducated students.

Notes: Blue $=$ my coding

Pink $=$ Peer 1 coding difference 
HSTA: A Case Study

Appendix O

\section{What HSTA Means To Me}

After four years of dedication to the HSTA Club, I have concluded that all of my hard work and commitment equals one thing: success. This club has encouraged me in many ways, for it has helped me to become involved in my community, learn important research and communication skills, and learn to manage my time to effectively fulfill all of my responsibilities.

Through HSTA, I was able to meet people and adjust to working with others as I completed my mandatory seventy-five community service hours. This not only helped towards my education, but also towards my life skills of recognizing need and interacting with others in my town, affording me a great deal of social success. I enjoyed helping to take care of animals at the local shelter, and I was inspired by local cancer survivors during Relay for Life events.

Furthermore, I was given the opportunity to interact with young children in my community through church and elementary school events, helping to build positive relationships between teenagers and youngsters in my hometown. All of this was invaluable to me.

Not only have my community service opportunities been a source of growth throughout my involvement with the HSTA program, but so has the knowledge I've gained from completing multiple projects and presentations that we have delivered to others. This has advanced my skills in technology and conducting experiments, while teaching me how to speak well and relate what I've learned to people who are interested in my research and ideas. Our symposium projects have allowed all of us to become successful communicators, which will be very important in our lives ahead. 
HSTA: A Case Study

$$
\text { Appendix O (cont) }
$$

As a high school student who has participated in many scholastic and local activities throughout my high school career, I have successfully learned how to budget my time in a way that allows me to balance both school and my private life. I have found that I can juggle the responsibilities and demands of the many clubs and programs in which I take part, and still fit them into the life of a regular teenager. I can directly relate my academic and social success, for which others have recognized me, to my involvement in the HSTA program. By showing management through completing community service hours, maintaining a high GPA, and participating in studies that we share with our community, others have grown fond of the achievements of HSTA students, opening many doors for my success after high school.

Finally, I have been very successful in participating in the diverse activities of the HSTA Club, allowing me opportunities that I might not have had otherwise. Summer camps provided a wealth of information for many of us. I feel a great sense of self-satisfaction after being able to be active leader in my club, my school, and my community, as well as a positive resource to those who question what the HSTA program can offer, both financially and academically. I have been able to meet many people at symposium and summer camps and institutions - people with the same determination to advance to college with the help of HSTA

One word that has been repeated throughout this essay is "success." HSTA has truly helped me to become a successful high school graduate who will go on to become a successful part of my community. I am confident that with the skills and knowledge I have gained through this program, I can truly achieve anything, and I'm ready to take on the challenges of what lies ahead. 
HSTA: A Case Study

\section{Appendix P}

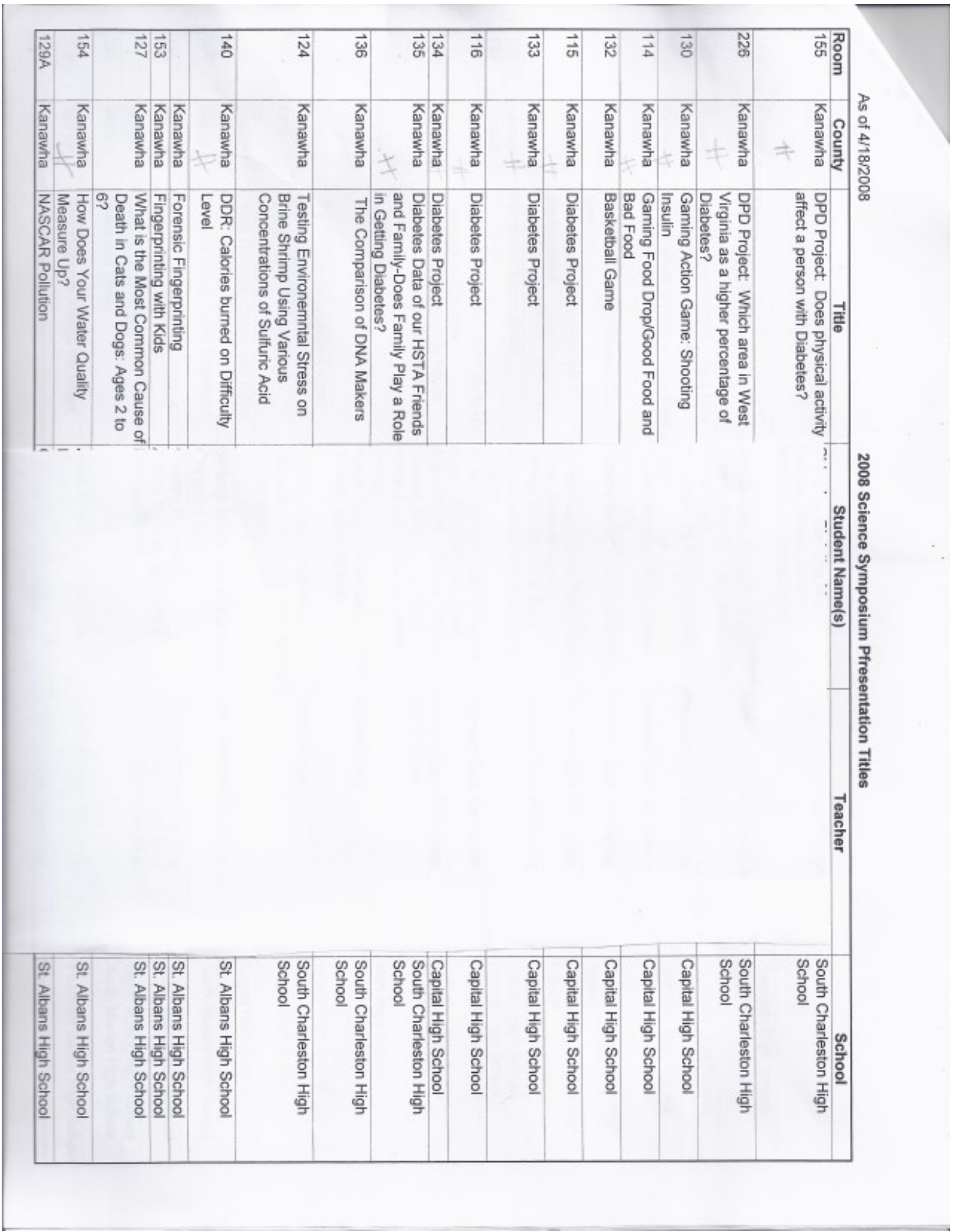


HSTA: A Case Study

\section{Appendix Q}

Peer comments on coded data and rough draft of chapters

Hey Cathy,

April, 2013

I like what you are trying to say but it gets lost in the long vignette you have at the end of the chapter. Can you make it shorter and just use the key points of how you saw a change from last year to this one? ..... Don't say persons use people.

\section{Hi Cathy,}

I think you need to consider sticking with the 4 themes as they appear and in the order that they appear under each set of data. I also believe you should mention summer institute. It appears in all three sets of data and is fairly strong in field site reports as well as essays. You could put it at the end of the discussion on extant data but don't leave it out.

\section{Coding:}

I think you can collapse the items under teachers, students, peers, leadership as I read them. They all tie into the local schools. 
HSTA: A Case Study

\section{Appendix R}

Community Service fund raiser

Include any media coverage and attach newspaper articles. Please see pictures of our

Diabetes Walk Community Service Activity.
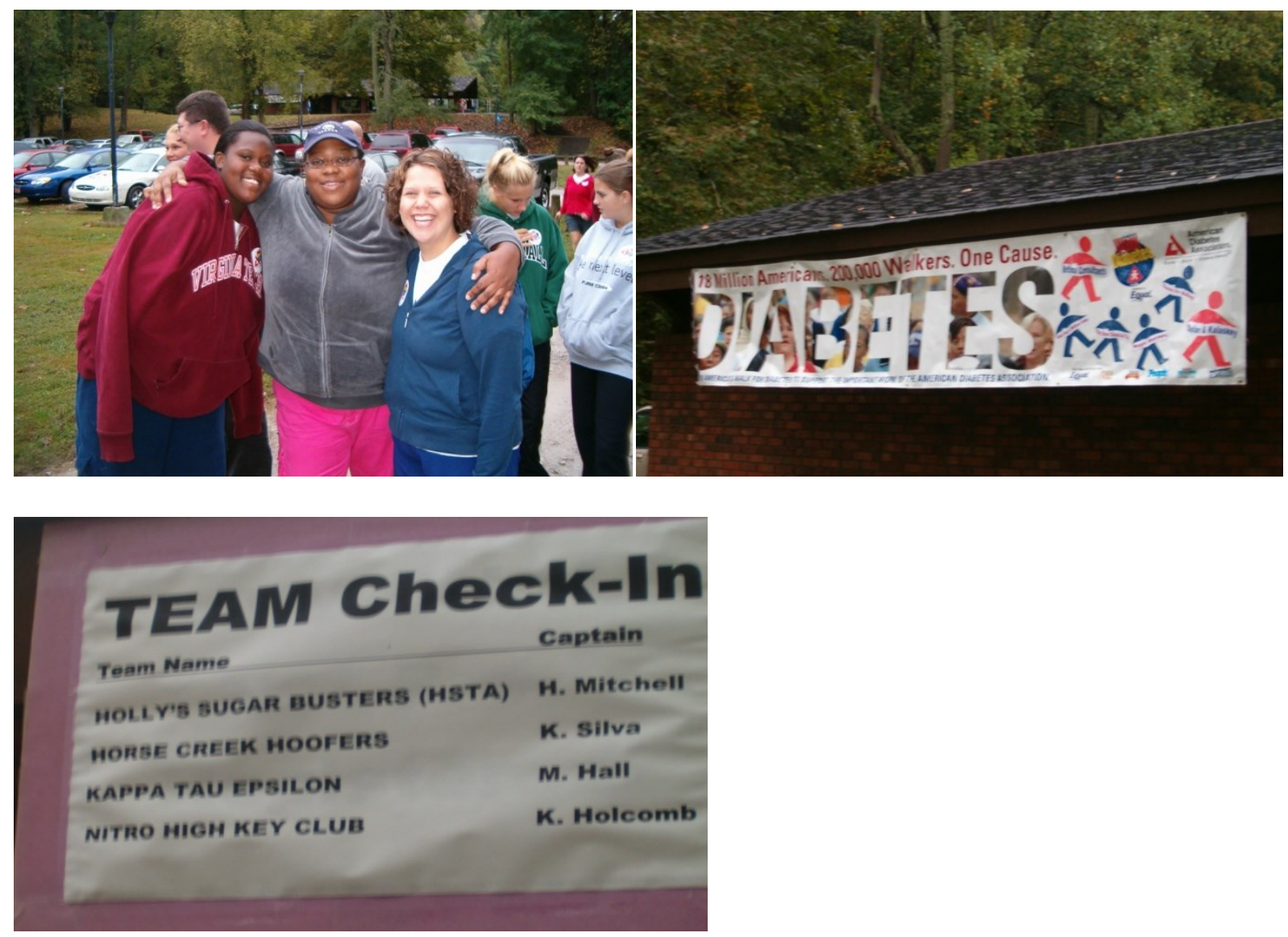


\section{Appendix S}

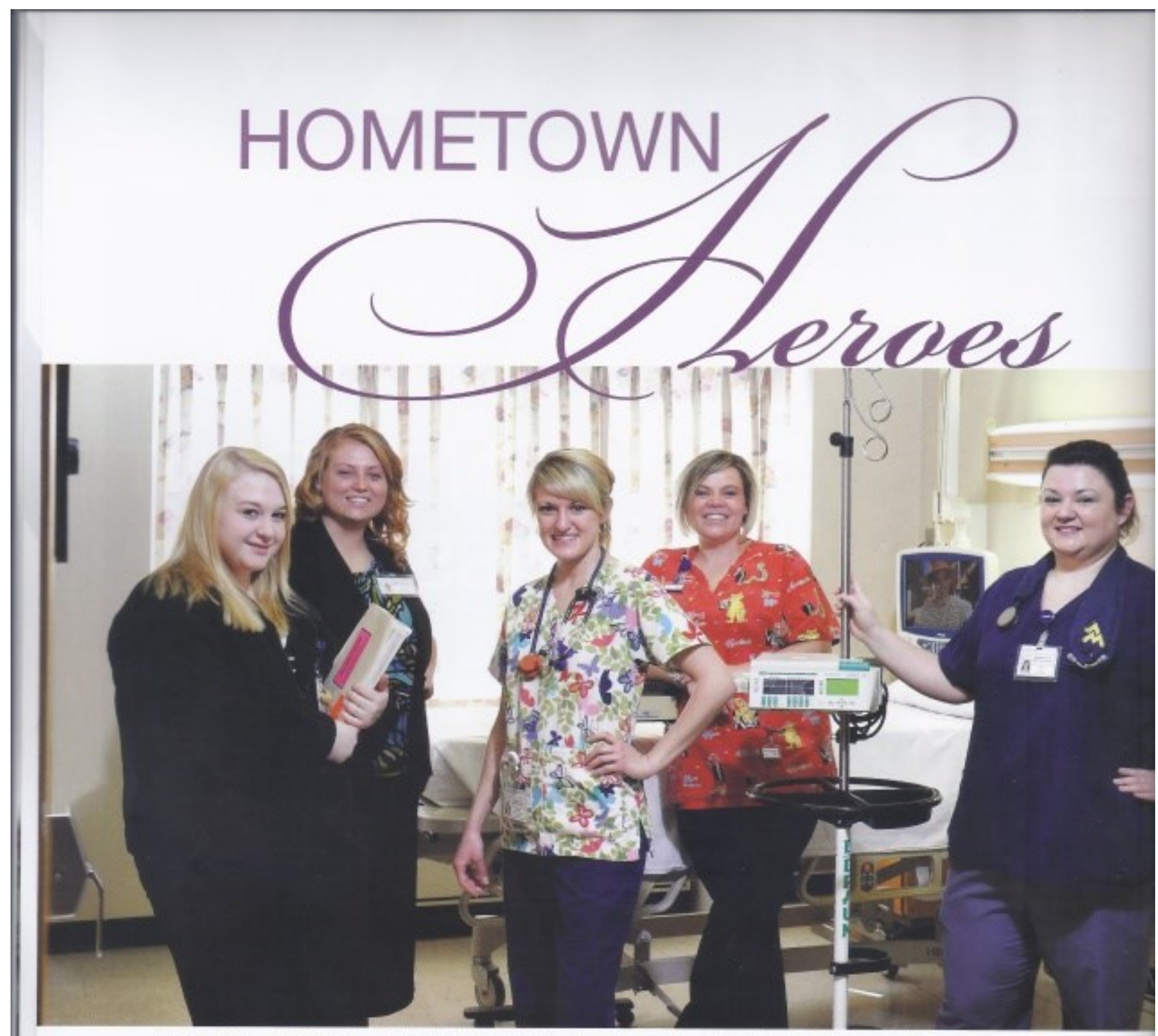

Webster County HSTA Alumni (left to right): Kelsie Henline, Sierra Miller, Carrie Henline Given, Katie Wetzel Atkins, Candy Cochran. Not pictured: Sara Barbe and Stephanie Hall

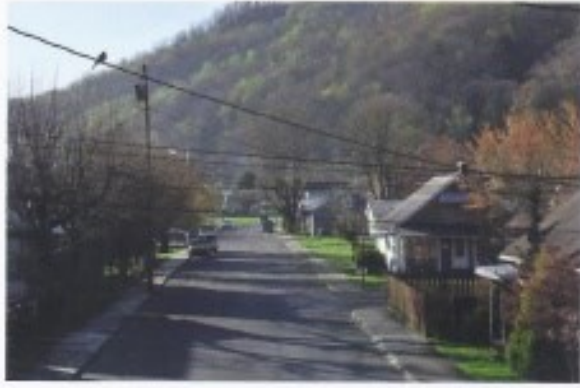

Written by Amy Johns

Photographed by Greg Ellis and Brian Persinger
WEBSTER SPRINGS, WEST VIRGINIA, is reached by narrow mountain roads that wind down to this lovely village in the valley. It's a world removed from fast food joints and big box stores. For quite a while in its recent past, Webster Springs was also far away from doctors, nurses, and other professionals who could provide healthcare to the people who call Webster County home.

But a new generation of young health professionals, inspired by this community, encouraged by teachers and family, and
University, are devoting their lives to practicing healthcare in their hometown Nearly 1,650 students statewide have become "HSTA kids" in the 17 years sir the Health Sciences Technology Acade began at WVU. HSTA encourages mino underserved and financially disadvanta high school students to study science a math, to go to college, and to consider careers that many never thought possit It attracts them with the promise of fun summer camps and free college tuition and nurtures them through community 
Appendix T
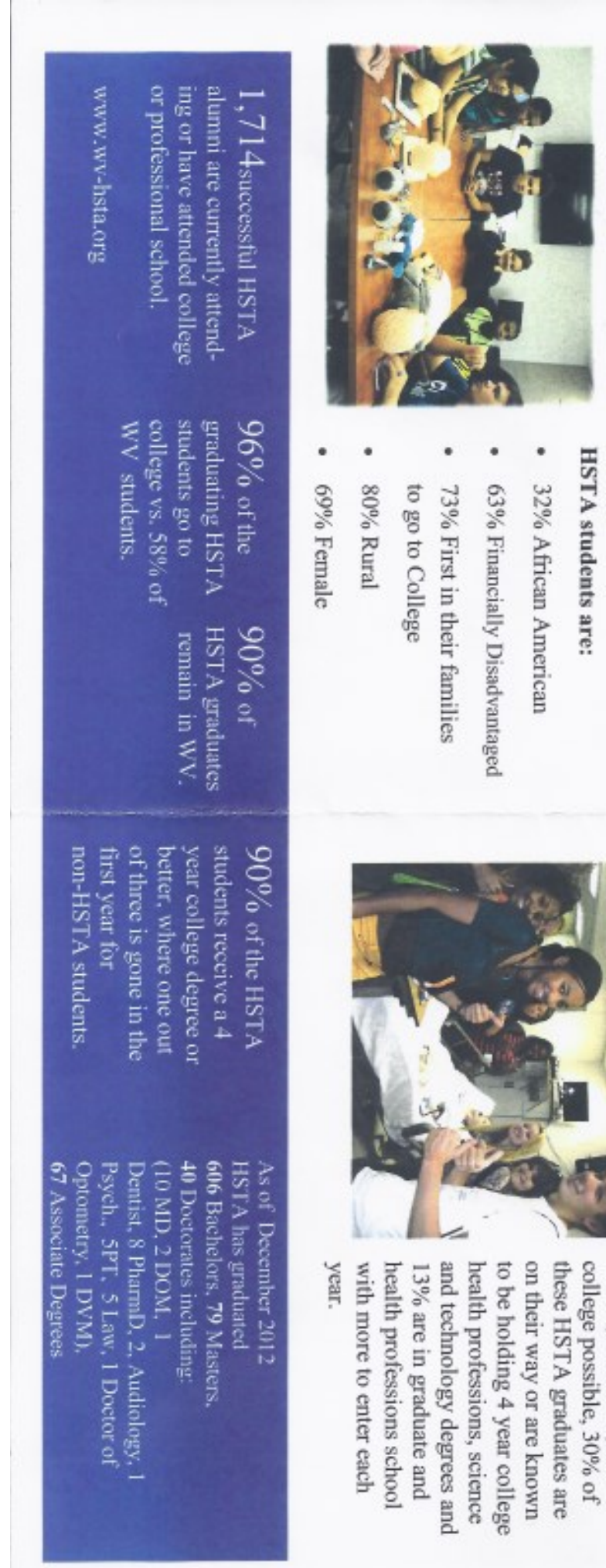

to

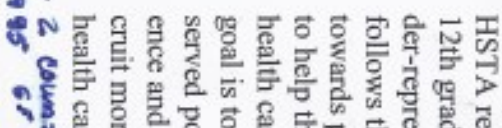

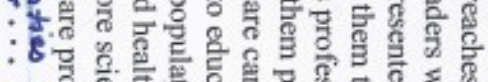

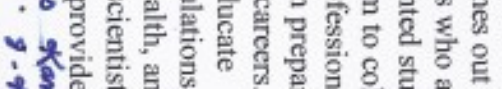

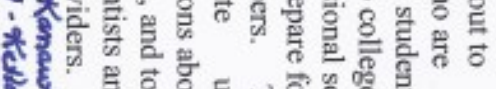

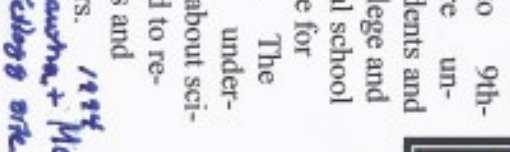
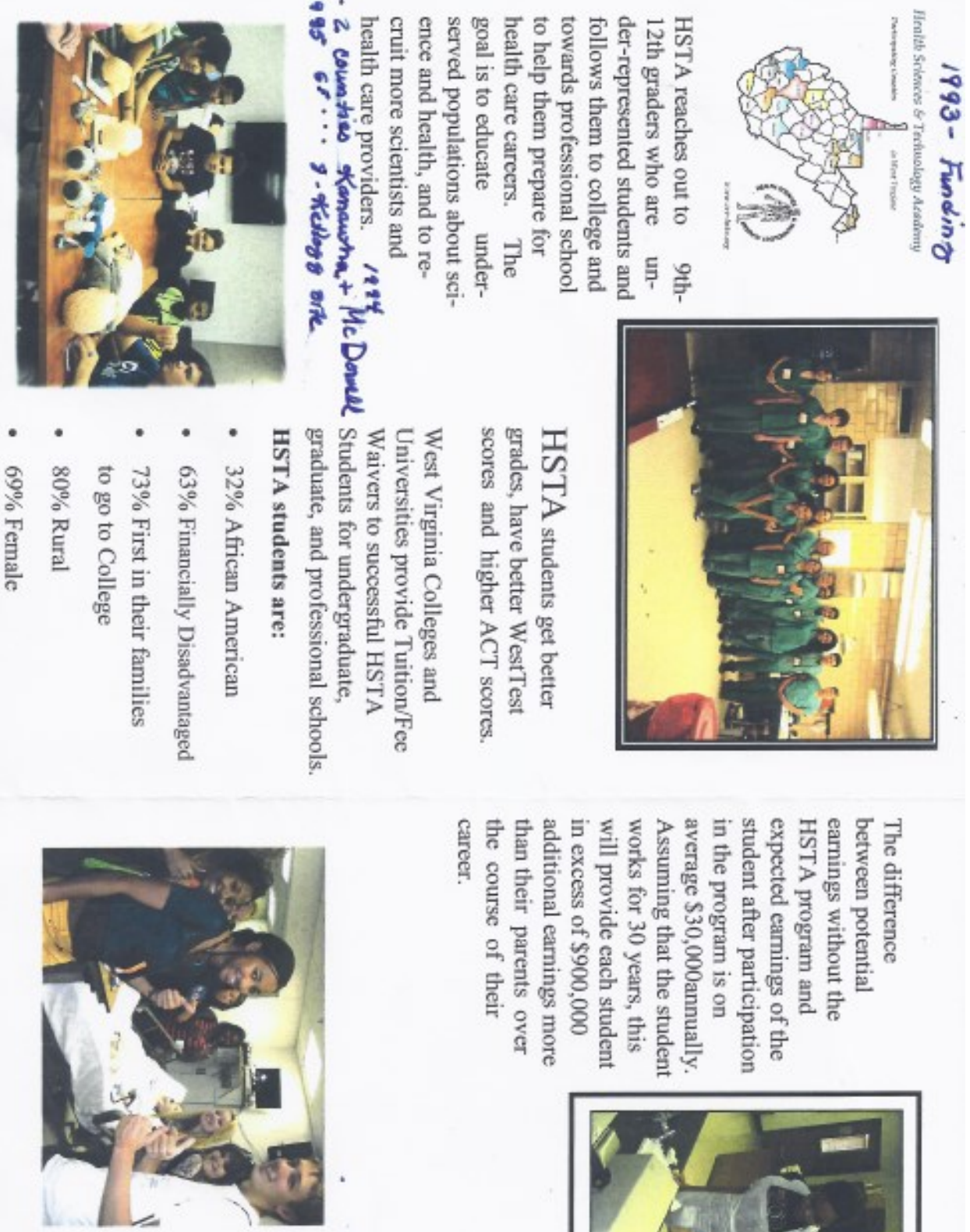

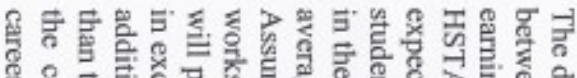

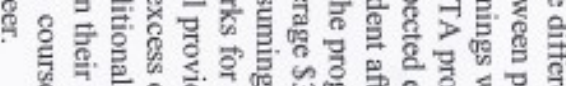
영

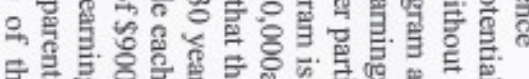

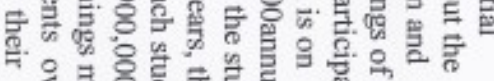

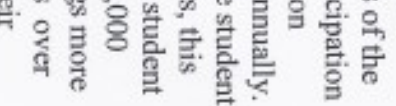

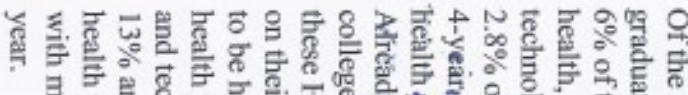

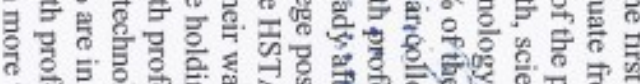

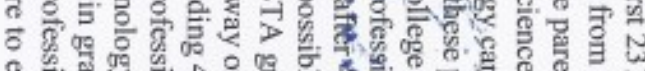

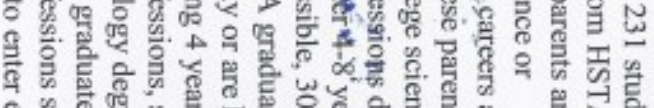

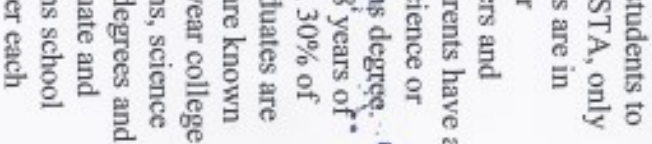

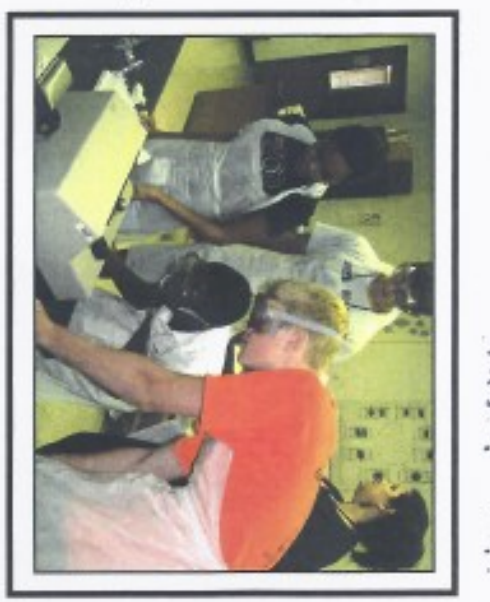


HSTA: A Case Study

\section{Appendix U}

Slide from presentation in Boston, MA, where a classroom teacher had the opportunity to present at the International Teacher-Scientist Partnership Conference on February 14, 2013.

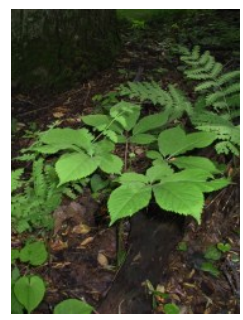

\section{West Virginia High School Students Doing Research} Through Teacher-Scientist Partnerships International Teacher-Scientist Partnership Conference Boston, MA February 14, 2013

Ann Chester, Ph.D. moderator Panelists:

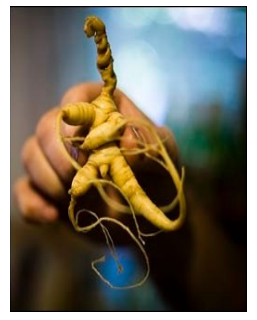

Sherry Woolridge - HSTA High School Teacher

Cathy Morton-McSwain- Research Liaison Jessica B Turner - Graduate Student

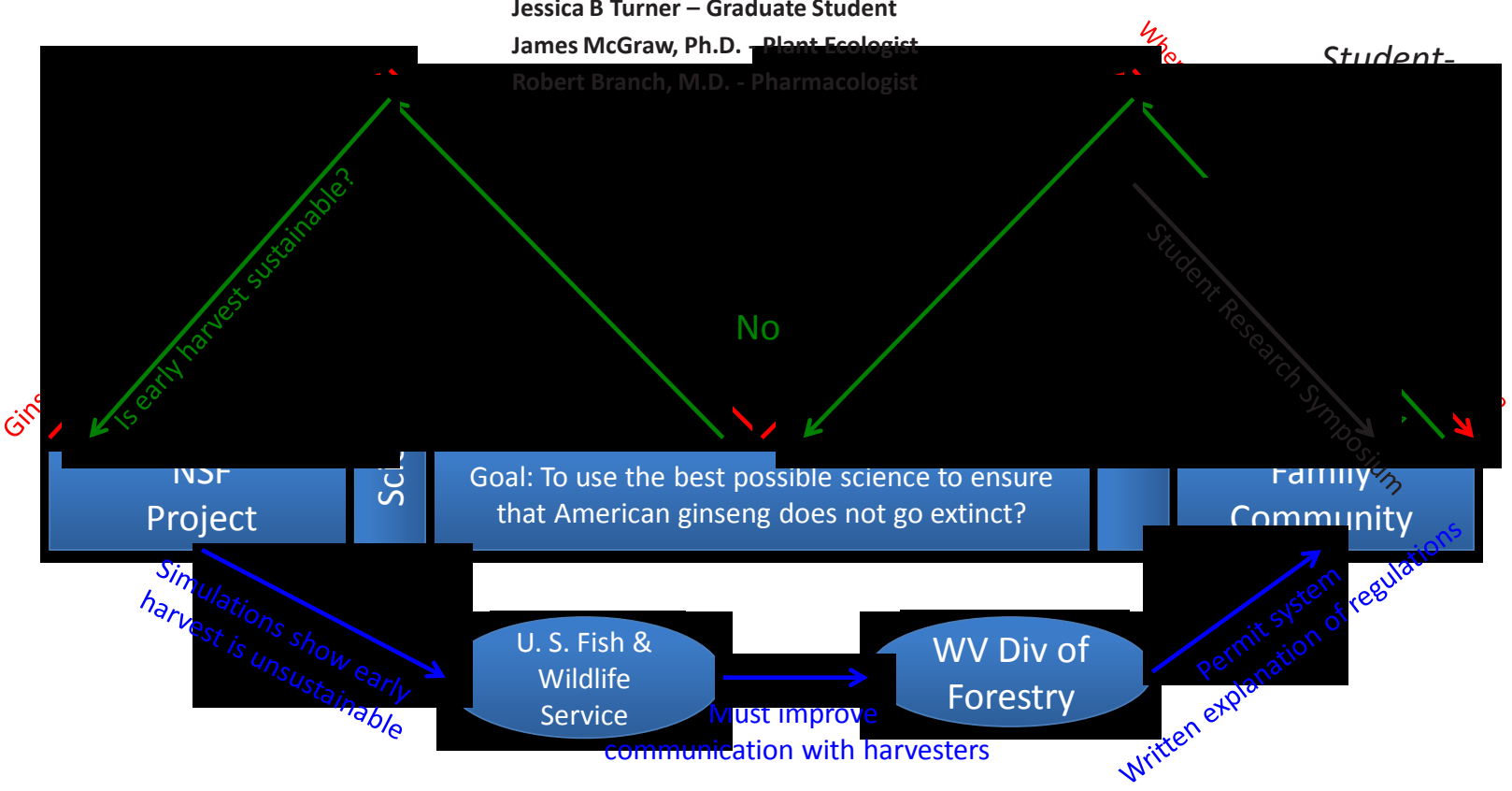


HSTA: A Case Study

\section{Appendix V}

ARTICLES: Peer review teacher co-authored publications

Bardwell, G, J. Hyde, J. Lewis, C. Morton-McSwain, J. Rye, and P. Simoyi "Teens Take a Healthy Interest in their Communities." ENC Focus. 8.1 (2001): 40-42. Print.

Bardwell, J., ANd E. Kincaid. "A Rationale for Culture Awareness in the Science Classroom." Science Teacher. 72.3 (2005): 32-35.

J.Rye, A. Richards, D. Mauk, B. WATerworth, J. Poling. Cool, T. "Science AS A Moving EXPERIENCE FOR ALl LEARNERS."SCIENCE TEACHERS. 74.9 (2007): 53-57.

Rye, J., N. O'Hara-Tompkins, J. Aleshire, and D. McClure. "Increasing Physical ACTIVITY OPPORTUNities IN A RURAL COMMUNity THROUGH A PARTICIPATORY SCHOOLBased Project that Engaged Youth." RuRal Educator. 30.1 (2008): 39-48. 
HSTA: A Case Study

Appendix W

Student project list re percentages of Health vs. Non Health

\begin{tabular}{|l|l|l|l|l|l|}
\hline \multicolumn{1}{|c|}{$\mathbf{2 0 0 7}$} & \multicolumn{1}{c|}{$\mathbf{2 0 0 8}$} & \multicolumn{1}{c|}{$\mathbf{2 0 0 9}$} & \multicolumn{1}{c|}{$\mathbf{2 0 1 0}$} & \multicolumn{1}{c|}{$\mathbf{2 0 1 1}$} & \multicolumn{1}{c|}{$\mathbf{2 0 1 2}$} \\
\hline 234 Projects & 249 Projects & 290 Projects & 180 Projects & 309 Projects & 400 Projects \\
\hline 116 Non Health & 133 Non Health & 206 Non Health & $\begin{array}{l}133 \text { Non } \\
\text { Health }\end{array}$ & $\begin{array}{l}\text { 226 Non } \\
\text { Health }\end{array}$ & $\begin{array}{l}\text { 176 Non } \\
\text { Health }\end{array}$ \\
\hline 115 Health & 96 Health & 79 Health & 46 Health & 83 Health & 224 Health \\
\hline 3 Unknown & 20 Unknown & 5 Unknown & 1 Unknown & & \\
\hline & & & & & \\
\hline $49.15 \%$ Health & $38.55 \%$ Health & $27.24 \%$ Health & $25.26 \%$ Health & $26.86 \%$ Health & 56\% Health \\
\hline
\end{tabular}


HSTA: A Case Study

\section{Appendix X}

\section{HSTA Mission Statement}

\section{Long Version Options}

1. Original: The hope of HSTA is to increase the number of African American and underrepresented high school students in West Virginia that pursue post-secondary education in the health sciences and to increase the number of health practitioners in the medically underserved communities of West Virginia.

2. New: HSTA increases the number of African American and underrepresented students in WV who pursue degrees in Health Sciences and STEM majors, thereby increasing the number of health practitioners and advocates in the medically underserved communities of West Virginia.

3. Short: Improving Health Care Through Education 
HSTA: A Case Study

\section{Appendix Y}

MultiFest, Charleston,WV. Making Gak with kids who stop by the booth.

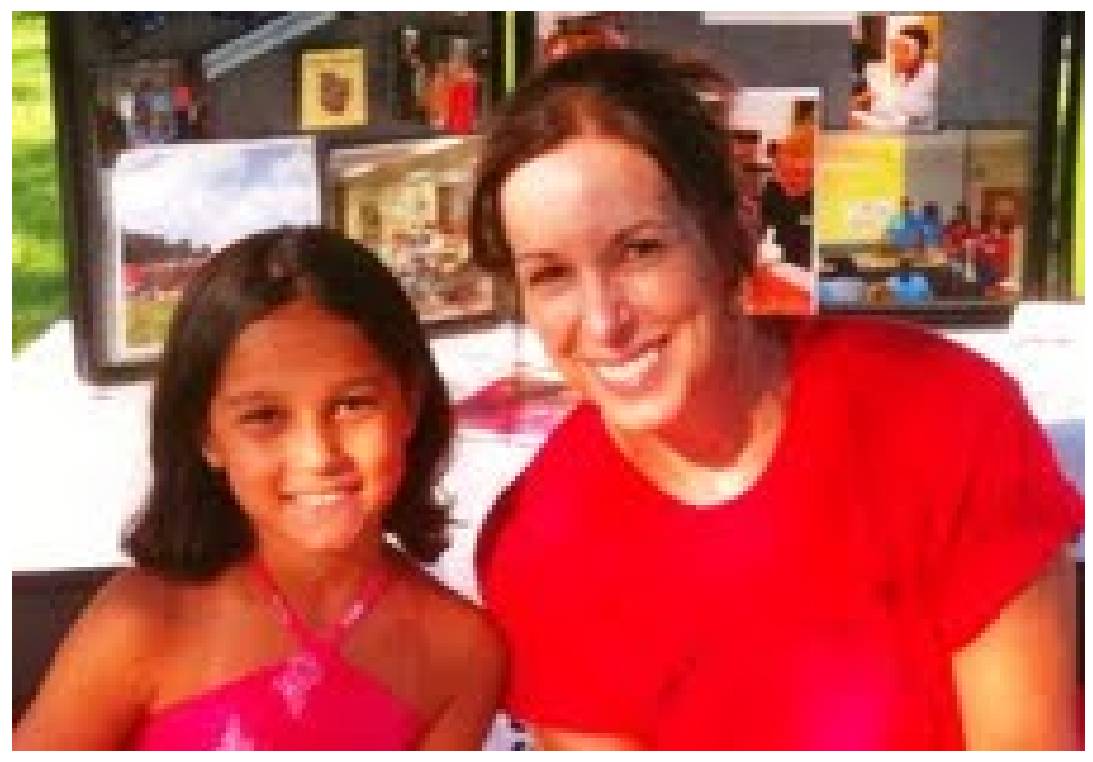

